\title{
Evaluation of control strategies for overhead work using electromyography of rotator cuff muscles
}

\author{
Hossein Motabar \\ West Virginia University, hm0084@mix.wvu.edu
}

Follow this and additional works at: https://researchrepository.wvu.edu/etd

Part of the Biomechanical Engineering Commons, Ergonomics Commons, and the Occupational Health and Industrial Hygiene Commons

\section{Recommended Citation}

Motabar, Hossein, "Evaluation of control strategies for overhead work using electromyography of rotator cuff muscles" (2020). Graduate Theses, Dissertations, and Problem Reports. 7734.

https://researchrepository.wvu.edu/etd/7734

This Dissertation is protected by copyright and/or related rights. It has been brought to you by the The Research Repository @ WVU with permission from the rights-holder(s). You are free to use this Dissertation in any way that is permitted by the copyright and related rights legislation that applies to your use. For other uses you must obtain permission from the rights-holder(s) directly, unless additional rights are indicated by a Creative Commons license in the record and/ or on the work itself. This Dissertation has been accepted for inclusion in WVU Graduate Theses, Dissertations, and Problem Reports collection by an authorized administrator of The Research Repository @ WVU.

For more information, please contact researchrepository@mail.wvu.edu. 
Evaluation of control strategies for overhead work using electromyography of rotator cuff muscles

Hossein Motabar

Follow this and additional works at: https://researchrepository.wvu.edu/etd

Part of the Biomechanical Engineering Commons, Ergonomics Commons, and the Occupational Health and Industrial Hygiene Commons 


\title{
Evaluation of control strategies for overhead work using electromyography of rotator cuff muscles
}

\section{Hossein Motabar}

\author{
Dissertation submitted to the \\ Benjamin M. Statler College of Engineering and Mineral Resources at \\ West Virginia University \\ in partial fulfillment of the requirement for the degree of
}

\author{
Doctor of Philosophy \\ in \\ Industrial Engineering
}

\author{
Ashish D. Nimbarte, Ph.D., Chair \\ Hongwei Hsiao, Ph.D. \\ Warren Myers, Ph.D. \\ Dan Nwaelele, Ed.D. \\ Gary Winn, Ph.D. \\ Department of Industrial and Management Systems Engineering

\section{Morgantown, West Virginia} \\ 2020
}

Keywords: shoulder, rotator cuff muscles, overhead work, fatigue, administrative controls Copyright 2020 Hossein Motabar 


\section{Abstract \\ Evaluation of control strategies for overhead work using electromyography of rotator cuff muscles}

\section{Hossein Motabar}

Work-related musculoskeletal disorders (MSDs) of shoulder have a significant impact on overall health and economics in the industrialized nations. Rotator cuff is the most frequently injured region in the shoulder complex. Overhead work is considered as one of the most predominant causes of rotator cuff injuries. The workers in construction, automotive, and aerospace industries are routinely exposed to overhead exertions. Elimination of overhead work is nearly impossible due to various task and technology constraints. Therefore, appropriate intervention strategies based on the engineering and administrative controls opt to be used to prevent the hazardous impact of overhead exertions. The objective of this study was to design administrative controls based on the principles of ergonomics and biomechanics and test their influence on the fatigue response of the rotator cuff muscles. As a first step towards developing such controls, a preliminary study was completed to understand baseline behavior of the rotator cuff muscles in terms of their strength, endurance, and fatigue response and subsequently two specific aims on control strategies were completed.

The first specific aim evaluated the effect of four different task rotation sequences on the activation and fatigue response of rotator cuff muscles. In the sequences, three different exertions (Hard $(\mathrm{H})$, Medium (M), and Low (L)) were performed in the following orders: increasing (LLMMHH), decreasing (HHMMLL), upward parabolic (HMLLMH), and downward parabolic (LMHHML). Trends in the median frequency of surface electromyography (EMG) data, maximum strength, and ratings of perceived exertion were used as the fatigue indicators. Despite the similar levels of muscle activation, the effect of task rotation sequence on muscle fatigue development was significant. The median frequency-based fatigue indicator reduced by $54 \%$ for supraspinatus, $53 \%$ for infraspinatus, and $39 \%$ for teres minor when high fatigue sequence (decreasing) was compared with low fatigue sequence (upward parabolic).

In the second specific aim, a moderate gripping exertion was added to the task rotation sequences to evaluate the effectiveness of a refresher exertion on the active recovery and the fatigue response of the rotator cuff muscles. On average, presence of the griping task reduced the percent drop in the median frequency by $36 \%$ for supraspinatus, $56 \%$ for infraspinatus, and $58 \%$ for teres minor when compared with the task rotation without gripping exertions (aim 1 study).

In conclusion, the results of this study indicate that performing tasks with a constant workload in different orders can alter rotator cuff muscles' fatigue development. A shorter duty cycle for the intense tasks, warm up exertions prior to the intense tasks, and low intensity/refresher exertions between the work cycles seem to be the key factors in designing control strategies based on task rotations. 
To

\begin{abstract}
My beloved wife Dr. Faezeh Motabar, Your endless love and support made it possible for me to finish this work Thank you for everything!
\end{abstract}

My dear parents Amir and Marzieh Motabar, Thank you for always believing in me

My brothers Omid and Hamidreza, Thank you for being my inspiration during tough days 


\section{Acknowledgments}

This dissertation would not have been possible without the continuous support and mentorship of my advisor Dr. Ashish Nimbarte. I would always be thankful for the great deal of knowledge and the problem solving skills he shared with me during these years. His encouragement and guidance made it possible to overcome all the challenges I faced throughout my Ph.D. endeavor.

I would also like to thank my committee members Dr. Hongwei Hsiao, Dr. Warren Myers, Dr. Dan Nwaelele, and Dr. Gary Winn for their invaluable suggestions and comments during this journey.

I thank my fellow colleagues in the Ergonomics Laboratory and the Industrial and Management Systems Engineering Department at West Virginia University for their assistance and support during these years.

Finally yet importantly, I would like to thank my wife, my parents, and my brothers who have always been my inspiration and support during my good and tough days. 


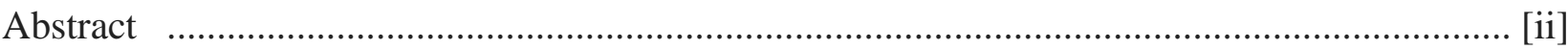

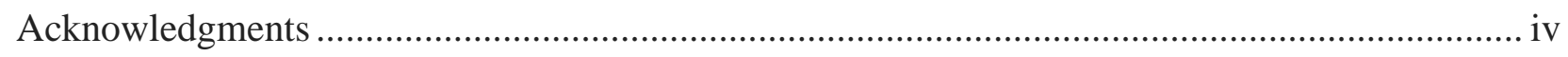

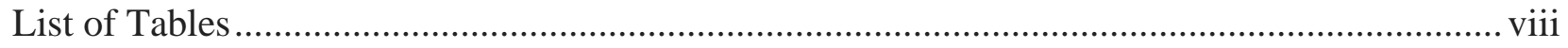

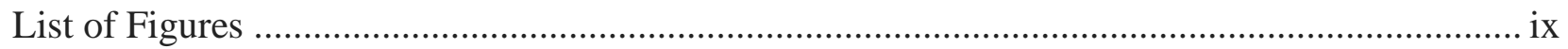

Chapter 1. Background...................................................................................................................... 1

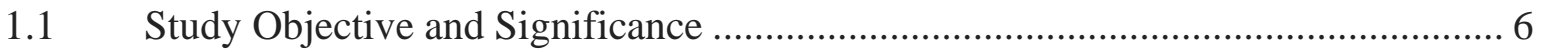

Chapter 2. Preliminary Study, Strength, endurance, and fatigue response of rotator cuff muscles during isometric exertions ..................................................................................8 8

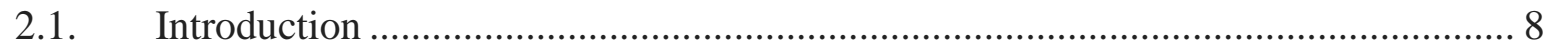

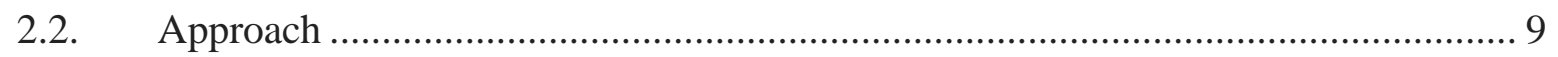

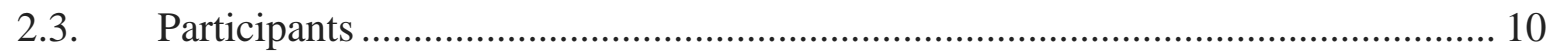

2.3.1. Sample size determination and statistical power analysis ............................... 10

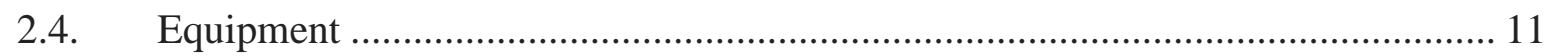

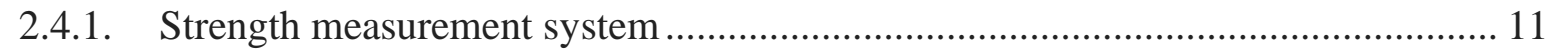

2.4.2. Electromyography (EMG) system............................................................ 12

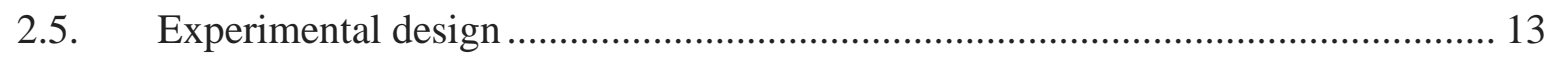

2.6. Data Processing and Statistical Analysis..................................................... 18

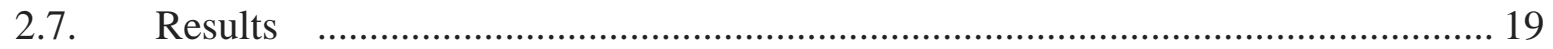

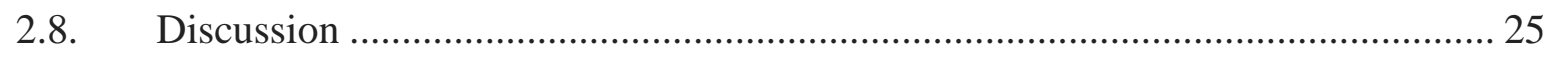

Chapter 3. Specific Aim \#1, The effect of task rotation on activation and fatigue response of rotator cuff muscles during overhead work................................................................ 29

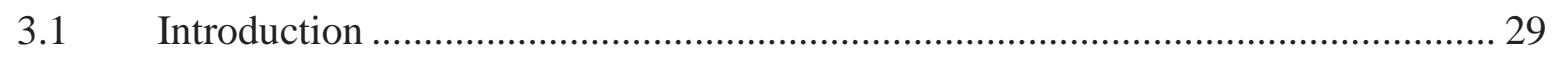

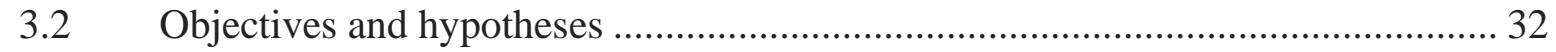

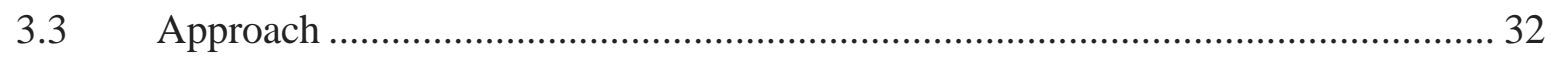

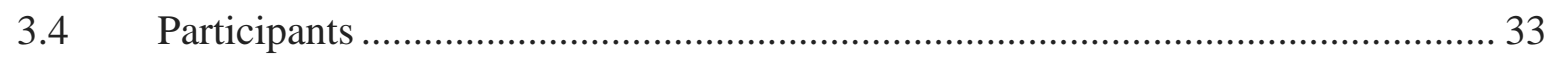

3.4.1 Sample size determination and statistical power analysis ................................. 33

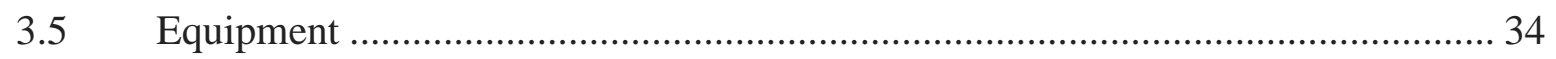

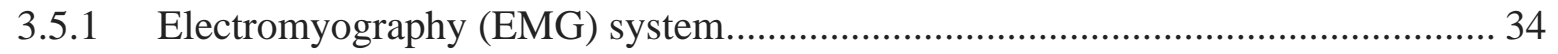

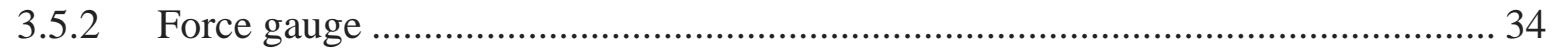

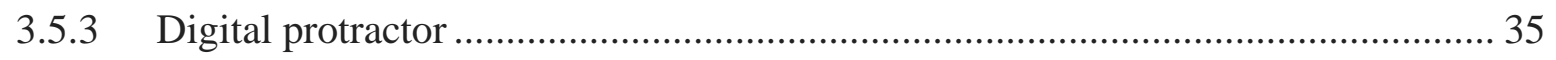


3.5.4 Adjustable work simulation system ………….................................................. 35

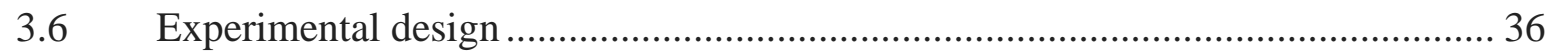

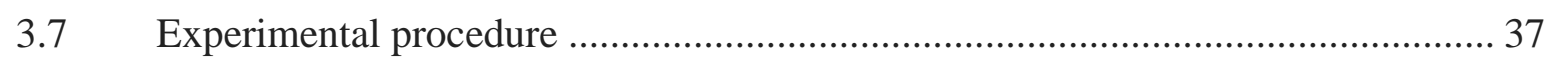

3.8 Data Processing and Statistical Analysis.............................................................. 40

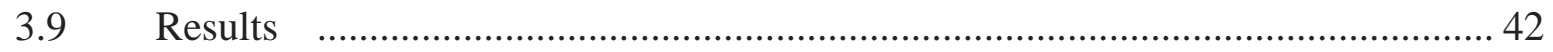

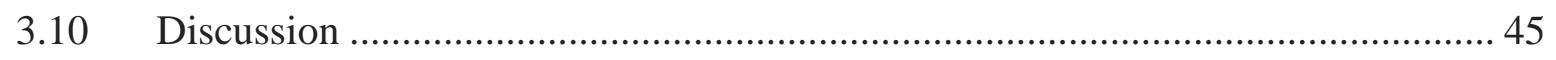

Chapter 4. Specific aim \#2, Effect of intermittent refresher exertions on the rotator cuff muscles' fatigue development........................................................................................................ 49

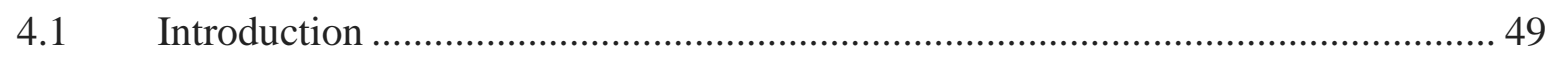

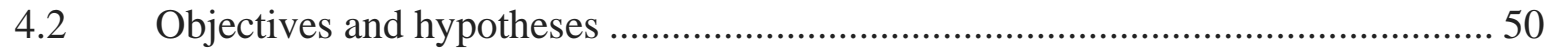

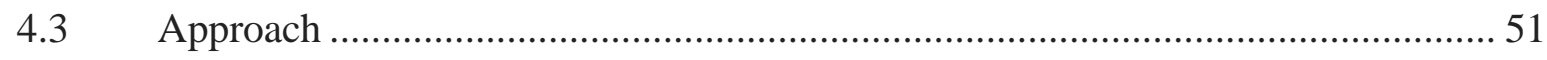

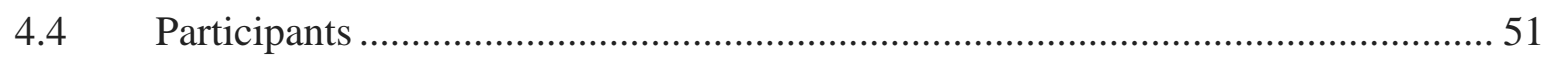

4.4.1 Sample size determination and statistical power analysis ..................................... 52

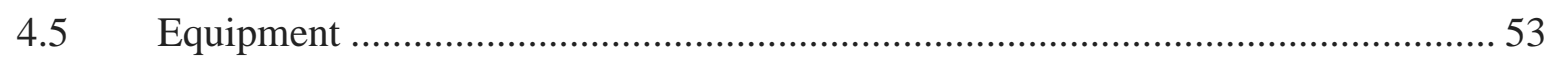

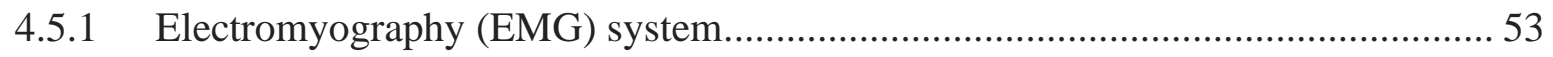

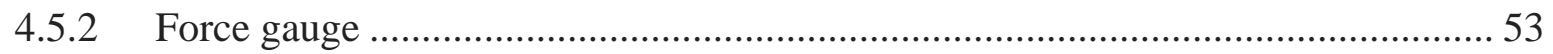

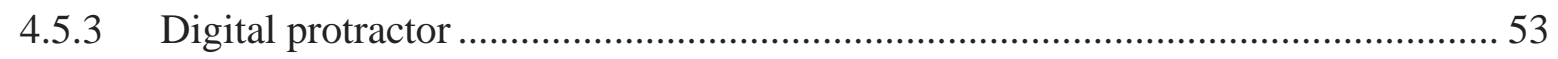

4.5.4 Adjustable work simulation system …………................................................. 53

4.5.1 Handgrip Dynamometer ……………………................................................. 53

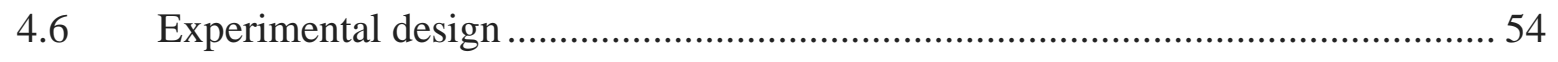

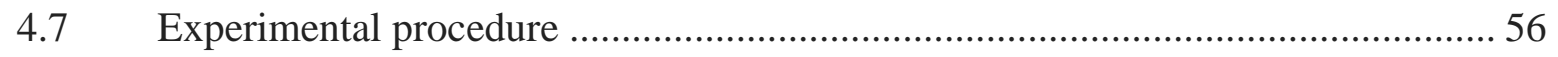

4.8 Data Processing and Statistical Analysis................................................................ 57

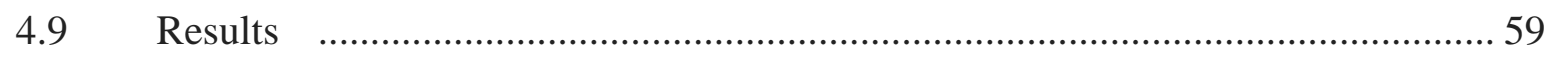

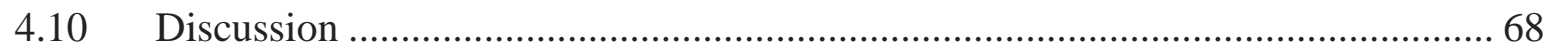

Chapter 5. Conclusion..................................................................................................................................... 72

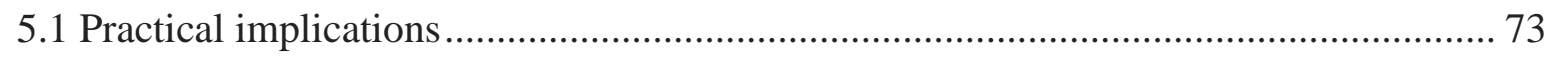

5.2 Limitations and future work....................................................................................... 74

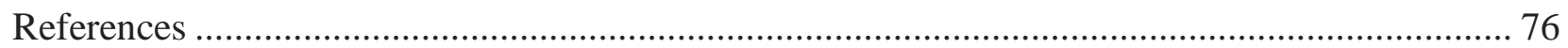

Appendix A: Literature review of the overhead studies on shoulder muscles ............................... 88

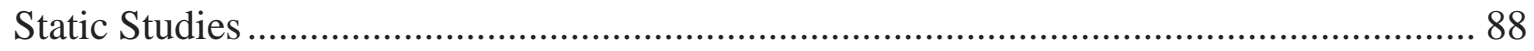

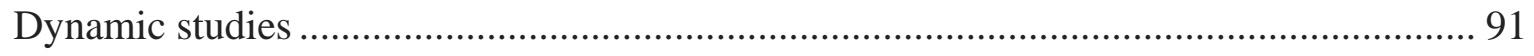


Appendix B: Preliminary study Consent form ............................................................. 102

Appendix C: Specific Aim \#1 and \#2. Consent form.............................................................. 107

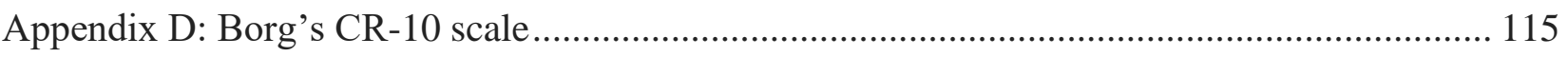

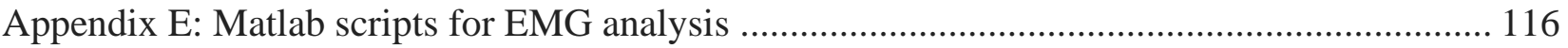

E.1 Matlab script for Median frequency computation ............................................ 116

E.2 Matlab script for average muscle activity computation ..................................... 119

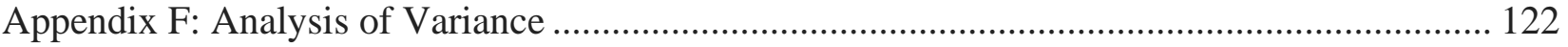




\section{List of Tables}

Table 1.statistical power corresponding to a different number of samples .............................. 11

Table 2. Surface EMG sensor placement for rotator cuff muscles ........................................ 17

Table 3. MVC postures and actions for rotator cuff muscles ............................................. 18

Table 4. Effect of \%MVC exertion levels on duration of exertion, median frequency slopes, and

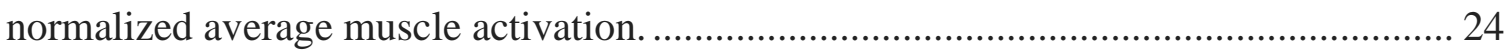

Table 5. Statistical power corresponding to a different number of samples ............................. 34

Table 6. Main effect of job rotation sequence on the normalized muscle activity and drop in the median frequency slope. Means (standard deviation (SD)) are statistically different if they do not share same letter.

Table 7. Main effect of job rotation sequence on the average RPE and normalized strength at MVC.

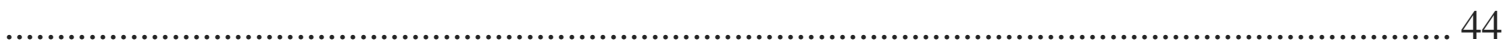

Table 8.statistical power corresponding to a different number of samples .............................. 52

Table 9. Main effect of job rotation sequence with the handgrip exertion on the normalized muscle activity and drop in the median frequency slope.

Table 10. A comparison of normalized muscle activity and drop in the median frequency slope for the rotation sequences with or without handgrip exertions.

Table 11. Main effect of job rotation sequence with the handgrip exertion on the drop in the normalized strength at MVC and average RPE.

Table 12. A comparison of normalized MVC drop and average RPE for the rotation sequences with or without handgrip exertions.

Table 13. Comparison of percent drop in the median frequency for the rotation sequences with and without handgrip exertions. 65

Table 14. Summary of the literature review of the overhead studies on shoulder muscles 94 


\section{List of Figures}

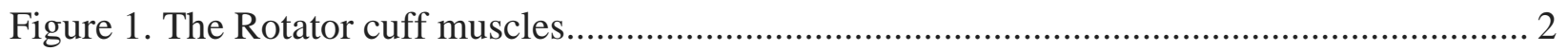

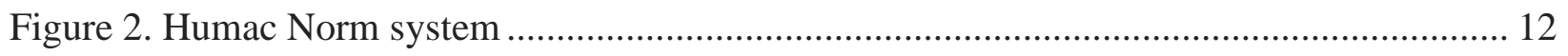

Figure 3. Parts of the Bagnoli -16 EMG system ............................................................. 13

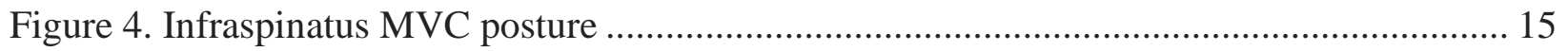

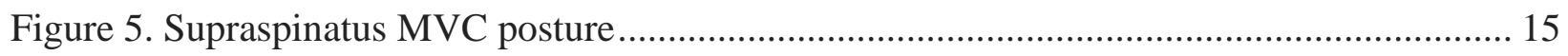

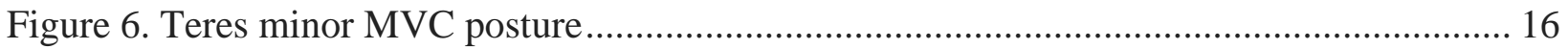

Figure 7. Real-time torque values displayed on the graphic display - bio-feedback feature of

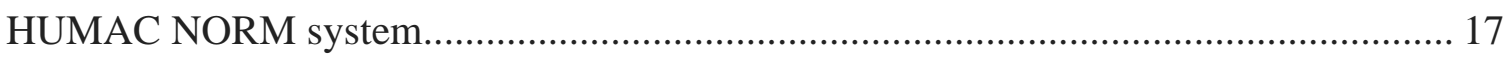

Figure 8. Magnitude of force and duration of exertion.................................................. 21

Figure 9. Average median frequency slopes at different \%MVC ........................................ 22

Figure 10. Median frequency data in the time domain at different \%MVC levels.................... 23

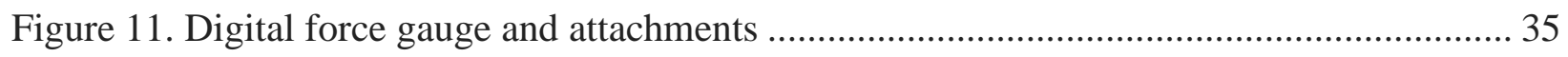

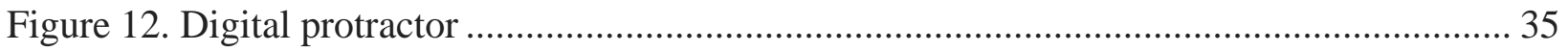

Figure 13. Adjustable work simulation system............................................................. 36

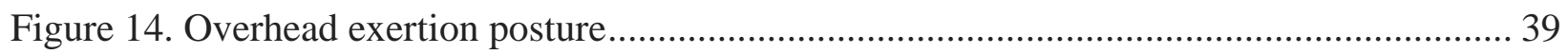

Figure 15. (A) Four rotation sequences used in this study: (1) decreasing, (2) increasing, (3) upward parabolic, (4) downward parabolic. Each bar represents a 5-minute session of overhead task at the specified \%MVC level. The arrows show the various measurements obtained during the sequences. (B) Task and rest order within each 5-minute session. ................ 41

Figure 16. Mean normalized muscle activity for the rotator cuff muscles at different job rotation sequences. Error bars represent standard error. .................................................. 43

Figure 17. Mean drop in the median frequency slope and strength at MVC for the job rotation sequences. Error bars represent standard error. ...................................................... 44

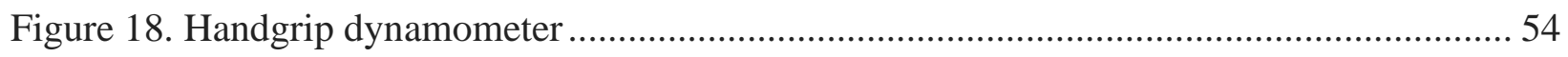

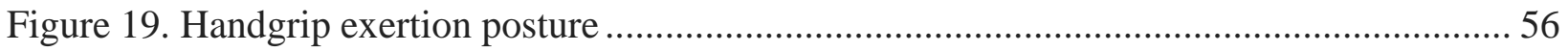

Figure 20. (A) Four rotation sequences used in this study: (1) decreasing, (2) increasing, (3) upward parabolic, (4) downward parabolic. Each bar represents a 5-minute session of overhead task at the specified \%MVC level. The arrows show the various measurements obtained during the sequences. (B) Overhead task, handgrip exertion, and rest order within each 5-

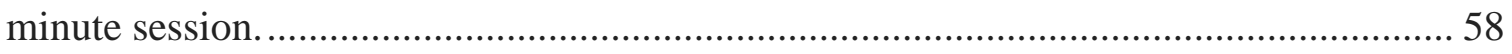


Figure 21. Mean normalized muscle activity for the rotator cuff muscles at different task rotation sequences with the handgrip exertion. Error bars represent standard error.................... 60

Figure 22. Mean drop in the median frequency slope and strength at MVC for the task rotation sequences with the handgrip exertion. Error bars represent standard error..................... 60

Figure 23. Mean normalized activity for the task rotation sequences with and without the handgrip

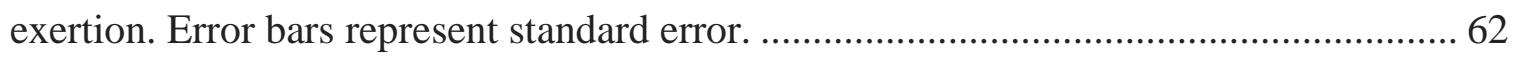

Figure 24. Mean drop in the median frequency slope for the task rotation sequences with and without the handgrip exertion. Error bars represent standard error. ............................. 62

Figure 25. Mean percent drop in the median frequency slope for the task rotation sequences with and without the handgrip exertion. Error bars represent standard error. ......................... 65

Figure 26. Mean drop in the strength at MVC for the task rotation sequences with and without the

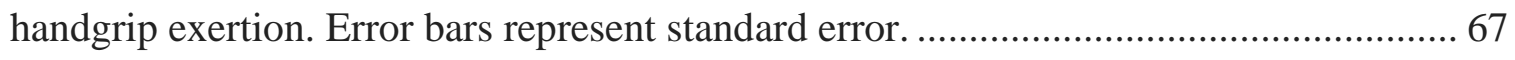

Figure 27. Mean RPE for the task rotation sequences with and without the handgrip exertion. Error

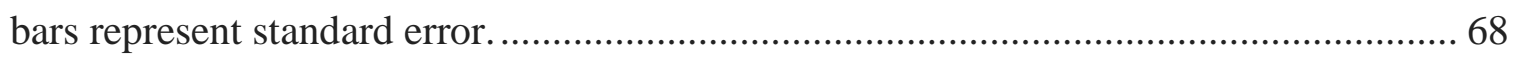

Figure 28. Suggested order for the tasks that are being done during a drywall installation ......... 74 


\section{Chapter 1. Background}

Work-related musculoskeletal disorders (MSDs) have a significant impact on overall health and economics. According to the American Academy of Orthopaedic Surgeons (AAOS) musculoskeletal disorders affect more than one out of two adult individuals in the United States. This ratio increases to three out of four in the elderly population (AAOS, 2009). Shoulder injuries are the most severe type of musculoskeletal disorders. Recovery of an injured shoulder takes a long time and only $50 \%$ of shoulder injuries fully recover after 6 months (Croft P et al., 1996). This number increases to only $60 \%$ at the end of the first year (Van der Windt et al., 1996). Shoulder injuries have caused the highest number of days away from work when compared with occupational injuries to all other body parts. The median days away from work caused by shoulder injuries was 23 days while the average of median days away from work was 8 for all other body parts combined (BLS, 2016). According to Bureau of labor statistics in 2016, 70,240 shoulder injuries have occurred with nearly $50 \%$ of them requiring more than 31 days away from work. In a report on worker compensation data in the state of Maryland, the average cost per shoulder injury was reported to be higher than the average cost per lower back injury claim $(\$ 25,378$ per claim compared to $\$ 22,447$ ) (Warnken, 2012). The data spanning from 2002 to 2010 revealed the mean direct costs of a shoulder MSD was \$60,298 per claim in the state of Washington (Anderson et al., 2015)

The glenohumeral, which is commonly known as shoulder joint, is characteristically unstable. It is classified as a ball and socket joint, but the articulating bones have a poor contact area. The head of the humerus (ball for this joint) is encapsulated within glenoid cavity of the scapula (socket for this joint) with contact region less than $30 \%$ of the humeral head. Such anatomical arrangement makes glenohumeral joint the most mobile joint in 
our body. However, the joint must rely heavily on the surrounding muscles to stabilize itself during physically demanding exertions. Among the various shoulder muscles, the rotator cuff muscles play an important role in stabilizing the GH joint (Figure 1). Infraspinatus, supraspinatus, teres minor and subscapularis are the rotator cuff muscles. The anatomical alignment of this group of muscles empowers them to compress the humeral head into the glenoid cavity (Lee et al., 2000; Labriola et al., 2005). The supraspinatus and subscapularis provide stability to the glenohumeral joint in the anterior direction in the mid-range of motion. The infraspinatus and teres minor are the generators of the posterior shear forces providing the stability to the joint in the end-range of motion (Lee et al., 2000). The stabilizing demands imposed on the rotator cuff muscles make them vulnerable to injuries, especially for the workers that routinely perform shoulder exertions (Ninković et al., 2014).

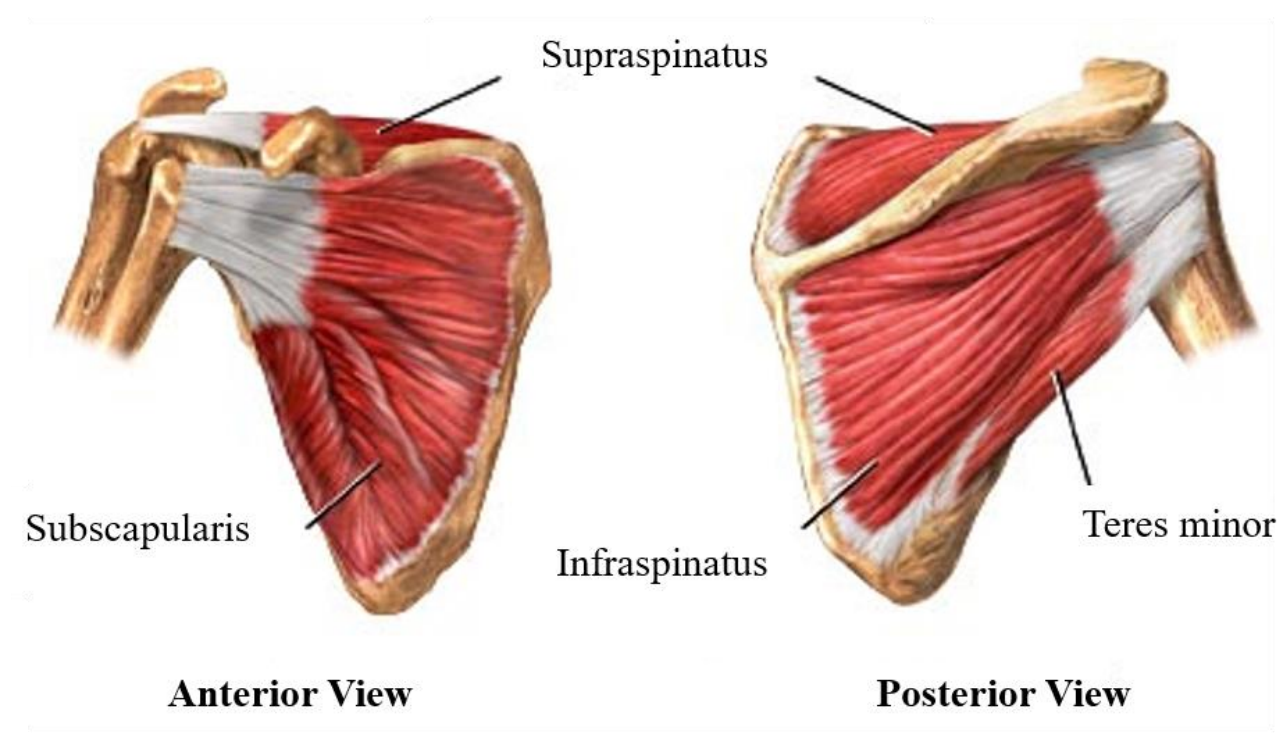

Figure 1. The Rotator cuff muscles

Figure is modified based on an image from https://medlineplus.gov 
The injuries of rotator cuff muscles are the third common types of injuries among all body parts after back and knee (Maffulli, 2011; Urwin et al., 1998). According to the statistics from the American Academy of Orthopedic Surgeons (AAOS) in 2006, out of 7.5 million people who met a doctor for shoulder injuries, 4.1 million suffered from rotator cuff problems (AAOS, 2009). Muscle tear is the most common injury of rotator cuff muscles. In previous cadaveric studies up to 39 percent of rotator cuff tear has been reported (Ward et al., 2006; Hatta et al., 2017). These tears could be symptomatic and asymptomatic and in both cases, can cause pain and limit the shoulder range of motion.

Multiple etiologies have been suggested in the pathogenesis of rotator cuff tear such as overhead exertions, repetitive stress and overexertion (Yamamoto et al., 2010). In particular, shoulder impingement syndrome, which accounts for $50 \%$ of clinically diagnosed shoulder disorders and can cause several shoulder problems including rotator cuff tears (van der Windt et al., 1996; Maciukiewicz et al., 2016), typically arises from working with overhead postures (Miranda et al., 2005; Svendsen et al., 2004; van Rijn et al., 2010; Maciukiewicz et al., 2016). In a study by Palmerud et al. (2000), it was shown that working overhead even without any hand load can increase the intramuscular pressure of Infraspinatus and Supraspinatus muscles above 40 mmhg. This intramuscular pressure can impair blood flow and cause muscle injury (Järvholm et al., 1991; Antony \& Keir, 2010). It has been reported that the risk of shoulder injury, pain, and discomfort can increase up to three times for the employees whose jobs involve overhead work (Miranda et al., 2005; Punnett et al., 2000). Based on previous observational studies, working with an overhead posture for more than $10 \%$ of total working time is a strong predictive factor of shoulder disorders (Punnett et al., 2000; Moriguchi et al., 2013). One of the results of overhead work is increase in shoulder muscle load, which can lead to fatigue and injury. In a previous study 
by Blache et al. (2015), it was reported that changing the height from shoulder level to eye level in a lifting task, resulted in $201 \%$ and $244 \%$ increase in supraspinatus and infraspinatus load respectively.

Overhead work has been considered as a common ergonomic risk factor in construction, manufacturing and assembly sectors (Hussain, 2004; Ferguson et al., 2011; Blache et al., 2015). It is also known that rotator cuff muscle strain and tear are among the common resultants of overhead work (Punnett et al., 2000; Nogueira et al., 2012; Blache et al., 2015; Maciukiewicz et al., 2016). In an observational study by Forde and Buchhols (2004) on construction workers, it was reported that workers spent up to 21 percent of the time doing overhead work. Welding, drilling, electric work, and drywall installation are among the most common overhead tasks in construction (Anton et al., 2001; Moriguchi et al., 2013; Dasgupta et al., 2016). As an example, drywall installers are required to raise, hold and install drywall panels, which can weigh up to $110 \mathrm{lb}$. Performing such tasks not only can cause shoulder MSDs but also affects the back, neck, hands, and wrist as well (Yuan et al., 2007).

Punnett et al. (2000) conducted a 10-month period case-referent study on 79 cases and 124 referents in an automobile assembly plant. It was reported that 51 percent of the workers were required to use severe flexion or abduction (>90 degrees) of one shoulder and 27 percent did so with both shoulders for at least 10 percent of the job cycle.

Although elimination of overhead work seems to be the best way to minimize shoulder MSDs, nature of the current industrial settings and high cost of modifying or redesigning the tasks that require overhead work, makes it nearly impossible to fully eliminate this type of exertions from the workplaces (American Automobile Manufacturers Association, 1999; Garg et al., 2006; Chopp et al., 2010). 
When a certain type of work activities cannot be eliminated or redesigned, engineering and administrative controls are used to reduce risk of injuries/accidents. Engineering controls are proven to decrease muscle loading, improve posture and in general, reduce risk of MSDs (Ferguson et al., 2011, 2012; Rashedi et al., 2014; Rempel et al., 2007, 2010). As an example, Ferguson et al. (2011) studied the effect of an ergonomic intervention (i.e. use of an automobile rotator) in an automotive assembly line and reported a decrease in musculoskeletal exposure in low back and shoulder region. In a study on drywall installers, an electronic lifting device was used as an intervention to lift and hold the drywall against the ceiling while workers fixed it in place. This intervention reduced the exposure of the workers to overhead work and other ergonomic risks such as lifting and manual material handling.

Specific to overhead exertions, Rashedi et al. (2014) evaluated the effect of a wearable assistive device for an overhead drilling task. They reported less shoulder muscle activity and improvements in the discomfort level of the participants while using the wearable device. However, they also found that the wearable device increased low back muscle activity. Some other challenges associated with the use of wearable devices include high cost and time-consuming adjustments of these devices. In order to work properly, wearable assistive devices must be adjusted in many ways (arm length, weight assist capacity, and degree of freedom) to properly fit the user. These adjustments as well as hygiene considerations makes such devices to be limited on one user which might not be financially practical for the production facilities. Furthermore, the use of wearable devices may reduce the physical load from a selected body region, the effect of these interventions on the whole body as well as compatibility with the other personal protective equipment (i.e. wearing the ergonomic assistive device with a fall protection harness or a coverall suit) may impose additional challenges. 
In addition to engineering controls, administrative controls are also used to prevent MSDs. Job/task rotation is one of the most commonly used administrative controls in the industry to avoid biomechanical overloading on a specific body part. In a study by Jorgensen et al. (2005), it was reported that $42.7 \%$ of the companies in the midwest US manufacturing sector use job rotation to prevent MSDs. Previous studies investigated the effects of different factors such as rotation

frequency (Horton et al., 2012), cycle time (Sood et al., 2017; Dickerson et al., 2015), task order (Keir et al., 2011; Raina and Dickerson, 2009; Horton et al., 2012), and task variation (Wells et al., 2010; Rissén et al, 2002; Frazer et al., 2003; Kuijer et al., 1999) on subjective and objective measures. These studies reported inconsistent results regarding the effectiveness of job/task rotation on preventing fatigue and discomfort.

\subsection{Study Objective and Significance}

Despite the frequency and severity of rotator cuff muscles disorders and its causal association with the work-related overhead exertions, very little research is done on design, development and evaluation of effective control strategies to prevent these disorders in the workplaces. In recent years, use of wearable assistive devices as an engineering control strategy has been proposed. However, short/long term impact of such devices on the health of rotator cuff muscles has yet to be fully understood. Regarding the administrative controls, to our knowledge, no work/knowledge is available in the literature that specifically target the safety of rotator cuff region/muscles during overhead exertions. To address this knowledge gap, the current study was aimed at developing and testing two administrative control strategies based on the principles of ergonomics and biomechanics. 
The first control strategy was designed using the concept of job rotation, in which the overhead exertions were systematically controlled using \% MVC demands to simulate increasing, decreasing, upward parabolic, and downward parabolic exertion patterns. The second control strategy was based on the knowledge that intermittent low to moderate exertions, also termed as "refresher exertions", can increase blood flow, diffusion of lactic acid buildup and thus reduce muscle fatigue. Specifically, in the second control strategy, moderate handgrip exertion was used as a refresher exertion and a series of such exertion were interjected within increasing, decreasing, upward parabolic, and downward parabolic exertion patterns.

Our central hypothesis is that the proposed control strategies would significantly influence the behavior of rotator cuff muscles during overhead exertions. Surface electromyography data was used to study the behavior of rotator cuff muscles in terms of their activation and localized muscle fatigue.

Results of this dissertation add new information to the body of knowledge on administrative control strategies. This is a significant contribution, as the area of research that deals with the control strategies that are focused on improving the health and safety of rotator cuff muscles is an understudied area and effective control strategies are absolutely essential to curtail the incidence of work-related MSDs. 


\section{Chapter 2. Preliminary Study}

\section{Strength, endurance, and fatigue response of rotator cuff muscles during isometric exertions}

\subsection{Introduction}

A preliminary study was conducted to obtain baseline load response relationship data for the rotator cuff muscles. Specifically, strength, endurance and activation behavior of rotator cuff muscles was studied.

The term "muscle strength" is defined as the maximum force that can be generated by a muscle or group of muscles (Chaffin et al., 2006). Body posture and joint angle have significant effects on muscle strength. Therefore, in order to compare the results of different subjects within a study or to compare results of different studies, muscle strength is typically measured using standardized postures. Such postures can also be used to obtain Maximum Voluntary Contraction (MVC) for the muscle of interest. Garg et al. conducted a study in 2005 to analyze the shoulder strength of female subjects in different overhead postures. They reported large variability in maximum strength and suggested a prescreening process prior to assigning workers to overhead tasks. In a cadaveric study by Keating et al. (1993), it was found that among the rotator cuff muscles, the subscapularis muscle was the strongest followed by Infraspinatus, Supraspinatus and Teres Minor. The moment contribution of each muscle was reported as subscapularis 53\%, Infraspinatus $22 \%$, Supraspinatus $14 \%$ and Teres minor $10 \%$ of the total rotator cuff moment.

Muscle MVC strength has been utilized in different studies to measure shoulder muscle fatigability (Sokk et al., 2007), muscle endurance (Rohmert 1960; Sato et al., 1984; Mathiassen et al., 1999; Garg at al., 2002; Roy et al., 2011), and to evaluate the load on neck and shoulder 
musculature (Nimbarte et al., 2010, 2012, 2014; Nimbarte et al., 2014). A negative exponential relationship between \% MVC and endurance time is known for different muscle groups including shoulder, i.e., low \%MVC trials provides infinite endurance time and 100\% MVC endurance time shows close to zero endurance time. Exertions in the range of 5 to $30 \% \mathrm{MVC}$ are considered lowintensity and this range is used as a guidance while recommending limit values for bodily exertions (Rohmert 1960; Sjøgaard et al., 2006). In a study performed by Jonsson (1982), muscular strain for different MVC exertions was studied using electromyography for the upper trapezius muscle. Limit values of $10 \%$ of MVC for mean load and $50 \%$ of MVC for peak load were recommended for the upper trapezius muscle.

Although some data is available for the shoulder muscle strength, endurance and acceptable muscle activation, data is certainly lacking for the rotator cuff muscles. Therefore, this study was aimed at generating and evaluating such data for the rotator cuff muscles. Strength of rotator cuff muscles at MVC was determined and subsequently the rotator cuff muscles were exposed to exertion at different \%MVC levels; endurance time and muscle physiological response, measured using surface electromyography (EMG), were recorded. Since muscle fatigue is considered as one of the precursors of MSD, the surface electromyography data was analyzed to understand fatigue trends.

\subsection{Approach}

A laboratory-based study was performed using human participants. MVC strength of three rotator cuff muscles, supraspinatus, infraspinatus and teres minor, was recorded. Subscapularis was excluded from this study because it is a deep muscle and surface EMG cannot be collected from it. For each muscle, endurance time and muscle activation data were recorded at four levels: $15 \%, 30 \%, 45 \%$ and $60 \%$ MVC. This range of $\%$ MVC was chosen based on a pilot study (Motabar 
et al., 2016) which showed that the exertions below 15\% MVC were generating very similar muscle activation levels and exertions above $60 \% \mathrm{MVC}$ were strenuous for majority of the participants. Four exertion levels within this range were selected to provide sufficient data points to establish relationship between \%MVC levels and the dependent variables.

\subsection{Participants}

Ten healthy male participants with no history of musculoskeletal diseases or shoulder pain were selected for the data collection. Participants were university going undergraduate and graduate students and their mean (SD) age, weight, and height were $24.2(5.1) \mathrm{yr} ., 78.33(7.8) \mathrm{kg}$, and $177.8(5.3) \mathrm{cm}$, respectively. All participants read and signed a consent form approved by the local Institutional Review Board (IRB) (Appendix B: Preliminary study Consent form).

\subsubsection{Sample size determination and statistical power analysis}

In this study, the operating characteristic (OC) curves were used to select the acceptable sample size and calculate the statistical power of the test. The calculations were based on the following formula (Montgomery, 2017).

$$
\begin{aligned}
& \Phi^{2}=\frac{n \sum_{i=1}^{a} \tau i^{2}}{a \sigma^{2}} \\
& \tau_{\mathrm{i}}=\mu_{\mathrm{i}}-\overline{-}
\end{aligned}
$$

Where,

$$
\begin{aligned}
& \Phi^{2}: \text { Noncentrality parameter } \\
& n: \text { number of participants } \\
& \alpha: \text { number of levels } \\
& \sigma^{2}: \text { estimate of the variance } \\
& \bar{\mu} \text { : Average of the individual treatment means }
\end{aligned}
$$




\section{$\mu_{\mathrm{i} ;}$ Specific treatment means}

Preliminary data obtained from three participants $(n=3)$ were used in the calculations. Estimated variance $\left(\sigma^{2}\right)$ and $\tau$ were calculated for the median frequency values and four levels of MVC percentage $(a=4)$. The statistical significance was set at $\alpha=0.05$. Table 1 shows the statistical power values corresponding to a different number of samples.

Table 1.statistical power corresponding to a different number of samples

\begin{tabular}{|c|c|c|c|c|c|}
\hline $\mathbf{n}$ & $\mathbf{\Phi}$ & $\mathbf{v}_{\mathbf{1}}$ & $\mathbf{v}_{\mathbf{2}}$ & $\boldsymbol{\beta}$ & Power (1- $\boldsymbol{\beta})$ \\
\hline $\mathbf{3}$ & 1.475 & 3 & 8 & 0.56 & 0.44 \\
\hline $\mathbf{5}$ & 1.904 & 3 & 16 & 0.19 & 0.81 \\
\hline $\mathbf{7}$ & 2.253 & 3 & 24 & 0.055 & 0.945 \\
\hline $\mathbf{9}$ & 2.555 & 3 & 32 & 0.015 & 0.985 \\
\hline
\end{tabular}

According to the results of power analysis, corresponding power for a sample size of nine would be $98.5 \%$. Therefore, nine participants should be enough for this study to reach the desired power.

\subsection{Equipment}

\subsubsection{Strength measurement system}

The HUMAC NORM (Computer Sports Medicine, Inc., MA, USA) system was used to conduct MVC trials Figure 2. The system consists of a dynamometer with 360 degree rotation ability and adjustable range of motion stops, multiple adapters for force exertion, movable and adjustable chair with a four point seatbelt harness, integrated computer system and a graphic display. For the data collection, the participants were seated in the chair and the seatbelt harness was fastened. The relative positions of the chair and dynamometer were adjusted for each 
participant to get the participant in the muscle specific MVC posture (Table 3). The HUMAC NORM system has an in-built bio-feedback feature, i.e., the participants can see real-time torque values on the graphic display during an exertion to assist them with maintaining a target force/exertion level.

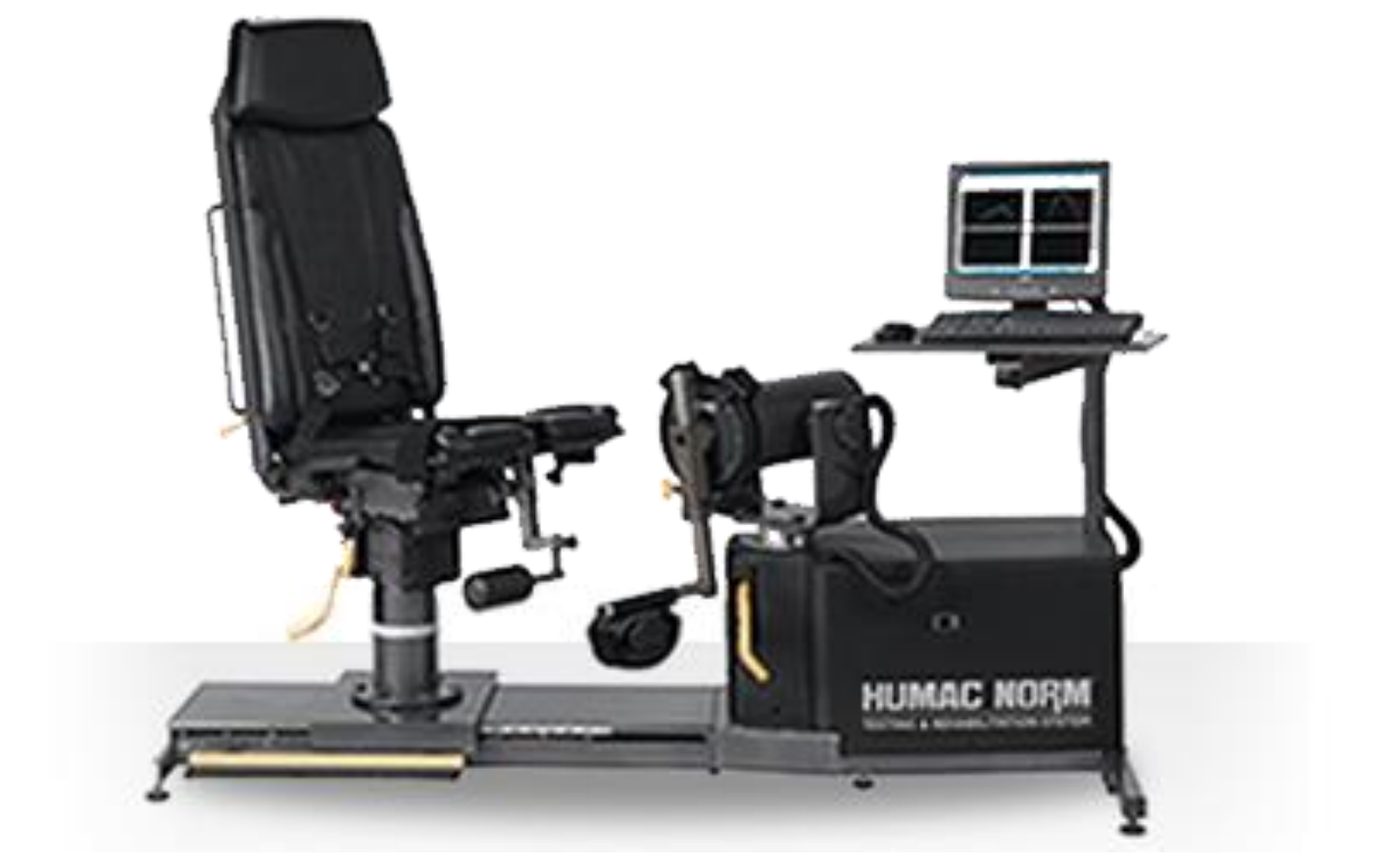

Figure 2. Humac Norm system

\subsubsection{Electromyography (EMG) system}

Bagnoli -16 desktop EMG system (Delsys Inc., Boston, USA) was used to measure rotator cuff muscles activity (Figure 3). The system mainly consists of EMG sensors (parallel bars from 99.9\% pure silver and $92 \mathrm{~dB}$ of Common-mode rejection ratio), a main amplifier unit, input modules, input cable, power supply, and other peripheral cables. To collect muscle activity, EMG sensors were placed on the participant and then connected to the input module. Signals were then transferred from the input module to the amplifier and from there to the computer. The muscle activity data was recorded at a frequency of $1000 \mathrm{~Hz}$. 


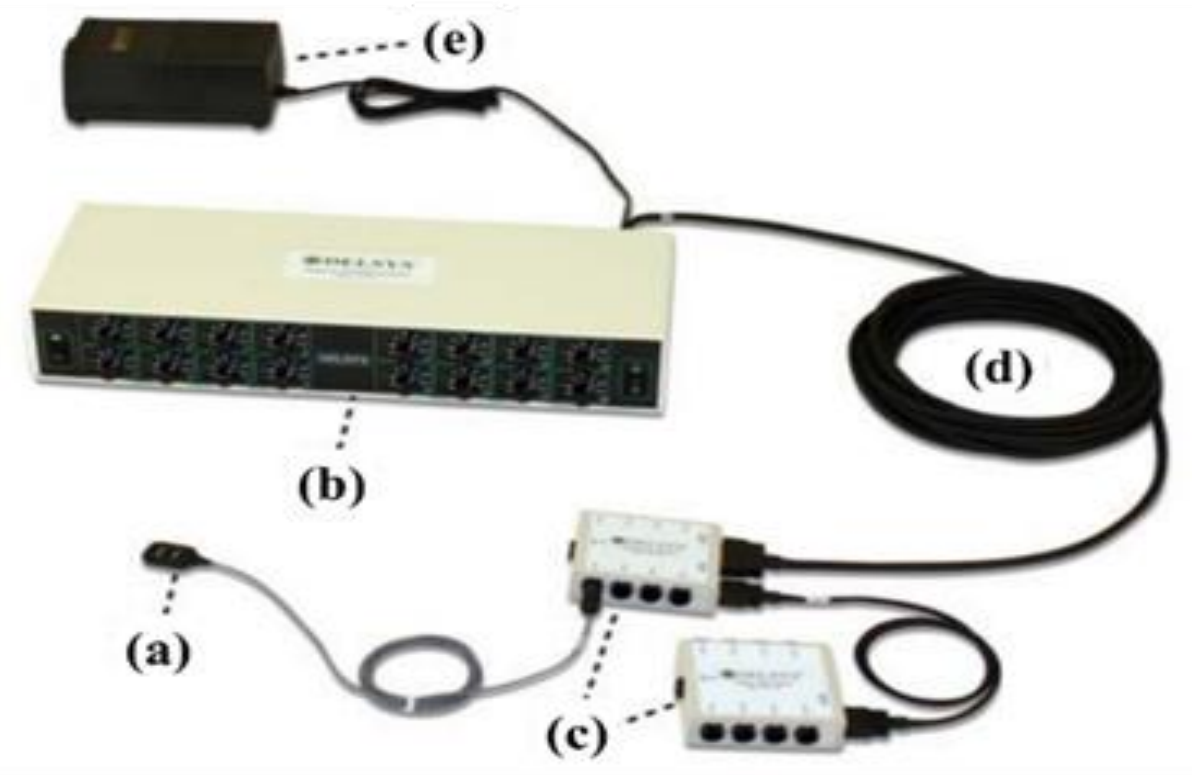

Figure 3. Parts of the Bagnoli -16 EMG system

(a) EMG sensor, (b) main amplifier unit, (c) input modules, (d) input module cable, and (e) power supply.

\subsection{Experimental design}

A two-part experiment was designed for this study. First, maximum voluntary contraction (MVC) was measured for Supraspinatus, Infraspinatus and Teres Minor muscles. Then, measured MVC was used as a reference for the second part of the experiment during which four exertions at $15 \%, 30 \%, 45 \%$ and, $60 \%$ of the MVC were conducted for each muscle. To avoid any systematic influences of fatigue and/or learning effects the testing order was randomized.

Each participant, upon arrival for data collection, was asked to provide their demographics (height, weight, and age) and was informed of the basic procedure to be used for the data collection process. To have proper contact, prior to the electrode placement, the skin over the anatomical landmark was shaved and wiped with alcohol. EMG sensor placement information can be seen in Table 2 (Boettcher et al., 2008; Perotto 2011; Xu et al., 2014). The participant was then seated in the HUMAC NORM and secured to the chair to ensure that no external forces or movements can 
affect the measurements. Next, the participants practiced force exertions using the HUMAC NORM system. The practice exertions allowed the participants to learn the muscle specific MVC postures and the bio-feedback feature of the HUMAC NORM system. Practice for each posture was performed once or twice and the participants were not required to exert the maximal force to avoid muscle fatigue. Sufficient rest-time 1-2 minutes was provided between practice and the actual MVC exertions. Muscle specific postures were used to measure MVC strengths of the rotator cuff muscle (Table 3) (Figure 4, Figure 5, Figure 6) (Boettcher et al., 2008; Perotto 2011; $\mathrm{Xu}$ et al., 2014). During each MVC trial, the participant was instructed to apply force slowly and steadily without jerking motion, until maximum exertion was reached. Each MVC trial lasted for approximately 7 to 9 seconds, 2-3 seconds for building the force/strength to maximum, 3 seconds to hold the maximum strength and 2-3 seconds to gradually return to a level of no force.

For each muscle, MVC measurement was repeated until three values within $10 \%$ of each other is measured (De luca et al., 1996). Adequate rest time was provided to the participant between each MVC measurement. Previous studies have shown a positive correlation between verbal encouragement and peak value of MVC (McNair et al., 1996). These studies concluded that when verbal encouragement is used there is a 5\% increase in peak MVC. In this study, we used verbal encouragement in all MVC trials to get the highest value of MVC.

Once the MVC trials were completed, the data was processed to determine $15 \%, 30 \%, 45 \%$ and $60 \%$ MVC levels. Subsequently, the test participant performed \%MVC exertion trials. For each rotator cuff muscle, four \%MVC exertions were conducted using MVC postures and action explained in Table 3. 


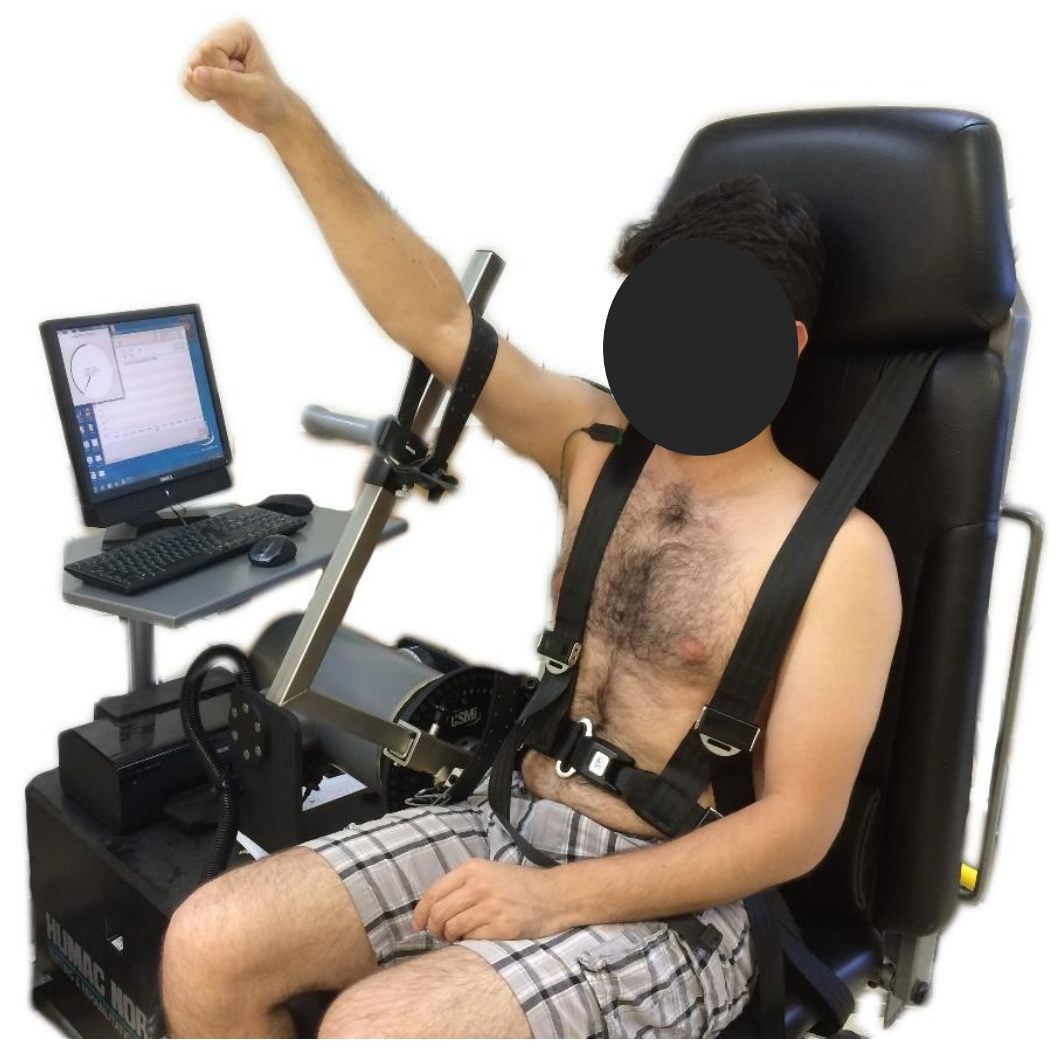

Figure 4. Infraspinatus MVC posture

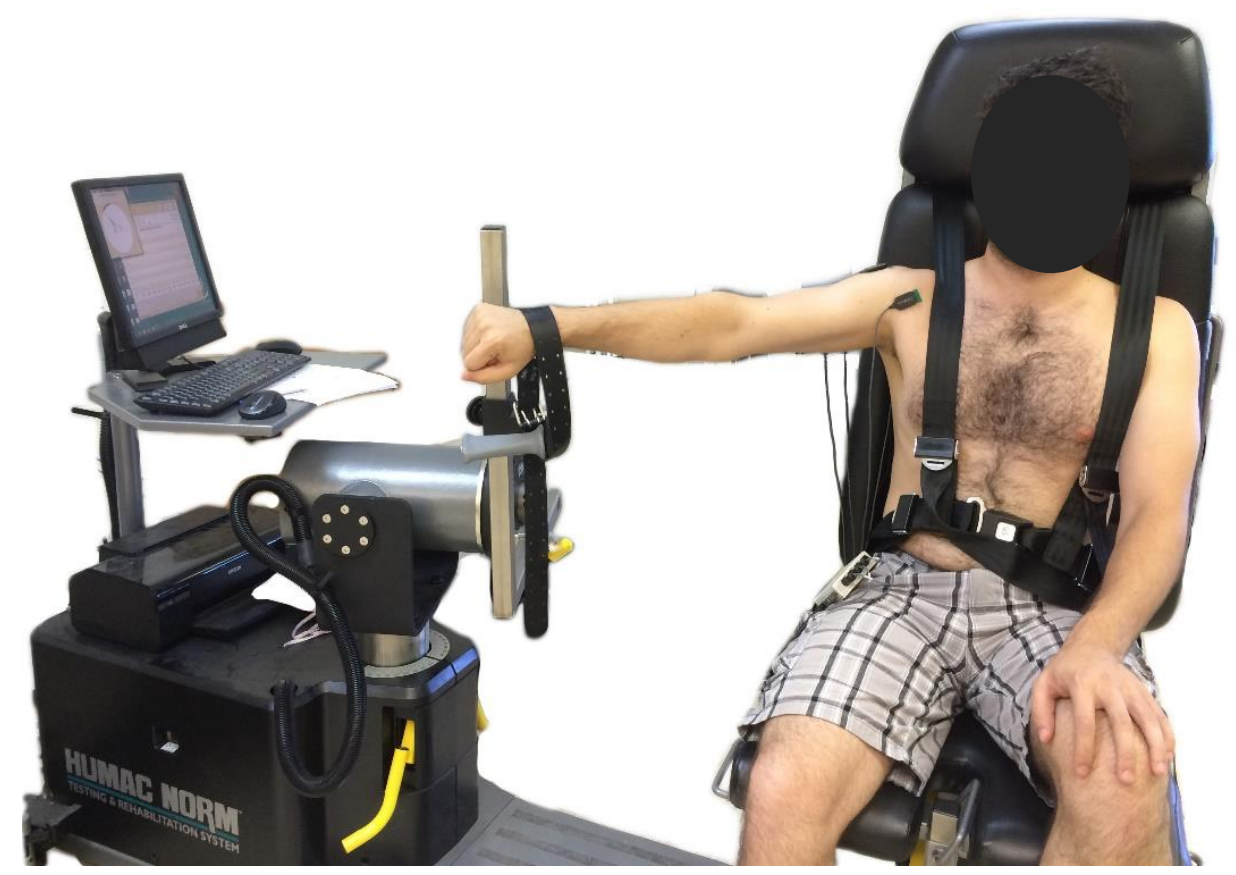

Figure 5. Supraspinatus MVC posture 


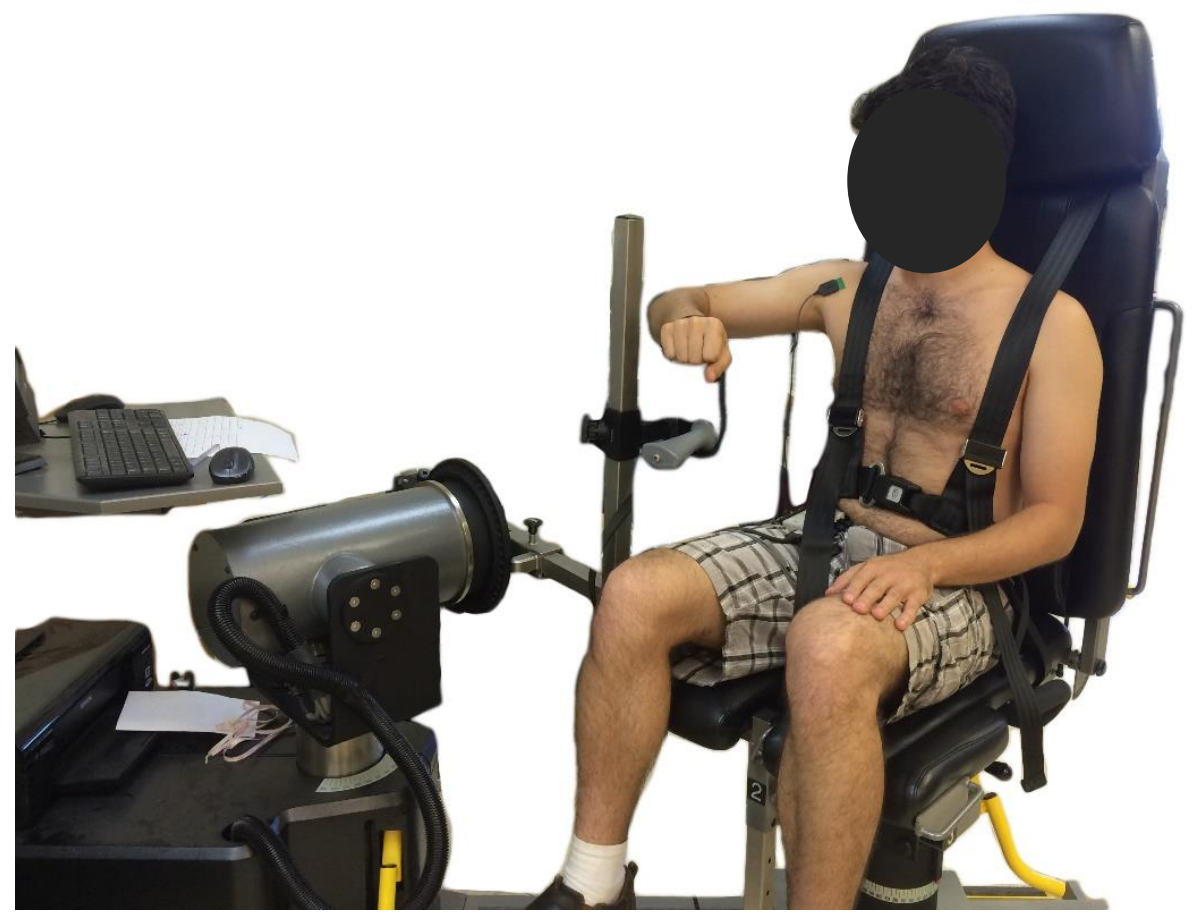

Figure 6. Teres minor MVC posture

Thus, each participant completed $12 \%$ MVC exertions. Independent of the muscle, the duration of each \% MVC trial was controlled at maximum one minute. Duration of one minute was selected based on the findings of our pilot study and literature review (Arnall et al., 2002; Al Zaman et al., 2007; Chopp et al., 2010; Conwit et al., 1999). As expected during the pilot study it was found that participants were able to exert force for a much longer duration ( $>1$ minute) during $30 \%$ MVC trials compared to $45 \%$ ( 1 minute) and 60\% MVC (<minute) trials. Therefore, to make the duration long enough such that it is sufficient to generate fatigue during $30 \%$ MVC trials and at the same time, it is tolerable to the participants during $60 \% \mathrm{MVC}$ trials, a duration of one minute was used. The biofeedback feature of the HUMAC NORM system (explained in section 2.4.1) was used to assist participants with controlling target force levels during the \% MVC trials (Figure 7). 


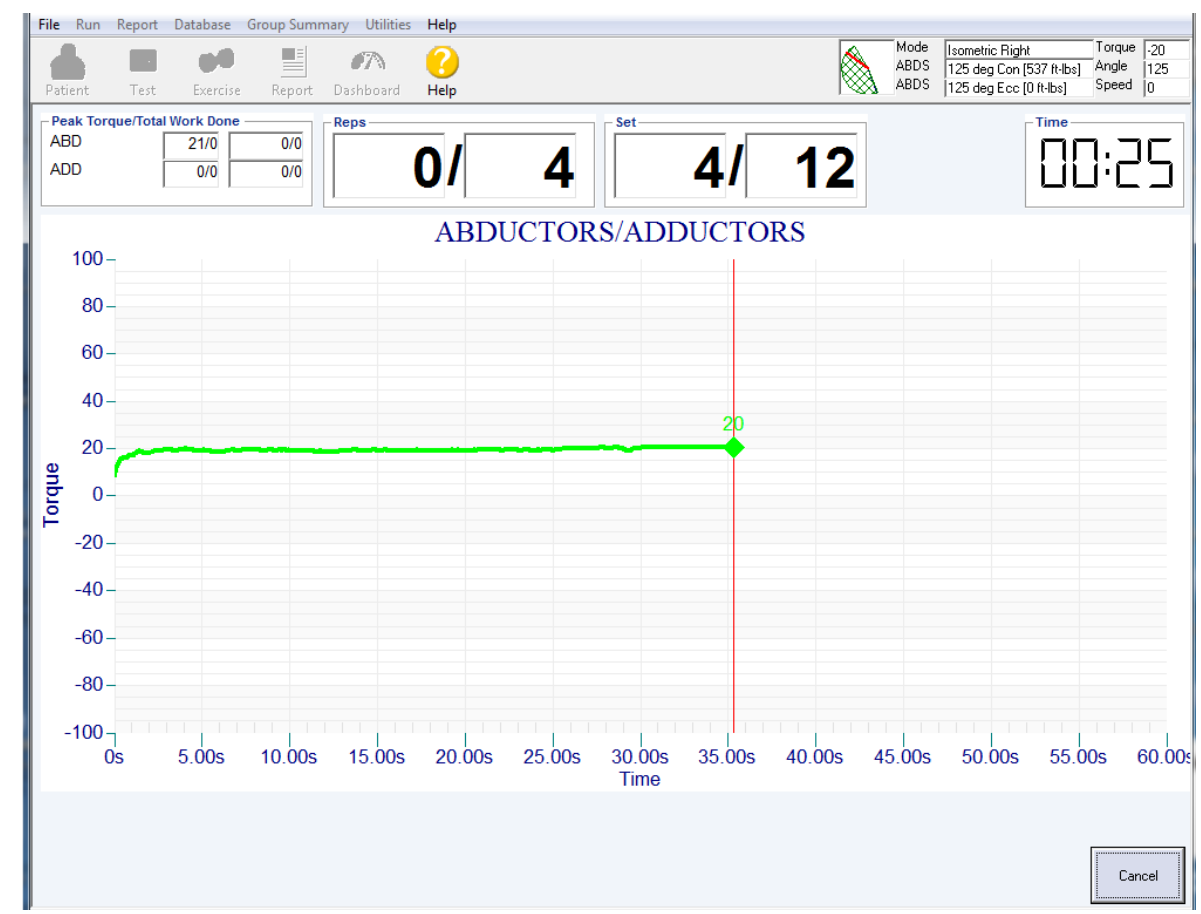

Figure 7. Real-time torque values displayed on the graphic display - bio-feedback feature of HUMAC NORM system

Each session was terminated at the end of 1 minute testing period or if the participant is exhausted or if the exerted torque level falls and stays below 5\% of the target value for more than 2 seconds. The EMG data was recorded continuously during the trial. Between each exertion, sufficient rest time was provided to the participant.

Table 2. Surface EMG sensor placement for rotator cuff muscles

\begin{tabular}{|l|l|}
\hline \multicolumn{1}{|c|}{ Muscle } & \multicolumn{1}{c|}{ EMG sensor placement } \\
\hline Supraspinatus & Slightly above the upper border of the spine of scapula \\
\hline Infraspinatus & $4 \mathrm{~cm}$ below the medial border of the spine of scapula \\
\hline Teres Minor & $\begin{array}{l}\text { One-third of the distance from acromion to the interior angle of scapula along } \\
\text { lateral border. }\end{array}$ \\
\hline
\end{tabular}


Table 3. MVC postures and actions for rotator cuff muscles

\begin{tabular}{|l|l|l|}
\hline \multicolumn{1}{|c|}{ Muscle } & \multicolumn{1}{|c|}{ MVC posture } & \multicolumn{1}{c|}{ MVC action } \\
\hline Supraspinatus & $\begin{array}{l}\text { The shoulder abducted in the scapular } \\
\text { plane to } 90^{\circ} \text { with elbow rotated internally } \\
\text { to } 45 \text { degrees. }\end{array}$ & $\begin{array}{l}\text { Arm abduction with resistant force } \\
\text { applied at wrist. }\end{array}$ \\
\hline Infraspinatus & $\begin{array}{l}\text { The shoulder flexed in sagittal plane to } \\
125 \text { degrees. }\end{array}$ & $\begin{array}{l}\text { Participant will resist a force applied } \\
\text { above the elbow toward the inferior } \\
\text { angle of the scapula. }\end{array}$ \\
\hline Teres Minor & $\begin{array}{l}\text { The shoulder abducted to } 90^{\circ} \text { in the } \\
\text { scapular plane with } 90^{\circ} \text { elbow flexion. }\end{array}$ & $\begin{array}{l}\text { Arm externally rotates with resistant } \\
\text { force applied at the wrist. }\end{array}$ \\
\hline
\end{tabular}

\subsection{Data Processing and Statistical Analysis}

The data was processed using MATLAB software (MathWorks Inc., Natick, MA, USA). Raw EMG signals were filtered using a band pass filter between $10-500 \mathrm{~Hz}$ and to eliminate ambient noise a notch filter was used at $60 \mathrm{~Hz}$. The filtered EMG data were demeaned, i.e., mean was subtracted from each data point to center the data at zero, and then full-wave rectified, i.e., converted to absolute values. The rectified signals were smoothed using a 100 data point sliding window. The resulting data were averaged to determine mean muscle activity. The mean muscle activity for the experimental trials were normalized with respect to mean muscle activity obtained during the MVC exertions to determine normalized muscle activity for the individual muscles. To estimate muscle fatigue filtered EMG data were transformed to the frequency domain using fast Fourier transformation to estimate median frequency. Exertion time was divided to 10 divisions and median frequency was calculated for each division. The 10-point data was fitted with a linear regression line and the slope of the line was computed. A decrease in the median frequency, indicated by negative slope, was considered as a sign of muscle fatigue (De Luca 1984; Niemeyer et al., 2004; Minning et al., 2007; Kai et al., 2012). 
The statistical analysis was performed to understand if the strength at MVC is different between the muscles, i.e., to test if muscle has any effect on the strength at MVC. Additionally, for each muscle the effect of \%MVC exertion level on endurance time, muscle fatigue and muscle activation was examined. Minitab 17 Statistical Software was used to perform the statistical analysis. General Linear Analysis of Variance (ANOVA) model in Minitab that analyzes repeated measures design was used to perform the statistical analysis. To test the effect of muscle on the strength at MVC, the independent variable muscle was treated as a fixed factor with three levels, i.e., Supraspinatus, Infraspinatus, and Teres minor. The dependent variable was the strength and the participant was treated as a random factor.

For each muscle to test the effect of \%MVC exertion level, the exertion level was treated as a fixed factor with four levels, i.e., 15\%, 30\%, 45\%, and 60\% MVC and the dependent variables were the endurance time, normalized muscle activity and muscle fatigue measured using the slope of the linear regression lines. The participant was treated as a random factor. Separate ANOVA was performed for one muscle and one dependent variable combination. The data were tested for normality and equality of variance prior to performing the ANOVA. The statistical significance was set as $\alpha=0.05$ and the significant effects were further evaluated by conducting comparisons between means using Tukey’s Honestly Significant Difference (HSD) all-pairwise comparison test.

\subsection{Results}

Average torque at MVC exertions were 34.96 (12.15) Nm for Supraspinatus, 60.00 (15.56) Nm for Infraspinatus and 48.93 (19.69) Nm for Teres Minor muscles. The corresponding force levels during the muscle specific MVC exertions, calculated by dividing torque with the arm length, i.e., the distance from the point of exertion and center point of the dynamometer were 85.05 
(32.65) N for Supraspinatus, 175.81 (30.22) N for Infraspinatus and 158.29 (51.44) N for Teres Minor muscles. The ANOVA indicates that the difference in mean force values were statistically significant among muscles ( $\mathrm{p}$-value $<0.001)$. A between muscle comparison test was conducted for MVC torque and results show that the corresponding means are significantly different for Supraspinatus-Infraspinatus, Supraspinatus -Teres Minor and, Infraspinatus-Teres Minor. Figure 8 shows the trend of average force exerted by participants and the average time of exertion for three muscles at each MVC level. All participants were able to exert the force for a full minute only for the Infraspinatus muscle during $15 \%$ MVC exertion. Mean exertion time for Supraspinatus and Teres Minor were 56.7(7) and 58.6(4), respectively during 15\%MVC trials. Mean exertion time decreased with an increase in $\% \mathrm{MVC}$. The effect of $\% \mathrm{MVC}$ on the mean exertion time was statistically significant (Table 4).

Results of post hoc comparison performed using the Tukey test indicated that mean exertion time for 15\% MVC was different than 45 and 60\% MVC, and 30\% MVC was different from 45 and 60\% MVC for Infraspinatus and Supraspinatus. For Teres Minor, 15\% MVC was different from $60 \%$ MVC. 
- Force, Supraspinatus $\quad \square$ Force, Infraspinatus $\quad \square$ Force, Teres minor

○ Time, Supraspinatus

$\Delta$ Time, Infraspinatus $\quad \square$ Time, Teres minor

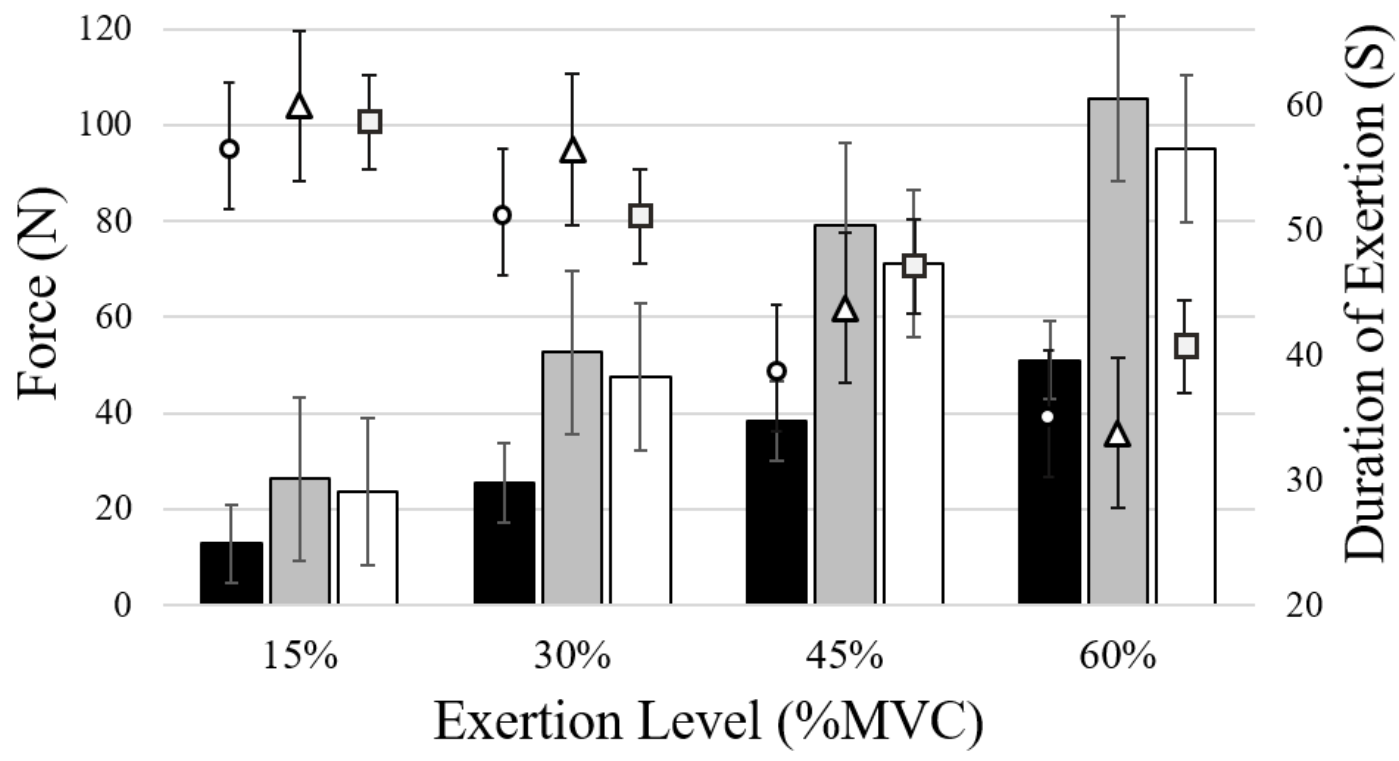

Figure 8. Magnitude of force and duration of exertion

Magnitude of force (represented using bars and primary axis on the left) and duration of exertion (represented using markers and secondary axis on right) at different \% MVC exertion levels. Error bars represent standard error.

The effect of \%MVC exertion on muscle fatigue measured using median frequency slope was statistically significant (Table 4). In general, the negative slope increased with the increase in \%MVC (Error! Reference source not found. and Figure 10). For Supraspinatus, when \%MVC was increased from $15 \%$ to $30 \%$ to $45 \%$ to $60 \%$, the negative slope increased by $23.5 \%, 11.2 \%$, and $2.7 \%$, respectively. For Infraspinatus, the negative slope increased by $17.1 \%, 12.2 \%$, and 9.4\%, respectively and for Teres Minor these changes were $107.7 \%, 8.7 \%$, and $-6.3 \%$ respectively. Results of the post hoc comparison performed using the Tukey test indicated that the slope for 15\% MVC was significantly different from $45 \%$ and $60 \%$ MVC trials for Supraspinatus; $15 \%$ 
MVC was significantly different from $60 \% \mathrm{MVC}$ for Infraspinatus, and for Teres Minor slope for $15 \%$ MVC trials was significantly different than all other \% MVC trials.

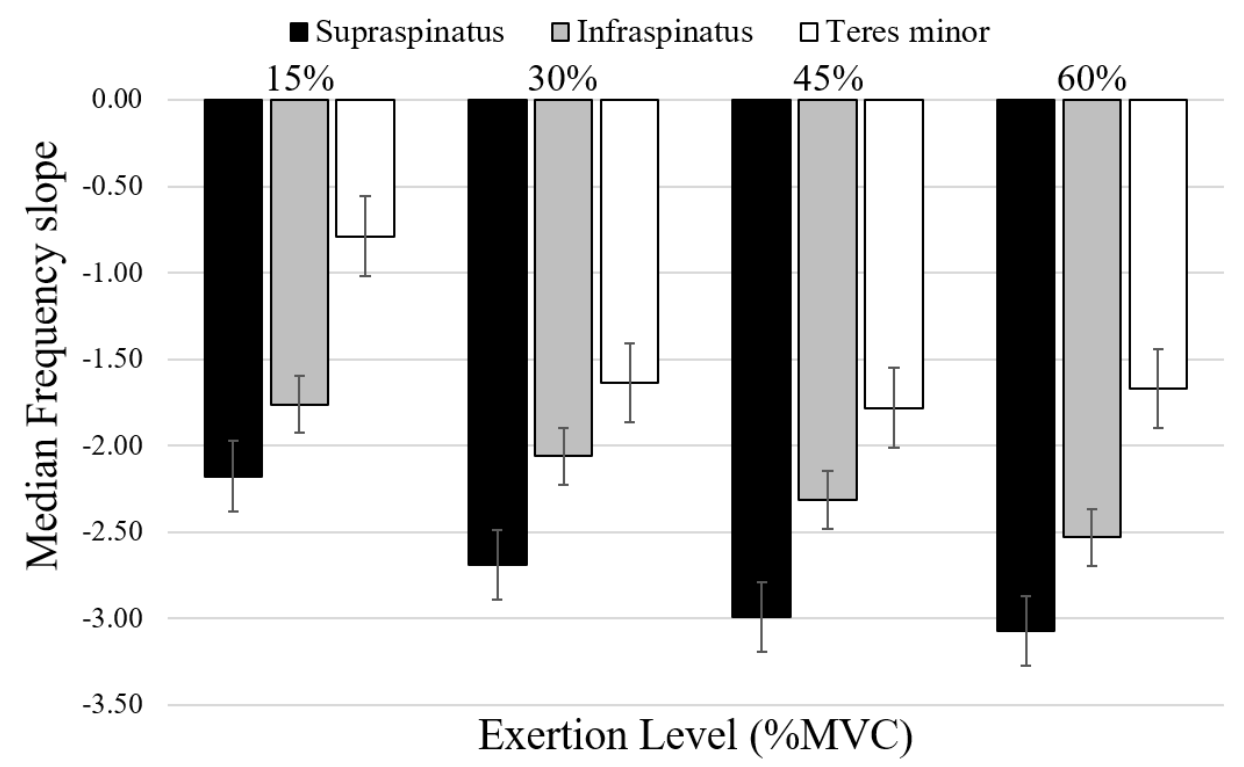

Figure 9. Average median frequency slopes at different \%MVC Error bars indicate standard error.

The effect of \%MVC exertion on average muscle activity was statistically significant (Table 4). In general, with an increase in the \%MVC exertion the EMG activity increased, however, a much smaller increase in the muscle activation was observed when exertion level was increased from $45 \%$ to $60 \%$ MVC. For Supraspinatus, an increase in $\%$ MVC from $15 \%$ to $30 \%$ to $45 \%$ led to an increase in average muscle activity by $20 \%$ and $30 \%$, respectively. Average muscle activity remained the same when $\% \mathrm{MVC}$ increased from $45 \%$ to $60 \%$. For Infraspinatus, an increase in $\% \mathrm{MVC}$ from $15 \%$ to $30 \%$ to $45 \%$ to $60 \%$, led to an increase in average muscle activity by $42 \%$, $32 \%$ and, 5\%, respectively and for Teres minor, these changes were $62 \%, 23 \%$ and, $23 \%$ respectively. 

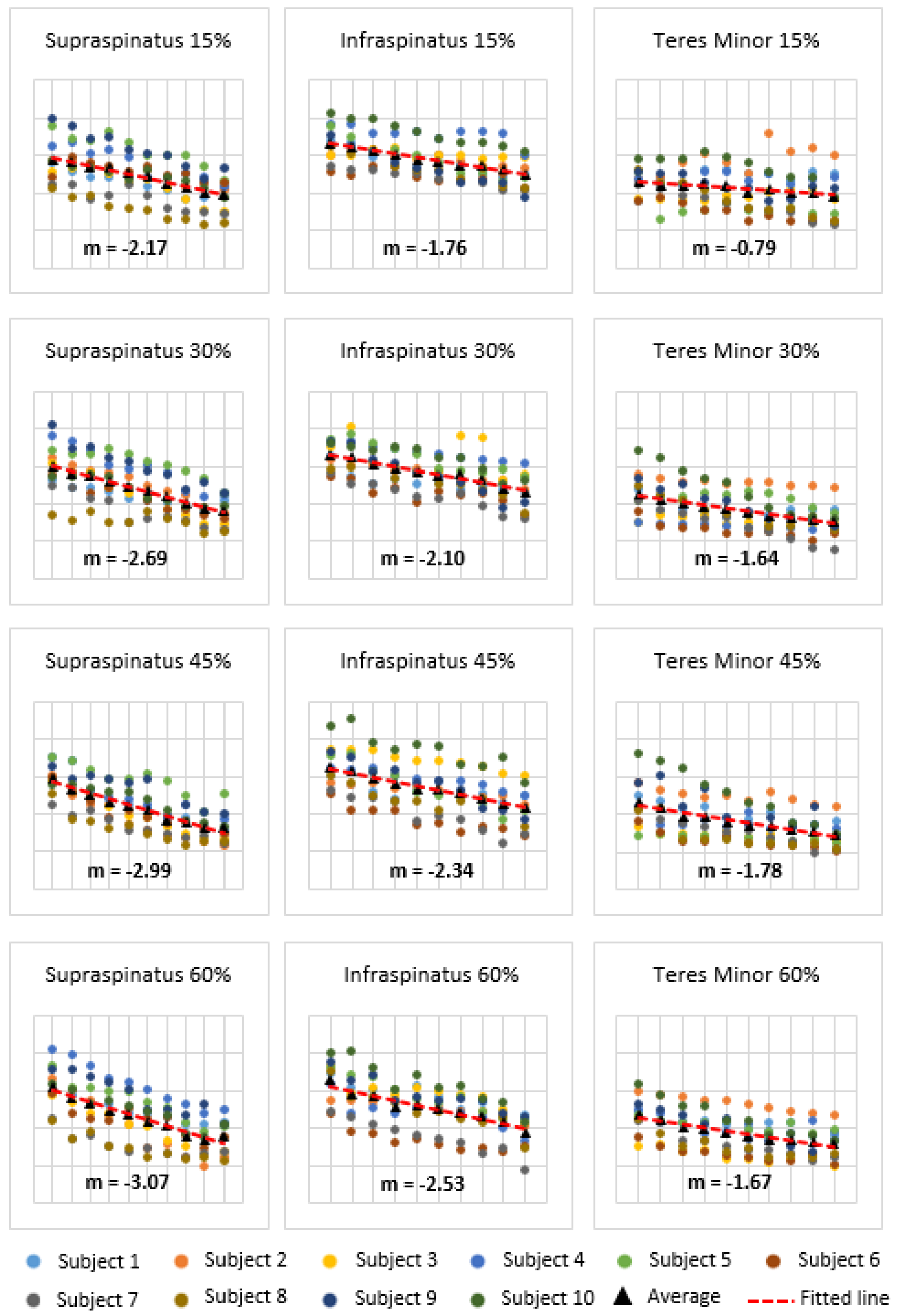

Figure 10. Median frequency data in the time domain at different \%MVC levels. 
Table 4. Effect of \%MVC exertion levels on duration of exertion, median frequency slopes, and normalized average muscle activation.

Means are statistically different if they do not share same letter.

Duration of exertion (S)

\begin{tabular}{lccccc}
\hline & \multicolumn{4}{c}{ Mean (SD) } & \multirow{2}{*}{ P-Value } \\
\cline { 2 - 5 } & $\mathbf{1 5 \%}$ & $\mathbf{3 0 \%}$ & $\mathbf{4 5 \%}$ & $\mathbf{6 0 \%}$ & \\
\cline { 2 - 5 } Supraspinatus & $56.7(7.15)^{\mathrm{A}}$ & $51.4(10.89)^{\mathrm{A}}$ & $39(13.06)^{\mathrm{B}}$ & $35.2(11.01)^{\mathrm{B}}$ & $<0.001$ \\
Infraspinatus & $60(0)^{\mathrm{A}}$ & $56.5(7.01)^{\mathrm{A}}$ & $43.8(15.31)^{\mathrm{B}}$ & $33.8(16.91)^{\mathrm{B}}$ & $<0.001$ \\
Teres minor & $58.6(4.43)^{\mathrm{A}}$ & $51.2(14.3)^{\mathrm{AB}}$ & $47.2(17.17)^{\mathrm{AB}}$ & $40.7(20.98)^{\mathrm{B}}$ & 0.003 \\
\hline
\end{tabular}

Median frequency slope

\section{Mean (SD)}

$\begin{array}{lllll} & & & & \text { P-Value }\end{array}$

\begin{tabular}{llllll}
\cline { 2 - 6 } Supraspinatus & $-2.17(0.66)^{\mathrm{A}}$ & $-2.69(0.94)^{\mathrm{AB}}$ & $-2.99(0.67)^{\mathrm{B}}$ & $-3.07(1.09)^{\mathrm{B}}$ & 0.003 \\
Infraspinatus & $-1.76(1.00)^{\mathrm{A}}$ & $-2.10(0.83)^{\mathrm{AB}}$ & $-2.34(1.08)^{\mathrm{AB}}$ & $-2.53(0.81)^{\mathrm{B}}$ & 0.018 \\
Teres minor & $-0.79(1.53)^{\mathrm{A}}$ & $-1.64(1.39)^{\mathrm{B}}$ & $-1.78(1.36)^{\mathrm{B}}$ & $-1.67(0.87)^{\mathrm{B}}$ & 0.011 \\
\hline
\end{tabular}

Normalized muscle activity $(\%)$

\begin{tabular}{lccccc} 
& \multicolumn{4}{c}{ Mean (SD) } & \multirow{2}{*}{ P-Value } \\
\cline { 2 - 5 } & $\mathbf{1 5 \%}$ & $\mathbf{3 0 \%}$ & $\mathbf{4 5 \%}$ & $\mathbf{6 0 \%}$ & \\
\cline { 2 - 5 } Supraspinatus & $29.1(12)^{\mathrm{A}}$ & $34.8(11)^{\mathrm{AB}}$ & $45.2(15)^{\mathrm{B}}$ & $44.7(13)^{\mathrm{B}}$ & 0.018 \\
Infraspinatus & $19.0(3)^{\mathrm{A}}$ & $26.9(5)^{\mathrm{AB}}$ & $35.6(8)^{\mathrm{AB}}$ & $37.6(10)^{\mathrm{B}}$ & $<0.001$ \\
Teres minor & $13.0(12)^{\mathrm{A}}$ & $21.0(16)^{\mathrm{B}}$ & $25.8(14)^{\mathrm{B}}$ & $31.7(12)^{\mathrm{B}}$ & 0.026 \\
\hline
\end{tabular}




\subsection{Discussion}

In this study, the strength, endurance and fatigue response of rotator cuff muscles at different \%MVC exertion levels were studied. Among the three studied muscles, Infraspinatus exhibited the highest strength followed by Teres Minor and Supraspinatus. Muscle strength is a function of muscle architectural parameters such as cross-sectional area, muscle fiber arrangement, muscle length and muscle volume (Lieber et al., 2000). Few studies have measured the architecture of rotator cuff muscles (Keating et al., 1993; Juul-Kristensen et al., 2000; Ward et al., 2006; Lovering and Russ, 2008) and reported that the average cross-sectional area of Infraspinatus and Supraspinatus is 9.8 and $4.0 \mathrm{~cm}^{2}$, respectively. The volume of Infraspinatus and Supraspinatus was also reported to be 84.4 and $29.7 \mathrm{~cm}^{3}$, respectively. A cadaveric study reported muscle length of $12.1 \mathrm{~cm}, 10.8 \mathrm{~cm}$, and $8.5 \mathrm{~cm}$ for Infraspinatus, Teres Minor and Supraspinatus, respectively (Ward et al., 2006). These physiological factors explain the higher strength observed for the Infraspinatus when compared with the other two rotator cuff muscles.

Endurance time is defined as the time period it takes for a muscle to lose its capability to exert a sustained force. As anticipated, all three muscles had a lower endurance time at higher MVC exertion levels. Previous studies have shown a negative exponential relationship between endurance time and exertion level (Rohmert 1960; Sato et al., 1984; Chaffin et al., 2006). Although in this study the trial duration was controlled at 60 seconds, the decreasing trend observed in the endurance time with an increase in the \%MVC exertion level is in accordance with the previous studies.

Despite the strength differences, the endurance time was found to be very similar among the rotator cuff muscles. The endurance time ranged between 58 to $60 \mathrm{~s}, 51$ to $56 \mathrm{~s}, 39$ to $47 \mathrm{~s}$ and 33 to $41 \mathrm{~s}$ at $15 \%, 30 \%, 45 \%$ and $60 \%$ exertion levels, respectively. Among the factors that can 
influence the endurance time muscle fiber type composition is reported to be the most determinative one (Srinivasan et al., 2007; Chaffin et al., 2006). Type I muscle fibers which are also known as slow twitch fibers have slower contraction time compared to type II muscle fibers and are resistant to fatigue and thus assist with enduring an exertion. Type I fiber content is reported to be around 54\%, 41\% and, $49 \%$ for Supraspinatus, Infraspinatus and Teres minor, respectively (Lovering and Russ, 2008). This distribution of type I and type II fibers is not very different for the rotator cuff muscles and thus explains the similarity in their endurance time observed in this study at different \%MVC levels.

During sustained static exertion, the high frequency, fast-twitch fibers drop out, while low frequency slow twitch fibers continue to be recruited (Kumar and Narayan, 1999). This causes a leftward shift in the power spectrum of the EMG data which can be measured using a drop in the median frequency. The results of this study indicate that the static exertions performed at $15 \%$ to $30 \%$ MVC produced maximum drop in the median frequency, indicating faster fatigue development for the rotator cuff muscles in this range. Typically, $\sim 30 \% \mathrm{MVC}$ is used as a guiding point while designing workplace exertions (Rohmert 1960; Sjøgaard et al., 2006). For the rotator cuff muscles since the maximum drop in the median frequency is at $15 \%$ to $30 \%$ MVC level, a lower guidance value for the workplace exertions must be used. Future research should look at exertion levels below 30\% MVC with more intervals to identify such guidance values. It is also important to note that the EMG parameters related to the mean activation and median frequency are more sensitive to changes in the exertion performed at the $15 \%$ and $30 \%$ MVC range.

Although lower median frequency and higher muscle activation was observed at higher force exertion levels, an inconsistent rate of change in the values of these parameters was observed for every $15 \%$ increase in the exertion level. The highest reduction in the median frequency was 
observed for an increase in the exertion level from 15 to $30 \%$ and the lowest reduction in the median frequency was observed for an increase in the exertion level from 45 to $60 \%$. A similar trend was also observed for the mean muscle activation data and it was more ostensible in Teres Minor when compared with the other two rotator cuff muscles. There are several possible reasons for this trend observed in the EMG data. In this study, standardized postures were used for MVC exertions, as reported in the literature. While performing isometric exertions at submaximal levels for sustained duration using such postures it is possible that passive tissues or other synergistic muscle(s) were recruited in order to maintain the required force. It is likely that the co-contraction of the synergistic muscles may have contributed to maintain the force requirement at higher force exertion levels. The lower differential observed in the mean activation and median frequency at higher exertion levels could also be due to muscle ischemia. Ischemia is a condition that arises from lack of blood supply, which results in lack of oxygen, and muscles will not be able to function properly at this condition. Some muscles will be ischemic at forces higher than $50 \%$ of MVC (Chaffin et al., 2006). In the current study, the mean activation and median frequency trends remained unaffected between 45 and $60 \%$ MVC indicating a possible ischemic behavior for the rotator cuff muscles above $45 \%$ MVC. Thus, the exertions performed at and above such a level are certainly deemed hazardous for the rotator cuff muscles.

There are a few limitations that need to be acknowledged. Only male participants were recruited for this study. Females have different muscle architecture and could have different strength and fatigue behavior. Future studies should be carried out on female participants. The participants were chosen from a student population with a narrow range of age. Therefore, effect of age was not studied. The data for this study were collected at a specific MVC postures that do not necessarily represent common working postures adopted by the employees of different 
industries. Further studies should look at various working postures, especially overhead postures to analyze the strength and fatigue of rotator cuff muscles.

In conclusion, rotator cuff muscles exhibited a different MVC strength decrease in the following order: Infraspinatus, Teres minor, and Supraspinatus. Despite these strength differences, the endurance time measured over a duration of $60 \mathrm{~s}$ at different $\% \mathrm{MVC}$ exertion levels was identical (minimum difference $=3 \mathrm{~s}$; maximum difference $=8 \mathrm{~s}$ ). A non-linear trend, i.e., higher change for increase from $15 \%$ to $30 \%$ and lower change for increase from $45 \%$ to $60 \%$, in the median frequency and mean muscle activation was observed with respect to the increase in the $\% \mathrm{MVC}$ exertion. 


\section{Chapter 3. Specific Aim \#1}

\section{The effect of task rotation on activation and fatigue response of rotator cuff muscles during overhead work.}

\subsection{Introduction}

Among all the etiologies in the pathogenesis of the shoulder and in particular rotator cuff injuries, posture and repetition have been a common concern in industrial workplaces (Bernard and Putz-Anderson, 1997; Thigpen et al., 2010; Nimbarte et al., 2013; Dasgupta et al., 2016; Frost et al., 2016; McDonald et al., 2016; Sun et al., 2017). Higher prevalence of shoulder musculoskeletal disorders (MSDs) has been reported in individuals whose jobs involve overhead work (Chopp et al., 2010; Putz-Anderson et al., 1997). Overhead work can increase the load on shoulder structure and in particular, rotator cuff muscles (Nussbaum 2001; Van rijn et al., 2010; Kolstrup 2012; Hanvold et al., 2015). Higher rotator cuff electromyography (EMG) activity has been reported while working overhead compared to other postures (Chopp et al., 2010; Blache et al., 2015). Other than muscle activity, different fatigue indicators (e.g. maximum strength, endurance time, and subjective ratings) have shown to be influenced by this type of work (Garg et al., 2006; Nimbarte et al., 2012; Dickerson et al., 2015; Sood et al., 2017).

Overhead work is defined as activities involving more than 90-degrees of arm flexion (above shoulder height). Two biomechanical properties of the shoulder muscles, mechanical compression, and high intramuscular pressure are the main causes of shoulder injuries while working overhead (Järvholm et al., 1988; Palmerud et al., 2000; Garg et al., 2006). The anatomical locations of the rotator cuff muscles increase the chance of their compression between the head of the humerus and acromion, which can lead to their mechanical impingement. Performing overhead work has been reported to cause high intramuscular pressure for the rotator cuff, which could 
impair blood circulation in the muscles and cause fatigue (Herberts et al., 1984). Herberts et al. reported an increase in the intramuscular pressure with an increase in exertion levels. They also reported that the infraspinatus and supraspinatus muscles showed high intramuscular pressure even during overhead exertions which were performed at low levels (10-20\%MVC). Increased risk of MSDs has been reported when overhead work is coupled with other ergonomics risk factors such as repetitive or extreme force (Putz-Anderson et al., 1997).

Considering the high pace of industrial tasks and the need for accuracy and fast adjustability to keep up with the demand especially in automotive and aerospace industries, it seems impossible to eliminate overhead and repetitive work from occupational settings (Sylla et al., 2014). Multiple engineering controls such as the use of ergonomic intervention devices and administrative controls such as job/task rotation have been utilized to reduce workers' exposure to awkward postures and repetitive work. Previous studies have evaluated the effect of task/job rotation parameters on pain, performance, and muscle fatigue development (Bernard and Putz-Anderson, 1997; Kuijer et al., 1999; Garg et al., 2006; Horton et al., 2012). In a study by Horton et al., two rotation cycles and two task orders were compared while performing the same tasks with no rotation. Performing only low intensity tasks or only high intensity tasks resulted in lower and higher fatigue respectively compared to performing the tasks rotationally. They also reported lower ratings of perceived exertion (RPE) with more frequent rotation. In another study, a constant workload was considered with different cycle times (Dickerson et al., 2015). Although endurance time was higher for the trials with shorter cycle time, EMG results did not follow a pattern and showed mixed results. They reported that cycle time affected fatigue development in some muscles with the infraspinatus having the highest fatigue development among shoulder muscles. In two similar studies by Kuijer et al., (1999, 2005) rotation among refuse collecting, street sweeping, and refuse truck driving 
workers was analyzed. The physical workload was reduced for refuse collectors only and because more employees were exposed to a higher demanding task (i.e. rotating from driving to refuse collecting) the overall number of low back complaints increased. In another study Keir et al., (2011) evaluated the effect of rotation between a lifting (12 Kg.) and gripping (20\% of maximum grip) task on muscle activity and ratings of perceived exertion. They reported a significant effect of task combination on both dependent variables. Sood et al. (2017) reported a substantial effect of duty cycle and tool mass on endurance time while working overhead. In the previous studies, shorter duty cycles or more frequently occurring rotations have been suggested to generate less fatigue and discomfort and increase endurance time. Studies that evaluated task order suggested that starting with intense tasks would result in higher fatigue development in comparison with starting with less demanding tasks (Horton et al., 2012; Raina and Dickerson, 2009). The reason being, when starting a work session with a lower intensity task, the task itself can serve as a warmup exercise that will reduce fatigue and improve performance (Bishop 2003).

Thus, the previous studies indicate that the effectiveness of job/task rotation depends on the nature of the tasks. To better investigate the effect of job/task rotation on muscle loading, it has been suggested to use the tasks that load the same group of muscles with a constant overall load (Horton et al., 2012; Dickerson et al., 2015). Only a few studies investigated the effect of different task rotation parameters on shoulder muscles during overhead work. In which either the overall workload was not constant (Garg et al., 2006; Sood et al., 2017) or only the effect of cycle time was studied (Dickerson et al., 2015). Among the studies that evaluated job/task rotation parameters, to our knowledge, no study has looked at the effect of job/task rotation based on different \%MVC exertions for rotator cuff muscles. The MVC being subject specific, can provide a general understanding of worker specific reactions to different job/task rotation sequences. 
Furthermore, designing a rotation sequence study based on \% MVC with a constant workload will provide general results which can be applied to a wide variety of tasks.

In this study, the effectiveness of task rotation in preventing rotator cuff muscle fatigue during overhead work was evaluated. Specifically, the effect of four task rotation sequences (increasing, decreasing, upward parabolic, and downward parabolic) with a constant workload that combines different $\% \mathrm{MVC}$ levels on the fatigue response of the rotator cuff muscles was studied.

\subsection{Objectives and hypotheses}

In this study, the effectiveness of task rotation in preventing rotator cuff muscle fatigue during overhead work was evaluated. Specifically, the effect of four task rotation sequences (increasing, decreasing, upward parabolic, and downward parabolic) with a constant workload that combines different $\% \mathrm{MVC}$ levels on the fatigue response of the rotator cuff muscles was studied. The following hypotheses were examined in this aim:

Null Hypothesis $\mathrm{H}_{\mathrm{o}}$ : task rotation sequence would have no effect on the fatigue response of rotator cuff muscles during overhead work.

Alternative Hypothesis $\mathrm{H}_{\mathrm{a}}$ : task rotation sequence would have an effect the fatigue response of rotator cuff muscles during overhead work.

\subsection{Approach}

A laboratory-based study was performed to evaluate the response of rotator cuff muscles to different task rotation sequences. There are four rotator cuff muscles, infraspinatus, supraspinatus, teres minor, and subscapularis. Surface EMG data were recorded from the infraspinatus, supraspinatus, and teres minor. Subscapularis being a deep muscle, it is not possible to record its activity using surface EMG and therefore subscapularis was not considered in this study. In 
addition, the strength at MVC and the ratings of perceived exertion (RPE) using Borg's CR-10 scale were also collected from the participants.

\subsection{Participants}

Twelve right-hand dominant participants ( 8 male and 4 female) were recruited for this study. The average height, weight, and age of the participants were $171.42 \pm 6.4 \mathrm{~cm}, 73.25 \pm 8.8 \mathrm{~kg}$, and $30 \pm 3.5$ years, respectively. Participants were free from any previous as well as ongoing shoulder, neck, and back musculoskeletal disorders and/or pain. All participants read and signed a consent form approved by the local Institutional Review Board (IRB). Copy of the consent form is included in Appendix C.

\subsubsection{Sample size determination and statistical power analysis}

Similar to the preliminary study, the operating characteristic (OC) curves were used to select the acceptable sample size and calculate the statistical power of the test. The calculations were based on the following formula (Montgomery, 2017).

$$
\begin{aligned}
& \Phi^{2}=\frac{n \sum_{i=1}^{a} \tau i^{2}}{a \sigma^{2}} \\
& \tau_{i}=\mu_{i-} \overline{-}
\end{aligned}
$$

Where,

$\Phi^{2}$ : Noncentrality parameter

$n$ : number of participants

$\alpha$ : number of levels

$\sigma^{2}$ : estimate of the variance

$\bar{\mu}$ : Average of the individual treatment means

$\mu_{\mathrm{i}}$ : Specific treatment means 
Estimated variance $\left(\sigma^{2}\right)$ and $\tau$ were calculated for the median frequency drop values in the studied four sequences $(a=4)$. The statistical significance was set at $\alpha=0.05$. Table 5 shows the statistical power values corresponding to a different number of samples.

Table 5. Statistical power corresponding to a different number of samples

\begin{tabular}{|c|c|c|c|c|c|}
\hline n & $\Phi$ & $v_{1}$ & $\mathbf{v}_{\mathbf{2}}$ & $\beta$ & Power (1- $\beta)$ \\
\hline 3 & 1.57 & 3 & 8 & 0.48 & 0.52 \\
\hline 4 & 1.81 & 3 & 12 & 0.27 & 0.73 \\
\hline 5 & 2.02 & 3 & 16 & 0.16 & 0.84 \\
\hline 6 & 2.22 & 3 & 20 & 0.06 & 0.94 \\
\hline 7 & 2.39 & 3 & 24 & 0.023 & 0.977 \\
\hline 8 & 2.56 & 3 & 28 & 0.013 & 0.987 \\
\hline
\end{tabular}

According to the results of the power analysis, the power for a sample size of seven or above would be higher than 0.95 . Therefore, at least seven participants were needed for this study to reach the desired power.

\subsection{Equipment}

\subsubsection{Electromyography (EMG) system}

As explained in preliminary study. (See section 2.4.2)

\subsubsection{Force gauge}

A digital force gauge (Mark-10 Corporation NY, USA) was used to measure the force values during the overhead isometric exertions (Figure 11). A single handle and a curved shape padded attachment enabled the participants to push the force gauge to the overhead adjustable stopper. A digital LCD enabled the participants to see real time force values to maintain the required force. 


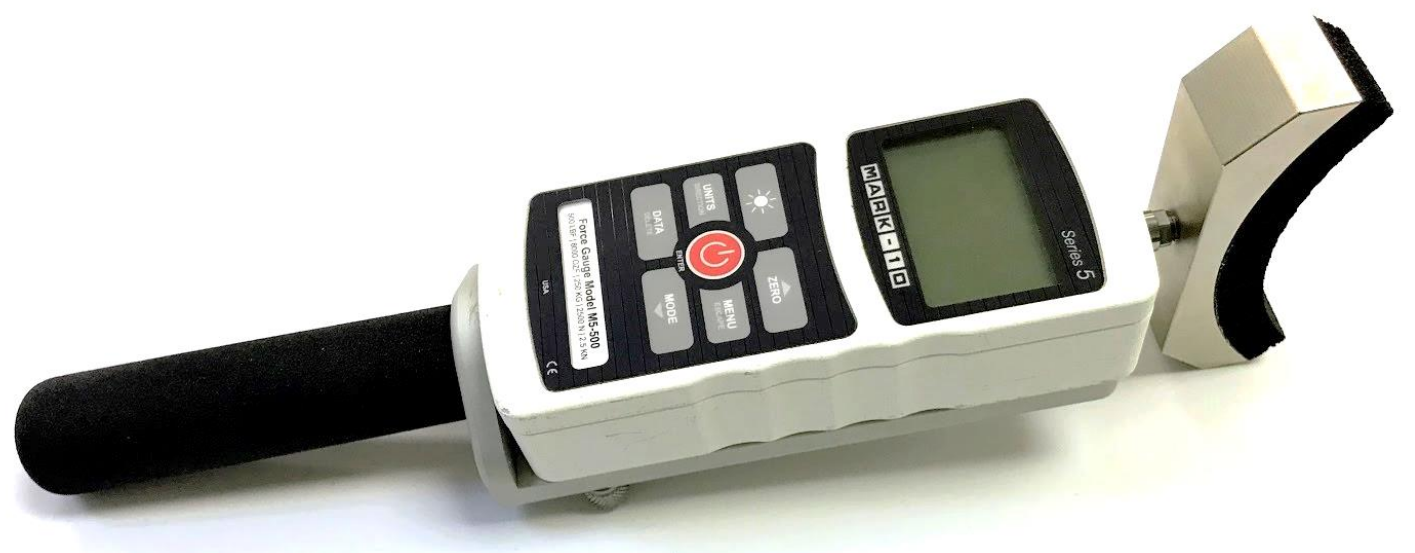

Figure 11. Digital force gauge and attachments

\subsubsection{Digital protractor}

A digital protractor (Guilin Gemred Sensor Technology Co., Guangxi, China) (Figure 12) was used to maintain the desired shoulder and elbow angles for the overhead exertions.

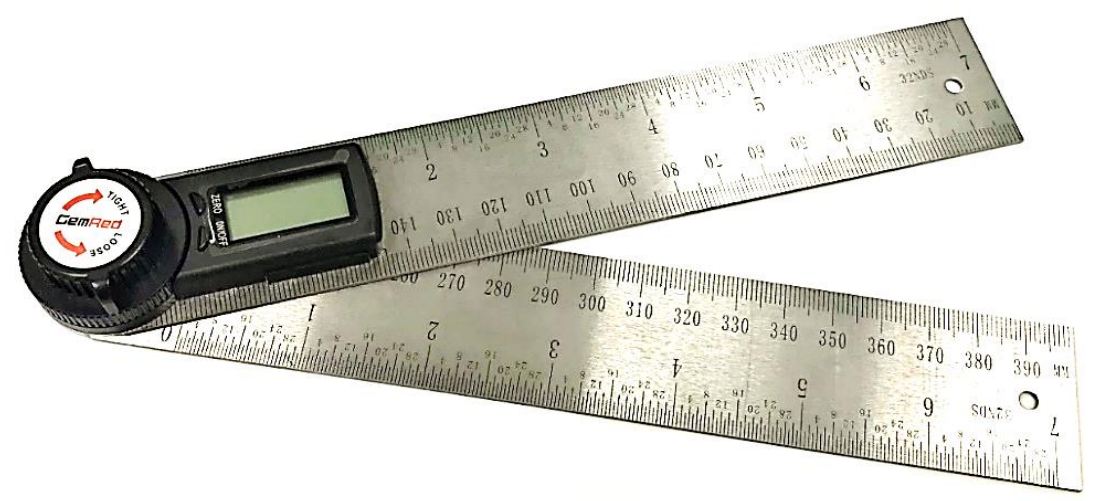

Figure 12. Digital protractor

\subsubsection{Adjustable work simulation system}

LIDO WORKSET (Loredan Biomedical Inc. CA, USA) (Figure 13) was used as an adjustable work simulator to help the participants maintain required overhead posture and be able to exert the target force. 


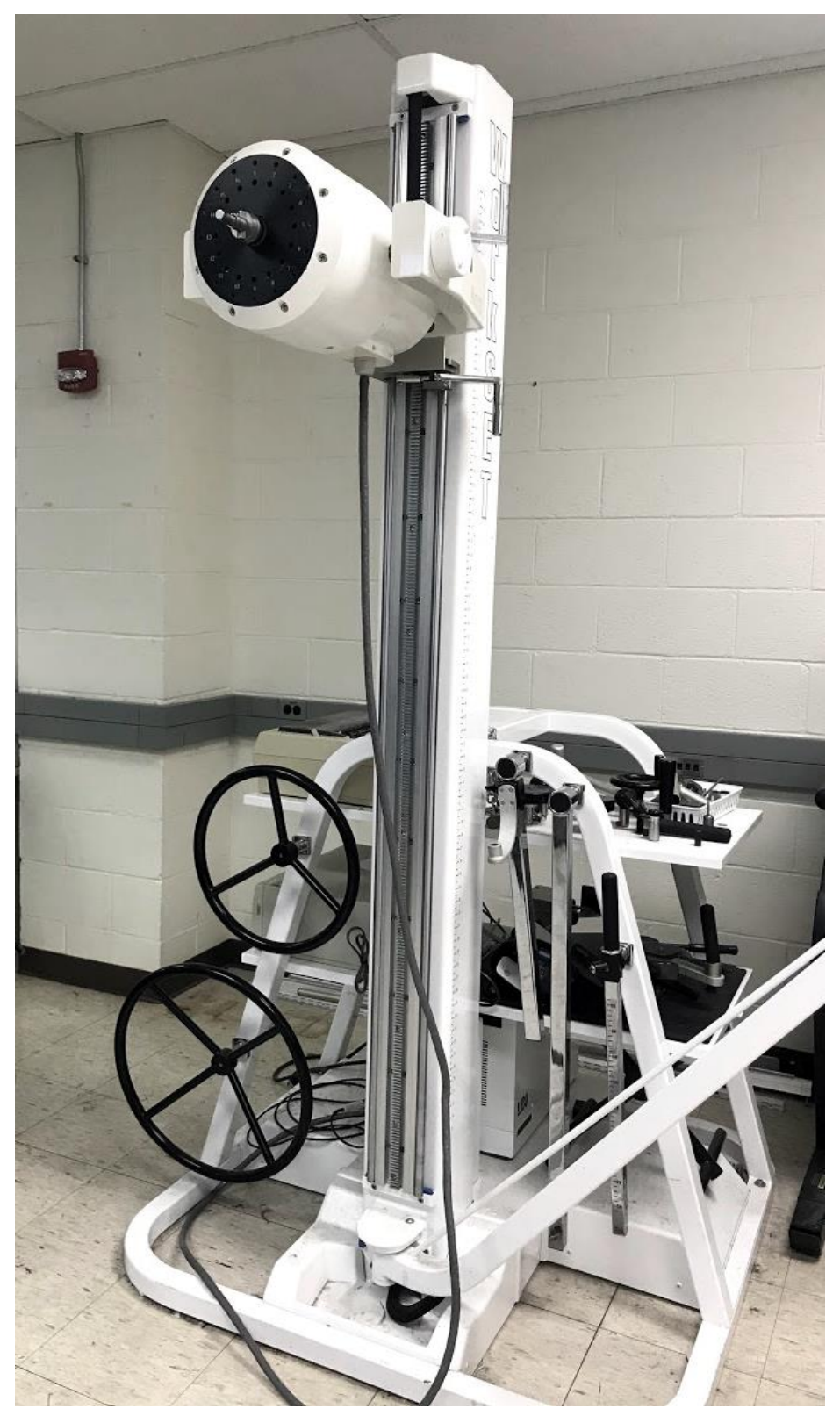

Figure 13. Adjustable work simulation system

\subsection{Experimental design}

The effect of task rotation sequence on the fatigue response of rotator cuff muscles was studied by controlling the task rotation sequence at four levels: 1) increasing, 2) decreasing, 3) upward parabolic and 4) downward parabolic (Figure 15). Based on the results of our previous study (Motabar et al., 2019), three different exertion levels (low (5\% MVC), medium (20\% MVC), 
and high $(35 \% \mathrm{MVC})$ ) were used to design the tasks rotation sequences. These submaximal exertions sufficiently activate the rotator cuff muscles and are in the safe loading range. Furthermore, a $15 \%$ gap between the exertion levels makes it possible to differentiate the difficulty level of the tasks.

There were six 5-minutes sessions within each sequence. Each session consisted of 10 overhead exertions (10 seconds long) and a rest period of 20 seconds after the exertions, totaling to 100 seconds of overhead work and 200 seconds of rest time (Figure 15). The total duration for a single task rotation sequence was 45 minutes. At the beginning and the end of each sequence strength measurement at MVC, as well as a 15 -second $30 \%$ MVC reference exertion were performed. The $30 \%$ MVC was chosen as the reference exertion based on the results of our previous study, as such exertion level do not create additional fatigue to the muscles and at the same time generate enough muscle activity required for the fatigue analysis (Motabar et al., 2019). A one-third duty cycle and two-third rest period were considered for all the rotation sequences. Since assembly time is measured per minute in the industrial settings (Garg et al., 2006), the experiment was designed to include one-minute cycles so that industrial tasks can be easily compared and matched with the study design.

\subsection{Experimental procedure}

Upon arrival, the data collection procedure was explained to the participants. Then they signed the IRB consent form and were prepared for the EMG data collection. Bagnoli -16 Desktop System (Delsys Inc., Boston, USA) was used to collect the EMG data. The EMG data were recorded at a frequency of $1000 \mathrm{~Hz}$ using parallel bars (99.9\% pure silver) active surface electrodes with $92 \mathrm{~dB}$ of common-mode rejection ratio (CMRR). The skin over the anatomical landmark of the rotator cuff muscles was cleaned with alcohol and shaved before placing the EMG electrodes. 
For supraspinatus the electrode was placed slightly above the upper border of the spine of scapula; for infraspinatus the electrode was placed $4 \mathrm{~cm}$ below the medial border of the spine of scapula and for teres minor the electrode was placed at one-third of the distance from acromion to the interior angle of the scapula (Motabar et al., 2019).

The participants were then moved to the workstation to perform overhead exertions. The workstation consisted of a column and base assembly with overhead height adjustable stopper. A digital force gauge (Mark-10 Corporation NY, USA) was utilized to measure the force values during the overhead exertions. A single handle and a curved shape padded attachment of the force gauge enabled the participants to push the force gauge against the overhead adjustable stopper. A digital screen of the force gauge enabled the participants to see real time force values during the exertion to maintain the required force level. In all overhead exertions, the participants maintained 120 degrees shoulder and 150 degrees elbow flexion (Figure 14). Many studies have identified such posture as the most common overhead posture in the industry (Garg et al., 2006; Park and Yoo, 2013; Dickerson et al., 2015). With participant standing at a specified location, shoulder and elbow elevation angles were measured by a digital protractor (Guilin Gemred Sensor Technology Co., Guangxi, China) and then the adjustable stopper was set as a reference for this posture. Three 5-second overhead MVC exertions were performed and maximum strength value was used as the strength at MVC. During all MVC exertions, verbal encouragement was given to the participants to enhance the results (McNair et al., 1996). Based on the strength at MVC, 5\%, 20\%, and 35\% strength values were calculated and used to perform overhead exertions during rotation sequences. 


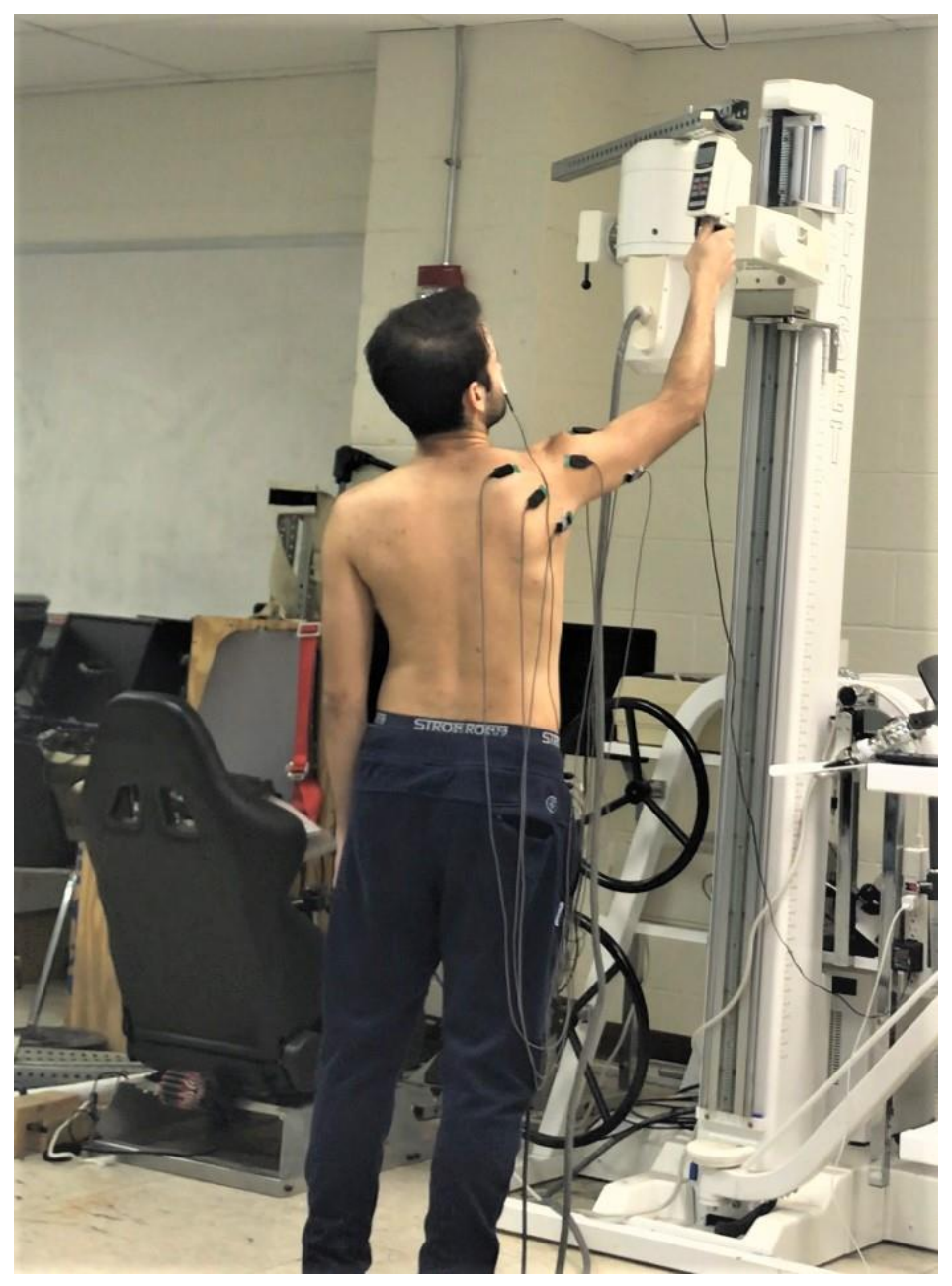

Figure 14. Overhead exertion posture

The participants completed four task rotation sequences in a random order. The EMG data were recorded during the MVC and reference exertions, as well as during the sessions of overhead exertions within the task rotation sequences. The RPE data were collected after the completion of each session. A rest period of 20 minutes was provided between the sequences to ensure full recovery of the rotator cuff muscles. Total data collection duration for an individual participant was approximately 270 minutes (4.5 hours) long - (15 minutes for preparation, 15 minutes for MVC exertions, 180 minutes for task rotation sequences and 60 minutes for rest periods). 


\subsection{Data Processing and Statistical Analysis}

The raw EMG data were filtered using a band pass filter between $10-500 \mathrm{~Hz}$ and to eliminate ambient noise a notch filter was used at $60 \mathrm{~Hz}$. The muscular load during the tasks rotation sequences was estimated in terms of normalized mean absolute values (MAV). The filtered EMG data were demeaned, i.e., mean was subtracted from each data point to center the data at zero, and then full-wave rectified, i.e., converted to absolute values. The rectified signals were smoothed using a 100 data point sliding window. The MAV were estimated by averaging the smoothed EMG data over the tasks rotation sequences. The MAV data were normalized with respect to maximum muscle activity recorded during the MVC exertions.

A decrease in the median frequency of the EMG data has been considered as a sign of muscle fatigue (De Luca 1984; Niemeyer et al., 2004; Minning et al., 2007; Kai et al., 2012; Alasim and Nimbarte, 2019). To calculate the median frequency, filtered EMG data from the reference contractions was transformed into the frequency domain using fast Fourier transformation. For each reference contraction, the data were divided into 10 divisions and median frequency was calculated for each division. A linear regression line was fitted to the 10-point data and the slope of the line was computed. The reference exertions before and after each task rotation sequence were used to estimate drop/change in the median frequency slopes. 


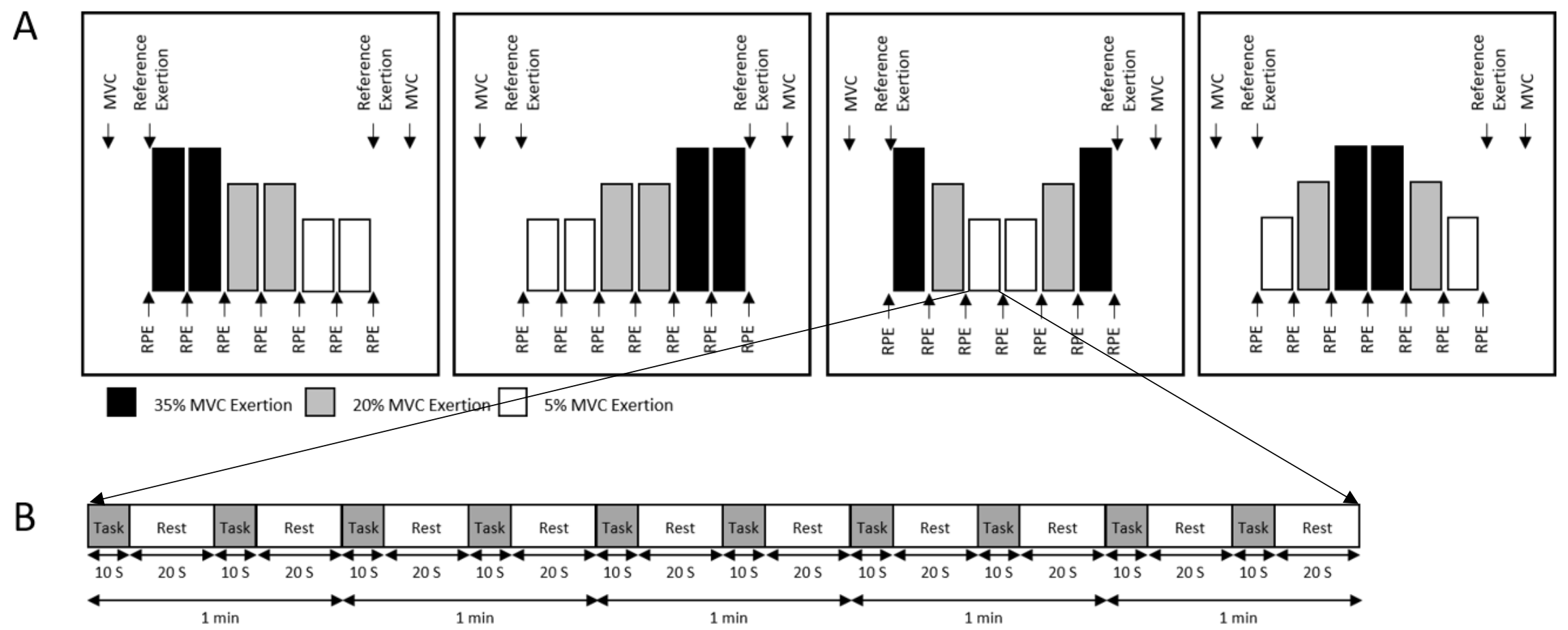

Figure 15. (A) Four rotation sequences used in this study: (1) decreasing, (2) increasing, (3) upward parabolic, (4) downward parabolic. Each bar represents a 5-minute session of overhead task at the specified \%MVC level. The arrows show the various measurements obtained during the sequences. (B) Task and rest order within each 5-minute session. 
The strength at MVC were normalized with respect to the weight of participant (Hurd et al., 2011) to have rational comparisons of muscle strength among the participants. A change/drop (\%) in the strength was also used to assess the muscle fatigue. The REP data were compared between the sequences by estimating average RPE per sequence.

Analysis of Variance (ANOVA) was performed to understand the effect of different task rotation sequences on the fatigue response of rotator cuff muscles. The rotation sequence was treated as a fixed factor with four levels, i.e. increasing, decreasing, upward parabolic, and downward parabolic. The dependent variables were the changes/drops in the median frequency slopes and strengths, and average RPE. The participant was treated as a random factor. Separate ANOVA was performed for each muscle and dependent variable combination. Normality of residuals and equality of variances were assessed as the assumptions for analysis of variance (ANOVA) and transformation was performed if required. The statistical significance was set as $\alpha=0.05$ and the significant effects were further evaluated by conducting comparisons between means using Tukey's Honestly Significant Difference (HSD) all-pairwise comparison test. Statistical analysis was performed using Minitab 17 statistical software (Minitab, LLC, USA).

\subsection{Results}

The task rotation sequence had no effect on the activity of rotator cuff muscles. Normalized MAV for the rotator cuff muscles ranged between $40.48 \%$ and $49.54 \%$ during the four sequences (Table 6, Figure 16). All three muscles demonstrated a drop in the median frequency slope after performing the job rotation sequence (Figure 17); infraspinatus showed the highest drop, followed by teres minor, and supraspinatus. The effect of sequence on the drop in the median frequency slope was statistically significant for all muscles. Performing the exertions in sequence 1 
(increasing) resulted in the highest drop in the median frequency slope followed by sequence 2 (decreasing), sequence 4 (downward parabolic), and sequence 3 (upward parabolic).

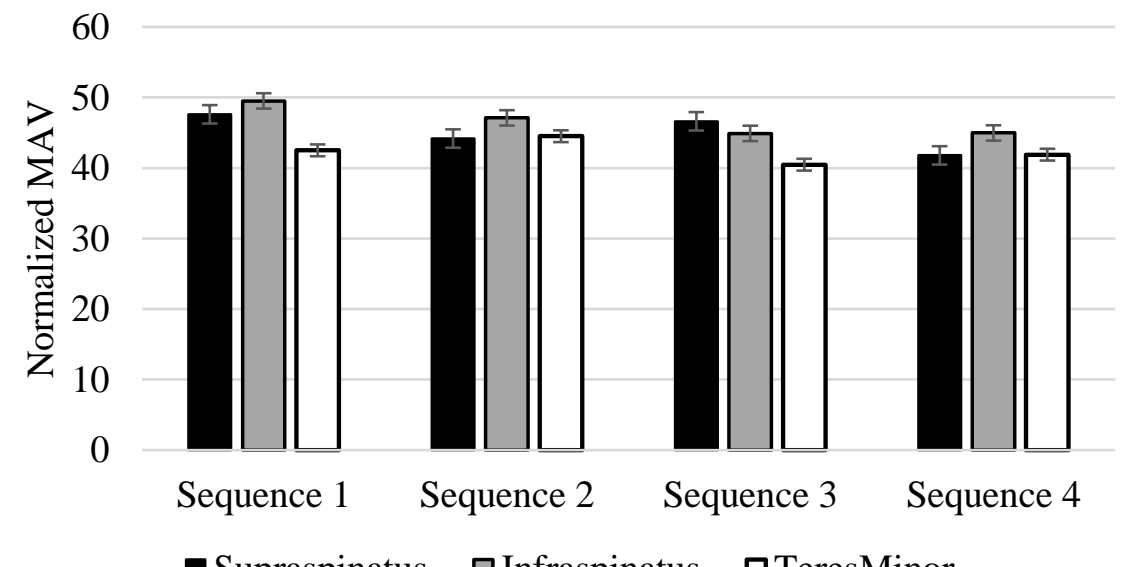

Figure 16. Mean normalized muscle activity for the rotator cuff muscles at different job rotation sequences. Error bars represent standard error.

Table 6. Main effect of job rotation sequence on the normalized muscle activity and drop in the median frequency slope. Means (standard deviation (SD)) are statistically different if they do not share same letter.

\begin{tabular}{lccccc}
\hline & Sequence 1 & Sequence 2 & Sequence 3 & Sequence 4 & p-value \\
\hline & & \multicolumn{4}{c}{ Normalized Muscle Activity (\%) } \\
\hline Supraspinatus & $47.61(8.2)$ & $44.17(10.1)$ & $46.62(9.9)$ & $41.79(7.9)$ & 0.49 \\
Infraspinatus & $49.51(10.9)$ & $47.11(12.2)$ & $44.90(12.6)$ & $44.97(8.9)$ & 0.74 \\
Teres minor & $42.50(7.6)$ & $44.51(10.1)$ & $40.47(9.2)$ & $41.89(6.7)$ & 0.64 \\
\hline & & Median Frequency Slope Changes & \\
\hline Supraspinatus & $-0.52(0.64)^{\mathrm{A}}$ & $-0.40(0.87)^{\mathrm{A}}$ & $-0.24(0.45)^{\mathrm{B}}$ & $-0.24(0.43)^{\mathrm{B}}$ & 0.01 \\
Infraspinatus & $-0.76(0.82)^{\mathrm{A}}$ & $-0.69(1.00)^{\mathrm{A}}$ & $-0.35(0.82)^{\mathrm{B}}$ & $-0.42(0.66)^{\mathrm{B}}$ & 0.004 \\
Teres minor & $-0.52(0.94)^{\mathrm{A}}$ & $-0.42(0.56)^{\mathrm{AB}}$ & $-0.32(0.53)^{\mathrm{B}}$ & $-0.33(0.56)^{\mathrm{B}}$ & 0.043 \\
\hline
\end{tabular}

Result of Tukey's HSD all-pairwise comparison test showed that the mean drops in the median frequency slope in sequences 1 and 2 were different from sequences 3 and 4 for 
supraspinatus and infraspinatus. For teres minor, the mean drops in the median frequency slope in sequence 1 was different from sequences 3 and 4 , and the mean values of sequence 2 were not different from other sequences.

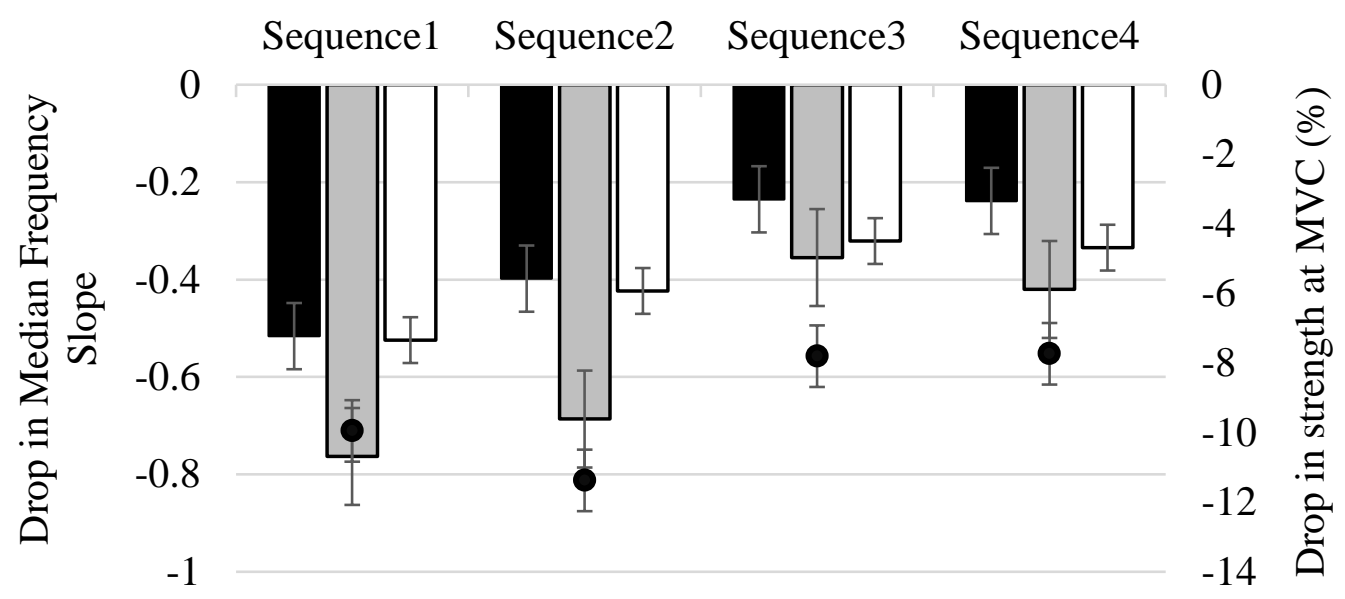

- Supraspinatus $\square$ Infraspinatus $\square$ Teres minor $\bullet$ Strength at MVC

Figure 17. Mean drop in the median frequency slope and strength at MVC for the job rotation sequences. Error bars represent standard error.

The mean RPE at different sequences had a trend similar to that of drop in the median frequency slopes with sequence one resulting in the highest RPE and sequence three resulting in the lowest RPE. Statistically, the task rotation sequence had no effect on the RPE (Table 7). A reduction in the strength at MVC was observed for all sequences (Figure 17). The highest reduction was observed for sequence 2 , followed by sequences 1,3 and 4 . Statistically, the task rotation sequence had no effect on the \% change in the strength at MVC (Table 7).

Table 7. Main effect of job rotation sequence on the average RPE and normalized strength at MVC.

\begin{tabular}{cccccc}
\hline & Sequence 1 & Sequence 2 & Sequence 3 & Sequence 4 & p-value \\
\hline Average RPE & $3.3(1.2)$ & $3.1(1.3)$ & $2.9(1.1)$ & $3.2(1.2)$ & 0.85 \\
\hline Normalized MVC Change (\%) & $-9.95(8.6)$ & $-11.37(6.9)$ & $-7.80(11.7)$ & $-7.73(13.7)$ & 0.91 \\
\hline
\end{tabular}




\subsection{Discussion}

Various types of task/job rotation methods have been evaluated in the past, which have led to equivocal results (Luger et al., 2014). In the present study, the effect of task rotation sequence was evaluated while the total workload was kept constant for all the sequences. Instead of performing specific industrial tasks, in this study the tasks used in the sequence were standardized based on \%MVC strength of individual participants so that the study findings can be universally applied to various work settings based on worker specific muscle strengths. The constant workload throughout the sequence generated a similar average muscle activity for all sequences. All three muscles were activated to a similar level and the average muscle activity was similar for all sequences. However, just performing the tasks in different orders resulted in different muscle fatigue development. Our results coincide with previous research in which task/job rotation influences muscle fatigue development during overhead work (Dickerson et al., 2015; Keir et al., 2011).

Among the studied fatigue indicators, changes in the median frequency was the only significant factor. Infraspinatus exhibited the highest fatigue development in all sequences followed by teres minor and supraspinatus. Based on the results, sequences 3 and 4 resulted in lower fatigue compared to sequences 1 and 2. Comparing the fatigue generated during sequence 1, which resulted in the highest fatigue to sequence 3, which resulted in the lowest fatigue, $54 \%$, $53 \%$, and $39 \%$ more fatigue, was recorded for supraspinatus, infraspinatus, and teres minor respectively (Figure 17). Previous studies have suggested a possible effect of cycle time on muscle fatigue development (Iridiastadi et al., 2006; Garg et al., 2006; Dickerson et al., 2015). Although the cycle time in our experiment was constant, performing two high (35\% MVC) exertions in a row could have caused the same effect as a longer cycle time for the sequences 1 and 2 . Sequence 
3 , which resulted in the least fatigue development, is the only sequence without two high exertions in a row. This could be one of the reasons for the lower muscle fatigue development for this sequence.

It has been shown that performing low intensity exertions before and after a fatiguing task can increase blood flow as well as diffusion of lactic acid buildup from a fatigued muscle. The occurrence of these two factors has been suggested to reduce muscle fatigue development (Bond et al. 1991, Sairyo et al. 2003). Sairyo et al. performed a study to compare the effect of active recovery, which can be defined as performing a low or medium exertion versus passive recovery, which can be just resting for a period of time. They reported an increase in intracellular $\mathrm{pH}(\mathrm{pHi})$ level shortly after starting active recovery while during the passive recovery increase in pHi level started after nearly two minutes. An increase in pHi level shows lactate elimination from the intracellular, which indicates less muscle fatigue. The low intensity exertions performed before and after the high intensity exertions in the sequences 3 and 4, may have assisted with the active recovery process, thus reducing the overall fatigue for these sequences.

In sequence 3, high exertions were separated from each other, which as discussed before creates less muscle fatigue because of the effect of cycle time. Medium and low intensity exertions were performed after the first high exertion, which can be considered as a form of active recovery to increase blood flow, diffuse lactic acid, and result in muscle fatigue reduction. In this sequence, another set of low and medium exertions were performed prior to the last high exertion, which may have worked as a form of warm up and prepared the muscles for the last high exertion. Thus, it seems like short cycle time, active recovery and warm up may have a concatenating effect resulting in the least muscle fatigue for sequence 3 . In a few previous studies, less muscle fatigue was reported when the task/job rotation was started with less demanding exertion which partly 
contracts with the less fatigue observed for sequence 3 (Raina and Dickerson, 2009; Horton et al., 2011). These previous studies however looked at the rotation between two specific tasks further suggesting that considering only one factor, such as cycle time, task intensity, and frequency of rotation cannot lead to a general conclusion of effectiveness of task rotation and a combination of these factors should be considered.

The second-best sequence in our study, in terms of muscle fatigue generation is sequence 4. Starting with low intensity exertion followed by medium exertion warmed up the muscles and after performing the two high exertions, having medium and low exertions acted as a form of active recovery and resulted in less muscle fatigue compared to sequences 1 and 2 . Sequence 1 started with two high exertions, which resulted in the highest muscle fatigue development. Comparing sequences 1 and 2 indicates higher effectiveness of warm up compare to active recovery after the high exertions. Therefore, it can be suggested that whenever it is impossible to have both warmup and active recovery, performing a warmup should be given a higher priority.

Although not statistically significant, strength at MVC followed the same pattern as the median frequency values. Strength at MVC significantly dropped after performing each sequence, but these changes were not statistically different between sequences. Liu et al. (1997) conducted an in vivo study to analyze the role of different muscle groups during shoulder elevation. They reported that along with the rotator cuff muscles, deltoid muscles also playing an important role in carrying the load during shoulder elevation. It has also been suggested that participants can voluntarily redistribute muscle activity while keeping a similar force level (Palmerud et al., 1995). Considering the significant fatigue development in rotator cuff muscles in this study, other muscles could have been recruited to generate the force at MVC exertions. Changes in MVC values, not being a muscle specific measure, does not seem to be an adequate method to measure fatigue 
development, especially in short exertions. This notion is also consistent with a study by Raina and Dickerson (2009) which concluded that due to strength and fatigue resistant variability among the population, changes in force production capability might not be an accurate method to differentiate task rotation sequences. Along with the median frequency and strength changes, RPE values though not statistically significant showed similar results, ranking the sequence 3 the lowest in terms of perceived exertion among all sequences. Considering the results of this study and previously reported data, macroscopic measures such as MVC and RPE do not seem to be sensitive enough to be used to differentiate task order effects on muscle loading.

There are some limitations that need to be considered when interpreting the results of this study. Our participants were recruited from a student population with limited industrial experiences and no history of musculoskeletal disorders. Furthermore, all participants were below 40 years old in this study. Older workers with more industrial experience and prior injuries might react differently to the task rotation sequences.

Based on the results of this study, it can be concluded that performing similar tasks with a constant workload in different orders can alter rotator cuff muscles' fatigue development. Although some fatigue measures were not significantly affected by task order, changes in the median frequency slope were significant for all muscles. A shorter duty cycle for the intense tasks, performing warm up exertions prior to the intense tasks, as well as performing low intensity exertions as a form of active recovery, seem to be the key factors in designing a task rotation sequence. 


\section{Chapter 4. Specific aim \#2}

\section{Effect of intermittent refresher exertions on the rotator cuff muscles' fatigue development.}

\subsection{Introduction}

Previous studies have suggested a correlation between hand load and shoulder muscle activation (Sigholm et al., 1983; Sporrong et al., 1996; Alizadehkhaiyat et al., 2011, Hodder and Keir, 2012; Sun and Nimbarte 2012). Sporrong et al. (1996) conducted a study to assess the effect of handgrip on shoulder muscle activity during arm flexion and abduction. Among the shoulder muscles, infraspinatus and supraspinatus affected the most by the gripping task, particularly in overhead postures. In another study, Alizadehkhaiyat et al. (2011) evaluated the effect of hand force on the glenohumeral joint loading. They reported an increased muscle activity for infraspinatus and supraspinatus with the presence of the handgrip. In general, an increase up to $22 \%$ has been reported for supraspinatus but results were inconsistent for infraspinatus. Some studies reported up to a $35 \%$ increase in infraspinatus muscle activity while other studies reported a decrease as much as $6.7 \%$. Plane of exertion and arm elevation angle have been reported as the main factors to alter the effect of handgrip on shoulder muscle activation. Along with the changes in the muscle activity, what is notable here is the effect of handgrip on redistribution of load among shoulder muscles. It has been shown in previous studies that performing a handgrip exertion can redistribute muscle load from deltoid muscles to either rotator cuffs or biceps brachii (Sporrong et al., 1995, 1996; Au and Keir, 2007; Antony and Keir, 2010; Hodder and Keir, 2012). Sporrong et al. reported a decrease in middle deltoid and an increase in supraspinatus EMG activity while performing a handgrip using a flexed shoulder posture. In a similar study by Hodder and Keir, redistribution was observed from deltoid muscles to biceps brachii. 
It is well known that in case of intense physical activity, lactate will be produced in the muscular system; therefore, presence of lactate has been used as an indicator of muscle fatigue (Ahmaidi et al., 1996; Monedero and Donne 2000; Sairyo et al., 2003). In a previous study, Sairyo et al. evaluated the effectiveness of active recovery versus passive recovery. After fatiguing exertions, they asked participants to perform a moderate activity and compared the results with when participants rested for the same period of time. Results showed an increase in intracellular $\mathrm{pH}(\mathrm{pHi})$ level shortly after starting active recovery, while in passive recovery increase in pHi level started after nearly two minutes. Increase in pHi level shows lactate elimination from the muscular system, which results in faster recovery (Sahlin 1986; Rontoyannis 1988). Furthermore, it has been shown that intermittent low to moderate exertions can increase blood flow as well as diffusion of lactic acid buildup. Occurrence of these two factors would reduce muscle fatigue development and/or faster recovery (Bond et al. 1991, Sairyo et al. 2003). Therefore, it can be concluded that in a short period of time, performing a low or moderate intermittent exertions (gripping in this study) could refresh the fatigued muscle. The phenomenon of shoulder muscle load redistribution and effectiveness of active recovery makes intermittent handgrip exertions a possible administrative control to refresh fatigued muscles and prevent injuries.

In this aim, the effectiveness of adding an intermittent handgrip exertion during overhead work in reducing shoulder muscle and in particular, rotator cuff muscles' fatigue was evaluated.

\subsection{Objectives and hypotheses}

Effect of intermittent handgrip exertions on the biomechanical behavior of the rotator cuff muscles was evaluated during four overhead task rotation sequences. As explained in the previous chapter, participants performed low (5\% MVC), medium (20\% MVC), and high (35\% MVC) isometric exertions in 4 different orders (increasing, decreasing, upward parabolic, and downward 
parabolic). Each overhead exertion followed by a rest period and a moderate handgrip exertion (30 $\% \mathrm{MVC}$ ) at the beginning and the end of each rest period. (Figure 20). EMG, strength at MVC, and RPE were collected to assess the effect of low intensity handgrip tasks (refresher exertions) on the fatigue recovery of the rotator cuff muscles.

The following hypotheses were examined in this aim:

Null Hypothesis, Ho: intermittent handgrip (refresher) exertion would have no effect on the rotator cuff muscles' fatigue development during overhead exertions.

Alternative Hypothesis, $\mathrm{H}_{\mathrm{a}}$ : intermittent handgrip (refresher) exertion would have an effect on the rotator cuff muscles' fatigue development during overhead exertions.

\subsection{Approach}

A laboratory-based study was performed to evaluate the effect of refresher exertions on rotator cuff muscles recovery during overhead work. Surface EMG data were recorded from the infraspinatus, supraspinatus, and teres minor. In addition, the strength at MVC and the ratings of perceived exertion (RPE) using Borg's CR-10 scale were also collected from the participants.

\subsection{Participants}

Twelve right-hand dominant participants ( 8 male and 4 female) were recruited for this study. The average height, weight, and age of the participants were $173.25 \pm 8.9 \mathrm{~cm}, 72.08 \pm \mathrm{kg}$, and 30 \pm 3.01 years, respectively. Participants were free from previous shoulder, neck, and back musculoskeletal disorders. All participants read and signed a consent form approved by the local Institutional Review Board (IRB). Copy of the consent form is included in Appendix C. 


\subsubsection{Sample size determination and statistical power analysis}

In this study, the operating characteristic (OC) curves were used to select the acceptable sample size and calculate the statistical power of the test. The calculations were based on the following formula (Montgomery, 2017).

$$
\begin{aligned}
& \Phi^{2}=\frac{n \sum_{i=1}^{a} \tau i^{2}}{a \sigma^{2}} \\
& \tau_{i}=\mu_{i}-\overline{-}
\end{aligned}
$$

Where,

$\Phi^{2}$ : Noncentrality parameter

$n$ : number of participants

$\alpha$ : number of levels

$\sigma^{2}$ : estimate of the variance

$\bar{\mu}$ : Average of the individual treatment means

$\mu_{\mathrm{i} ;}$ Specific treatment means

Estimated variance $\left(\sigma^{2}\right)$ and $\tau$ were calculated for the median frequency values and four levels of MVC percentage ( $a=4)$. The statistical significance was set at $\alpha=0.05$. Table 8 shows the statistical power values corresponding to a different number of samples.

Table 8.statistical power corresponding to a different number of samples

\begin{tabular}{|c|c|c|c|c|c|}
\hline $\mathbf{n}$ & $\boldsymbol{\Phi}$ & $\mathbf{v}_{\mathbf{1}}$ & $\mathbf{v}_{\mathbf{2}}$ & $\boldsymbol{\beta}$ & Power (1- $\boldsymbol{\beta})$ \\
\hline $\mathbf{4}$ & 1.68 & 3 & 12 & 0.32 & 0.68 \\
\hline $\mathbf{5}$ & 1.88 & 3 & 16 & 0.23 & 0.77 \\
\hline $\mathbf{6}$ & 2.06 & 3 & 20 & 0.12 & 0.88 \\
\hline $\mathbf{7}$ & 2.22 & 3 & 24 & 0.065 & 0.935 \\
\hline $\mathbf{8}$ & 2.37 & 3 & 28 & 0.025 & 0.975 \\
\hline
\end{tabular}


According to the results of the power analysis, the power for a sample size of eight or above would be higher than 0.95 . Therefore, at least eight participants were needed for this study to reach the desired power.

\subsection{Equipment}

\subsubsection{Electromyography (EMG) system}

Same as aim\#1 (See section 2.4.2)

\subsubsection{Force gauge}

Same as aim\#1 (See section 3.5.2)

\subsubsection{Digital protractor}

Same as aim\#1 (See section 3.5.3)

\subsubsection{Adjustable work simulation system}

Same as aim\#1 (See section 3.5.4)

\subsubsection{Handgrip Dynamometer}

A handgrip dynamometer (Sammons Preston Rolyan, IL, USA) (Figure 18) was used to perform the handgrip (refresher) exertions. This dynamometer can measure the maximum strength, as well as allow the user to exert forces at a prescribed exertion level. 


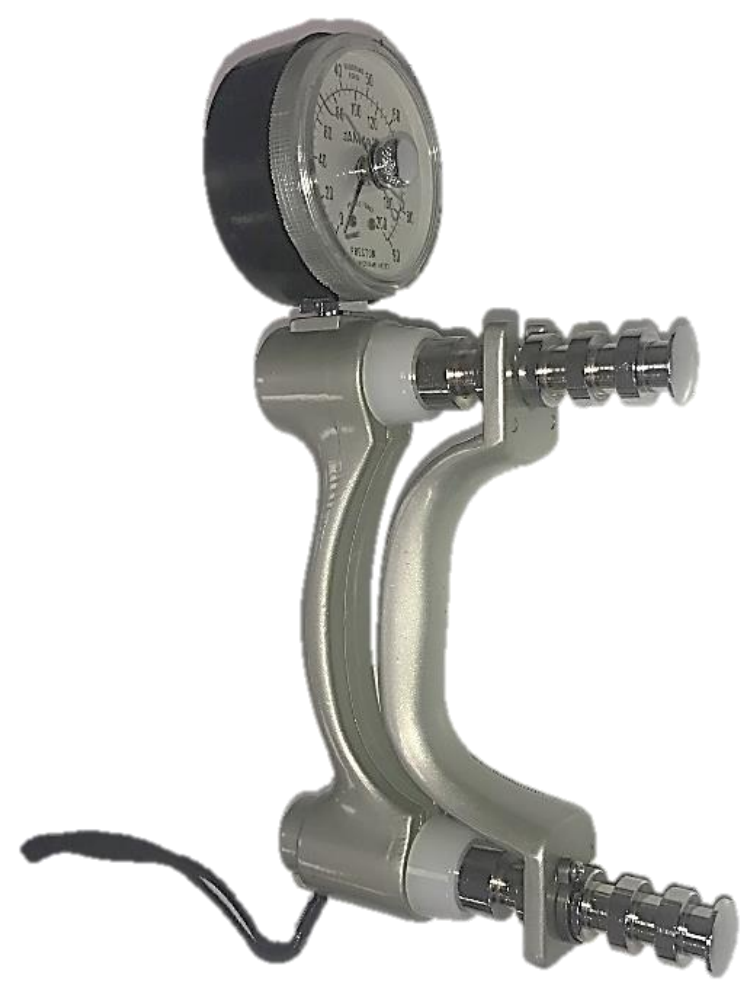

Figure 18. Handgrip dynamometer

\subsection{Experimental design}

This study was conducted to test whether handgrip exertions can be used as a refresher exercise for rotator cuff muscles during overhead work. To test the effect of handgrip exertions, two five-second handgrip exertions were added to the beginning and the end of the rest period of the task rotation sequences that were explained in the previous chapter. For more detail on the task rotation sequences, see section 3.6. The handgrip exertions were performed at 30\% MVC level. This force level is the most commonly used value for handgrip exertions in the literature and has been used as the minimum \%MVC to affect shoulder muscle activity (Sporrong et al., 1995, 1996; Smets et al., 2009; Antony and Keir, 2010; Keir and Brown, 2012; Hodder et al., 2012). 
A pilot study was performed to further verify the \% MVC level and the posture for the gripping task. Two \% MVC levels, 30\% and 50\%, were tested. Both \%MVC levels showed an effect on the rotator cuff muscles' activity but difference between the two levels was not significant. Therefore, $30 \% \mathrm{MVC}$ was chosen to prevent excessive muscle exertion and fatigue. Four different postures and three planes of exertions (sagittal, scapular, and frontal) were tested to find the posture with the most effect on rotator cuff muscles EMG activity. The postures were 0/90, 60/90, 90/120, 120/150, where the first number represents shoulder flexion and the second number represents elbow flexion (i.e., 60/90 represents 60 degrees of shoulder flexion and 90 degrees of elbow flexion). Handgrip exertions performed in the scapular plane with 60/90 posture had a pronounced effect on the rotator cuff electromyography activity. Therefore, this posture was selected for the handgrip exertions (Figure 19).

Similar to the aim\#1, the independent variable, task rotation sequences, was controlled at four levels. Three dependent variables were considered for this study, which include muscle fatigue (measured by two methods, 1) Using the slope of the linear regression lines of the median frequency values and 2) Using the percent drop in the median frequency values), strength at MVC, and RPE. The experiment consisted of three equal sections, one-third overhead (duty cycle) exertions, one-third handgrip exertions, and one-third rest period. 


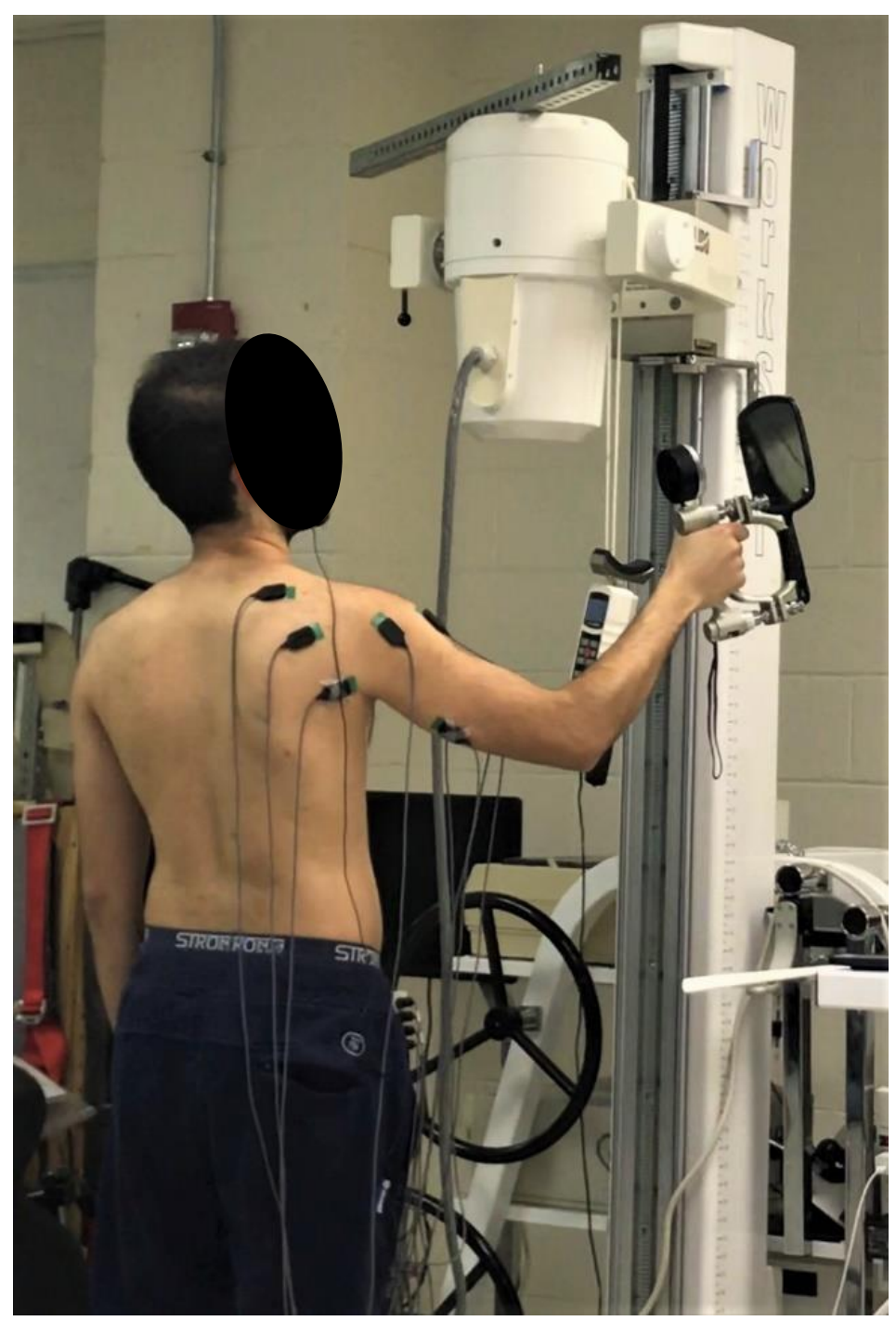

Figure 19. Handgrip exertion posture

\subsection{Experimental procedure}

A procedure similar to the previous aim was followed for this study (see section 3.7), with an exception of five-second 30\% MVC handgrip exertions performed at the beginning and the end of the rest time (Figure 20). In this study, each five-minute session consisted of 100 seconds of overhead task/exertions, 100 seconds of handgrip task/exertions, and 100 seconds of rest. A five-second 30\% MVC handgrip exertion, ten seconds rest, and another five-second 30\% MVC 
handgrip exertion were follow every ten seconds of overhead task. Same as the previous aim, total data collection duration for an individual participant was around 260 minutes long - (10-15 minutes for preparation and 235 to 245 minutes for task rotation sequences.

\subsection{Data Processing and Statistical Analysis}

The data was processed, and the statistical analysis was performed in the same manner as aim\#1 (see section 3.8). Moreover, it has been suggested that a $12.25 \%$ or higher changes in the median frequency of shoulder muscles can be an indicator of muscle fatigue (Alasim, 2020). Muscle specific percent drop in the median frequency was calculated for both with and without task handgrip rotation studies. Using the data obtained during the reference exertion that was performed after each sequence, a linear regression line was fitted to the 10-point data of the median frequency. The regression equation was then used to calculate percent drop in the median frequency for each muscle. The data from this aim (task rotation sequences with the handgrip exertion) was compared with the previous aim (task rotation sequences without handgrip exertion) using 2-sample t-test. 
1

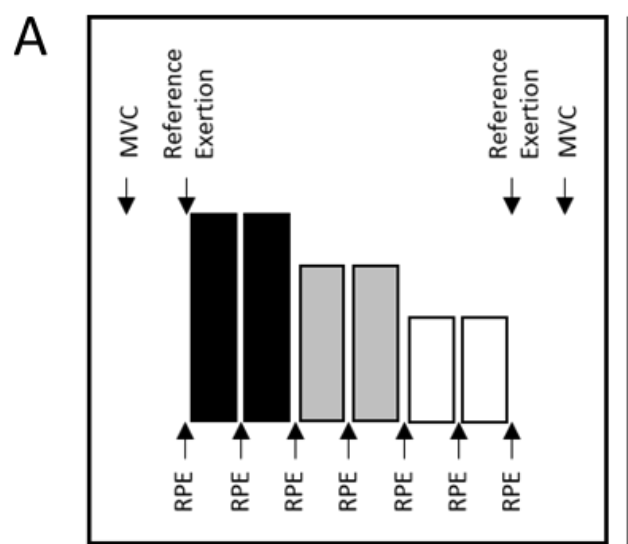

$35 \%$ MVC Exertion $20 \%$ MVC Exertion

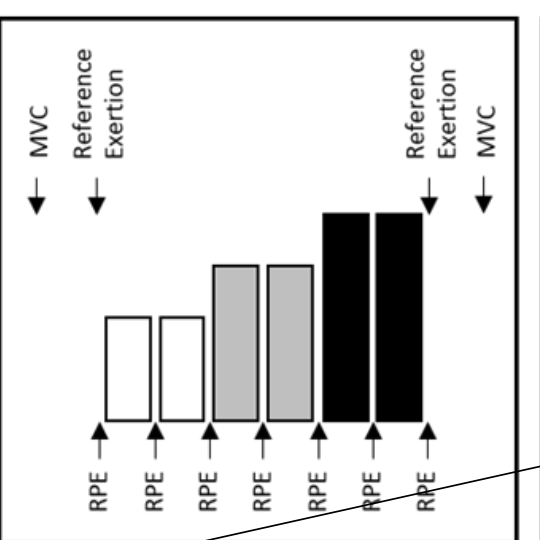

$5 \%$ MVCExertion

B

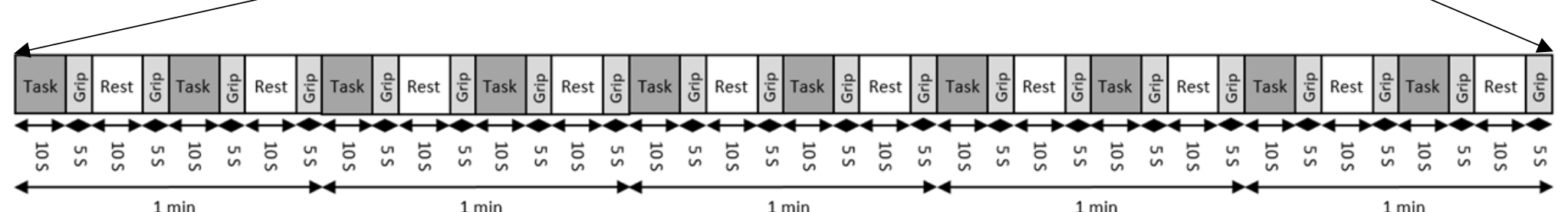

Figure 20. (A) Four rotation sequences used in this study: (1) decreasing, (2) increasing, (3) upward parabolic, (4) downward parabolic. Each bar represents a 5-minute session of overhead task at the specified \%MVC level. The arrows show the various measurements obtained during the sequences. (B) Overhead task, handgrip exertion, and rest order within each 5-minute session. 


\subsection{Results}

The task rotation sequences performed with the handgrip exertion had no effect on the activity of rotator cuff muscles. The normalized muscle activities of supraspinatus, infraspinatus, and teres minor ranged between $38.5 \%$ to $41.4 \%, 44.8 \%$ to $48.5 \%$, and $42.9 \%$ to $46.6 \%$ respectively Figure 21, Table 9. Similar to the aim 1 findings, all sequences produced a drop in the median frequency slope for all three muscles (Figure 22, Table 9). Performing the exertions in sequence 1 (decreasing) resulted in the highest drop in the median frequency slope followed by sequence 2 (increasing), sequence 3 (upward parabolic), and sequence 4 (downward parabolic). However, the effect of sequence with the handgrip exertion on the drop in the median frequency slope was statistically not significant for any of the muscles.

Table 9. Main effect of job rotation sequence with the handgrip exertion on the normalized muscle activity and drop in the median frequency slope.

\begin{tabular}{lccccc}
\hline & Sequence 1 & Sequence 2 & Sequence 3 & Sequence 4 & $p$-value \\
\hline Supraspinatus & $41.45(7.55)$ & $38.52(5.91)$ & $40.93(6.58)$ & $38.92(6.87)$ & 0.68 \\
Infraspinatus & $46.49(6.05)$ & $44.79(7.99)$ & $48.46(9.50)$ & $45.77(8.52)$ & 0.66 \\
Teres minor & $44.06(5.83)$ & $44.99(9.10)$ & $46.57(8.90)$ & $42.93(6.84)$ & 0.70 \\
\hline & & Median Frequency Slope Changes (SD) & \\
\hline Supraspinatus & $-0.37(0.57)$ & $-0.23(0.62)$ & $-0.24(0.76)$ & $-0.17(0.65)$ & 0.16 \\
Infraspinatus & $-0.44(0.61)$ & $-0.27(0.86)$ & $-0.25(0.82)$ & $-0.17(0.93)$ & 0.29 \\
Teres minor & $-0.36(0.83)$ & $-0.25(1.12)$ & $-0.21(0.59)$ & $-0.22(0.85)$ & 0.65 \\
\hline
\end{tabular}


60.00

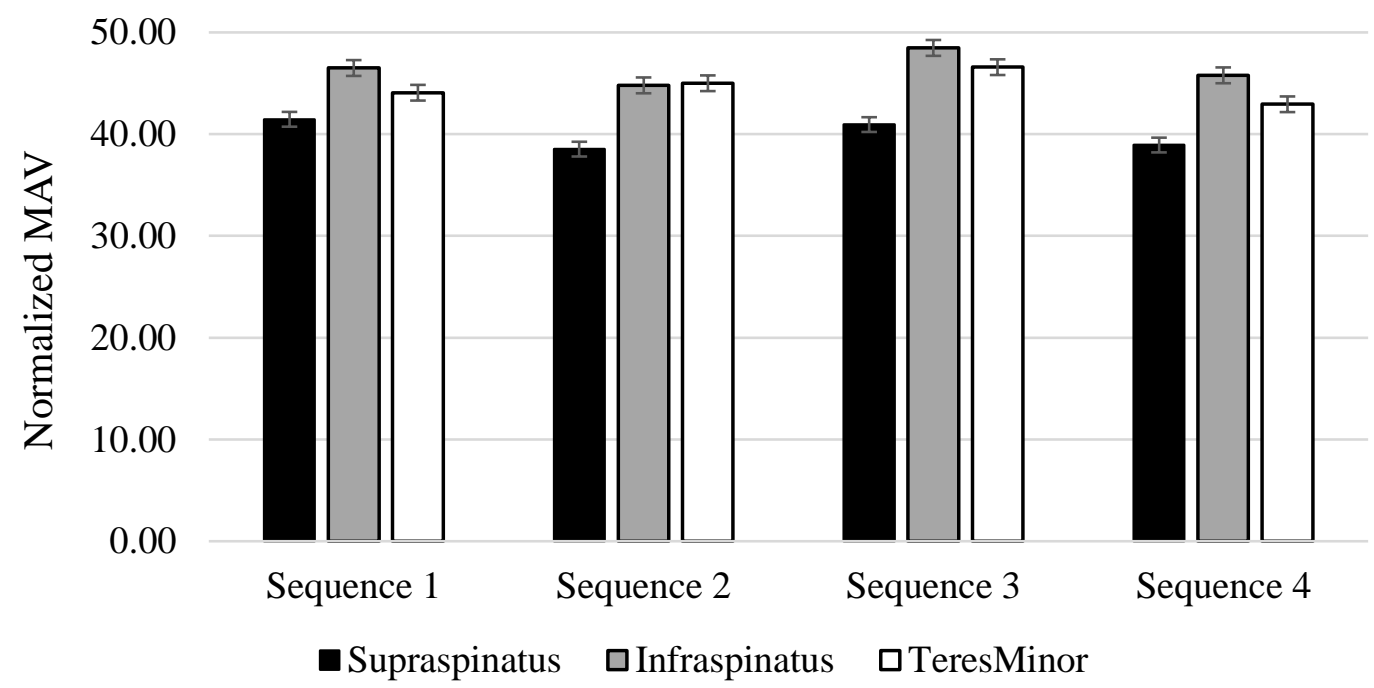

Figure 21. Mean normalized muscle activity for the rotator cuff muscles at different task rotation sequences with the handgrip exertion. Error bars represent standard error.

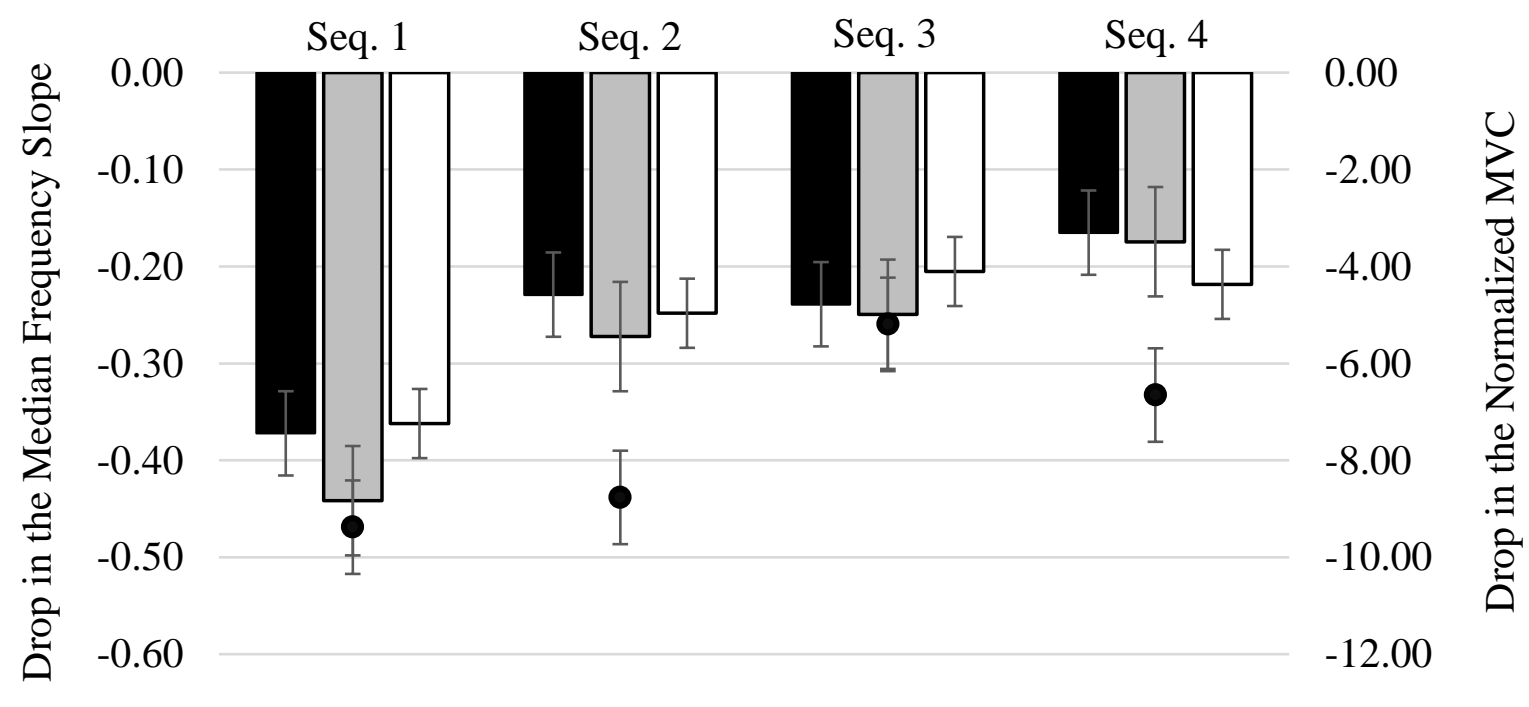

- Supraspinatus $\quad$ Infraspinatus $\quad$ T Teres minor $\bullet$ NMVC

Figure 22. Mean drop in the median frequency slope and strength at MVC for the task rotation sequences with the handgrip exertion. Error bars represent standard error. 
Figure 23 and Figure 24 show the muscle-specific differences in the normalized muscle activity and the drop of median frequency slopes for the task rotation sequences performed with and without the handgrip exertions. Although similar muscle activity pattern was recorded, all three muscles exhibited lower median frequency drop, which indicates less muscle fatigue after performing the task rotation sequences with the handgrip exertions. For supraspinatus, drop in the median frequency reduced by $27.9,42.4$, and $30.8 \%$ for sequences 1,2 , and 4 , respectively, and increased by $1.6 \%$ for sequence 3 . For infraspinatus, drop in the median frequency reduced by $42.1,60.3,29.8$, and $58.5 \%$ for sequences $1,2,3$ and 4, respectively. For teres minor, drop in the median frequency reduced by $52.6,63.8,42.2$, and $48.0 \%$ for sequences $1,2,3$, and 4 , respectively. However, the results of the 2-sample t-test indicated no significant differences in the mean normalized muscle activity and mean drop in the median frequency slope for the sequences performed with and without the handgrip exertions (Table 10). 

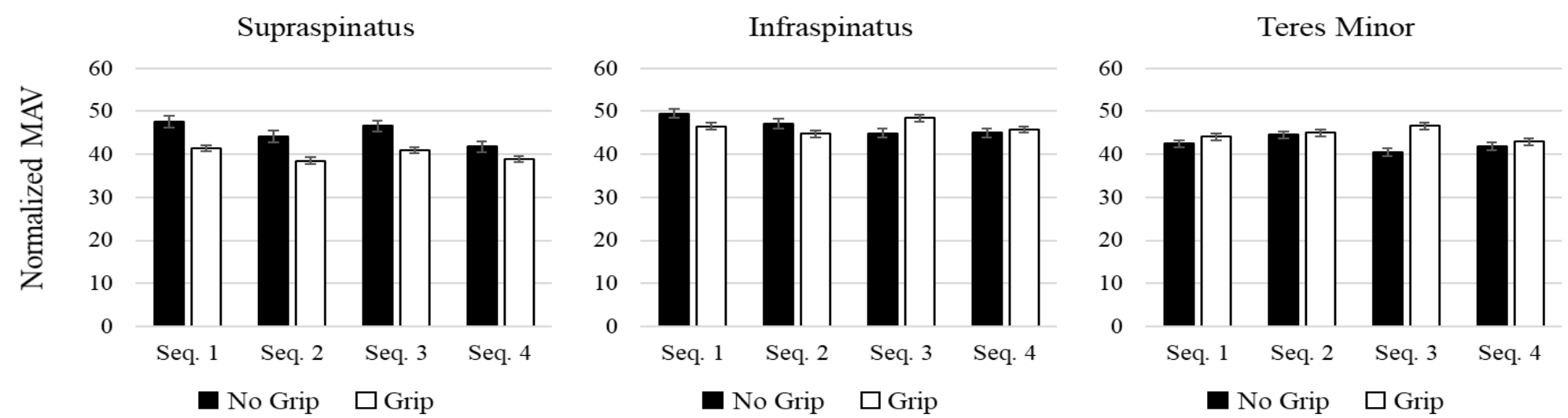

Figure 23. Mean normalized activity for the task rotation sequences with and without the handgrip exertion. Error bars represent standard error.
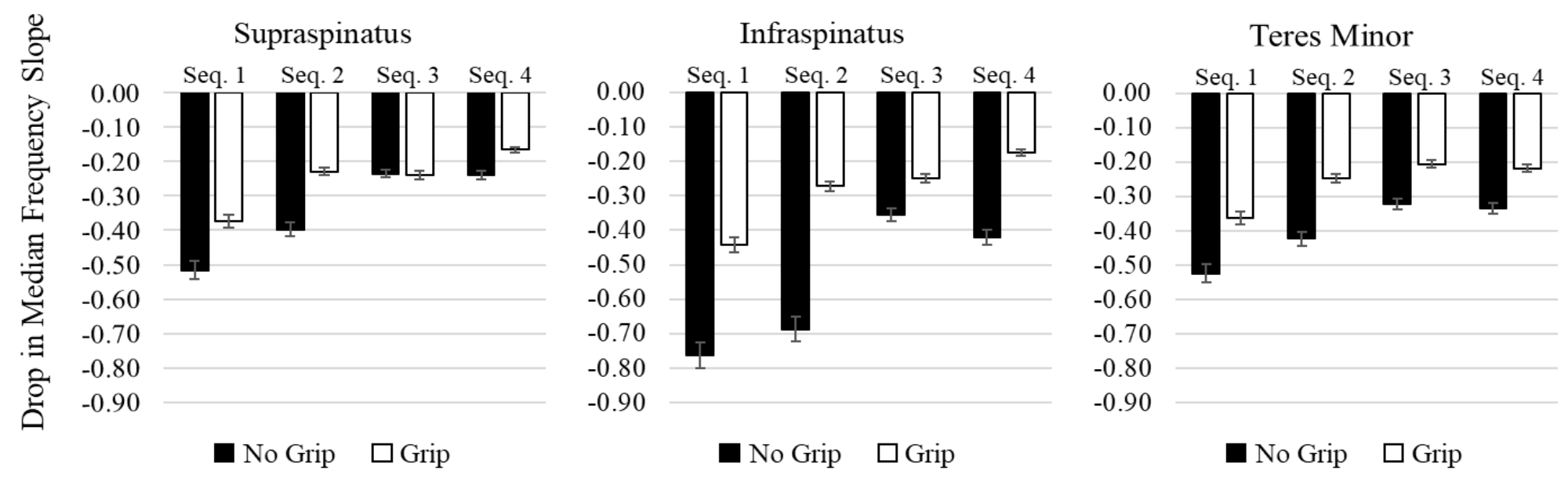

Figure 24. Mean drop in the median frequency slope for the task rotation sequences with and without the handgrip exertion. Error bars represent standard error. 
Table 10. A comparison of normalized muscle activity and drop in the median frequency slope for the rotation sequences with or without handgrip exertions.

\section{Normalized Muscle Activity (\%) (SD)}

\begin{tabular}{|c|c|c|c|c|c|c|c|c|c|c|c|c|}
\hline & \multicolumn{3}{|c|}{ Sequence 1} & \multicolumn{3}{|c|}{ Sequence 2} & \multicolumn{3}{|c|}{ Sequence 3} & \multicolumn{3}{|c|}{ Sequence 4} \\
\hline & No Grip & Grip & p-value & No Grip & Grip & p-value & No Grip & Grip & p-value & No Grip & Grip & p-value \\
\hline Supraspinatus & $\begin{array}{c}47.61 \\
(8.2)\end{array}$ & $\begin{array}{c}41.45 \\
(7.5)\end{array}$ & 0.08 & $\begin{array}{l}44.17 \\
(10.1)\end{array}$ & $\begin{array}{c}38.52 \\
(5.9)\end{array}$ & 0.13 & $\begin{array}{c}46.62 \\
(9.9)\end{array}$ & $\begin{array}{c}40.93 \\
(6.6)\end{array}$ & 0.14 & $\begin{array}{c}41.79 \\
(7.9)\end{array}$ & $\begin{array}{c}38.92 \\
(6.9)\end{array}$ & 0.37 \\
\hline Infraspinatus & $\begin{array}{l}49.51 \\
(10.9)\end{array}$ & $\begin{array}{c}46.49 \\
(6.0)\end{array}$ & 0.43 & $\begin{array}{l}47.11 \\
(12.2)\end{array}$ & $\begin{array}{c}44.79 \\
(8.0)\end{array}$ & 0.60 & $\begin{array}{l}44.90 \\
(12.6)\end{array}$ & $\begin{array}{c}48.46 \\
(9.5)\end{array}$ & 0.46 & $\begin{array}{c}44.97 \\
(8.9)\end{array}$ & $\begin{array}{c}45.77 \\
(8.5)\end{array}$ & 0.83 \\
\hline Teres Minor & $\begin{array}{c}42.50 \\
(7.6)\end{array}$ & $\begin{array}{c}44.06 \\
(5.8)\end{array}$ & 0.59 & $\begin{array}{l}44.51 \\
(10.1)\end{array}$ & $\begin{array}{c}44.99 \\
(9.1)\end{array}$ & 0.91 & $\begin{array}{c}40.47 \\
(9.2)\end{array}$ & $\begin{array}{c}46.57 \\
(8.9)\end{array}$ & 0.12 & $\begin{array}{c}41.89 \\
(6.7)\end{array}$ & $\begin{array}{c}42.93 \\
(6.8)\end{array}$ & 0.72 \\
\hline
\end{tabular}

Median Frequency Slope Changes (SD)

\begin{tabular}{|c|c|c|c|c|c|c|c|c|c|c|c|c|}
\hline & \multicolumn{3}{|c|}{ Sequence 1} & \multicolumn{3}{|c|}{ Sequence 2} & \multicolumn{3}{|c|}{ Sequence 3} & \multicolumn{3}{|c|}{ Sequence 4} \\
\hline & No Grip & Grip & p-value & No Grip & Grip & p-value & No Grip & Grip & p-value & No Grip & Grip & p-value \\
\hline Supraspinatus & $\begin{array}{l}-0.52 \\
(0.64)\end{array}$ & $\begin{array}{l}-0.37 \\
(0.57)\end{array}$ & 0.58 & $\begin{array}{l}-0.40 \\
(0.87)\end{array}$ & $\begin{array}{l}-0.23 \\
(0.62)\end{array}$ & 0.61 & $\begin{array}{l}-0.24 \\
(0.45)\end{array}$ & $\begin{array}{l}-0.24 \\
(0.76)\end{array}$ & 0.99 & $\begin{array}{l}-0.24 \\
(0.43)\end{array}$ & $\begin{array}{l}-0.17 \\
(0.65)\end{array}$ & 0.76 \\
\hline Infraspinatus & $\begin{array}{l}-0.76 \\
(0.82)\end{array}$ & $\begin{array}{l}-0.44 \\
(0.61)\end{array}$ & 0.31 & $\begin{array}{l}-0.69 \\
(1.00)\end{array}$ & $\begin{array}{l}-0.27 \\
(0.86)\end{array}$ & 0.31 & $\begin{array}{l}-0.35 \\
(0.82)\end{array}$ & $\begin{array}{l}-0.25 \\
(0.82)\end{array}$ & 0.77 & $\begin{array}{l}-0.42 \\
(0.66)\end{array}$ & $\begin{array}{l}-0.17 \\
(0.93)\end{array}$ & 0.48 \\
\hline Teres Minor & $\begin{array}{l}-0.52 \\
(0.94)\end{array}$ & $\begin{array}{l}-0.36 \\
(0.83)\end{array}$ & 0.67 & $\begin{array}{l}-0.42 \\
(0.56)\end{array}$ & $\begin{array}{l}-0.25 \\
(1.12)\end{array}$ & 0.65 & $\begin{array}{l}-0.32 \\
(0.53)\end{array}$ & $\begin{array}{l}-0.21 \\
(0.59)\end{array}$ & 0.62 & $\begin{array}{l}-0.33 \\
(0.56)\end{array}$ & $\begin{array}{l}-0.22 \\
(0.85)\end{array}$ & 0.71 \\
\hline
\end{tabular}


Table 11. Main effect of job rotation sequence with the handgrip exertion on the drop in the normalized strength at MVC and average RPE.

\begin{tabular}{cccccc}
\hline & Sequence 1 & Sequence 2 & Sequence 3 & Sequence 4 & $p$-value \\
\hline Normalized MVC Change (\%) & $-9.4(8.7)$ & $-8.8(5.6)$ & $-5.2(12.2)$ & $-6.7(9.8)$ & 0.69 \\
\hline Average RPE & $3.1(1.7)$ & $3.1(1.8)$ & $2.9(1.3)$ & $2.8(1.9)$ & 0.71 \\
\hline
\end{tabular}

Table 12. A comparison of normalized MVC drop and average RPE for the rotation sequences with or without handgrip exertions.

\begin{tabular}{|c|c|c|c|c|c|c|c|c|c|c|c|c|}
\hline & \multicolumn{12}{|c|}{ Normalized MVC Drop (\%) (SD) } \\
\hline & \multicolumn{3}{|c|}{ Sequence 1} & \multicolumn{3}{|c|}{ Sequence 2} & \multicolumn{3}{|c|}{ Sequence 3} & \multicolumn{3}{|c|}{ Sequence 4} \\
\hline & No Grip & Grip & p-value & No Grip & Grip & p-value & No Grip & Grip & p-value & No Grip & Grip & $p$-value \\
\hline $\begin{array}{l}\text { Normalized MVC } \\
\text { Drop (\%) }\end{array}$ & $\begin{array}{l}-9.95 \\
(8.6)\end{array}$ & $\begin{array}{l}-9.4 \\
(8.7)\end{array}$ & 0.69 & $\begin{array}{c}-11.37 \\
(6.9)\end{array}$ & $\begin{array}{l}-8.8 \\
(5.6)\end{array}$ & 0.34 & $\begin{array}{l}-7.80 \\
(11.7)\end{array}$ & $\begin{array}{c}-5.2 \\
(12.2)\end{array}$ & 0.61 & $\begin{array}{l}-7.73 \\
(13.7)\end{array}$ & $\begin{array}{l}-6.7 \\
(9.8)\end{array}$ & 0.57 \\
\hline
\end{tabular}

\section{Average RPE (SD)}

\begin{tabular}{|c|c|c|c|c|c|c|c|c|c|c|c|c|}
\hline & \multicolumn{3}{|c|}{ Sequence 1} & \multicolumn{3}{|c|}{ Sequence 2} & \multicolumn{3}{|c|}{ Sequence 3} & \multicolumn{3}{|c|}{ Sequence 4} \\
\hline & No Grip & Grip & $p$-value & No Grip & Grip & $p$-value & No Grip & Grip & $p$-value & No Grip & Grip & $p$-value \\
\hline Average RPE & $3.3(1.2)$ & $3.1(1.7)$ & 0.69 & $3.1(1.3)$ & $3.1(1.8)$ & 0.94 & $2.9(1.1)$ & $2.9(1.3)$ & 0.98 & $3.2(1.2)$ & $2.8(1.9)$ & 0.34 \\
\hline
\end{tabular}




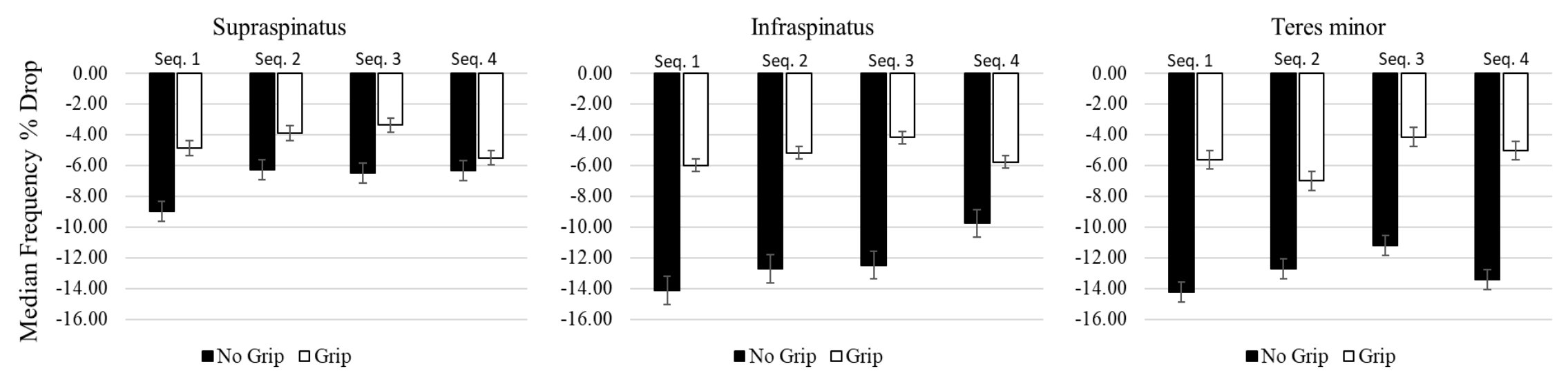

Figure 25. Mean percent drop in the median frequency slope for the task rotation sequences with and without the handgrip exertion. Error bars represent standard error.

Table 13. Comparison of percent drop in the median frequency for the rotation sequences with and without handgrip exertions.

\begin{tabular}{|c|c|c|c|c|c|c|c|c|c|c|c|c|}
\hline & \multicolumn{12}{|c|}{ \% Drop in Median Frequency (SD) } \\
\hline & \multicolumn{3}{|c|}{ Sequence 1} & \multicolumn{3}{|c|}{ Sequence 2} & \multicolumn{3}{|c|}{ Sequence 3} & \multicolumn{3}{|c|}{ Sequence 4} \\
\hline & No Grip & Grip & p-value & No Grip & Grip & p-value & No Grip & Grip & $p$-value & No Grip & Grip & $p$-value \\
\hline Supraspinatus & $\begin{array}{l}-8.98 \\
(8.8)\end{array}$ & $\begin{array}{l}-4.86 \\
(9.0)\end{array}$ & 0.272 & $\begin{array}{l}-6.28 \\
(5.7)\end{array}$ & $\begin{array}{l}-3.89 \\
(2.6)\end{array}$ & 0.325 & $\begin{array}{l}-6.49 \\
(2.6)\end{array}$ & $\begin{array}{l}-3.38 \\
(5.4)\end{array}$ & 0.097 & $\begin{array}{l}-6.34 \\
(5.2)\end{array}$ & $\begin{array}{c}-5.50 \\
(5.3)\end{array}$ & 0.703 \\
\hline Infraspinatus & $\begin{array}{r}-14.10 \\
(11.3)\end{array}$ & $\begin{array}{c}-6.00 \\
(9.2)\end{array}$ & 0.069 & $\begin{array}{c}-12.72 \\
(8.8)\end{array}$ & $\begin{array}{r}-5.17 \\
(6.1)\end{array}$ & 0.025 & $\begin{array}{c}-12.47 \\
(8.0)\end{array}$ & $\begin{array}{r}-4.19 \\
(6.1)\end{array}$ & 0.01 & $\begin{array}{l}-9.76 \\
(5.9)\end{array}$ & $\begin{array}{c}-5.76 \\
(2.3)\end{array}$ & 0.193 \\
\hline Teres Minor & $\begin{array}{c}-14.22 \\
(7.8)\end{array}$ & $\begin{array}{c}-5.63 \\
(9.5)\end{array}$ & 0.025 & $\begin{array}{c}-12.70 \\
(8.1)\end{array}$ & $\begin{array}{c}-7.00 \\
(6.4)\end{array}$ & 0.07 & $\begin{array}{c}-11.19 \\
(8.4)\end{array}$ & $\begin{array}{c}-4.14 \\
(4.5)\end{array}$ & 0.021 & $\begin{array}{c}-13.40 \\
(8.2)\end{array}$ & $\begin{array}{l}-5.01 \\
(8.3)\end{array}$ & 0.022 \\
\hline
\end{tabular}


Figure 25 and Table 13 show the muscle-specific differences in the percent drop of median frequency for the job rotation sequences performed with and without the handgrip exertions. The highest drop in the median frequency for supraspinatus was $8.98 \%$, which was recorded after sequence 1 without handgrip and was lowered to $4.86 \%$ drop after performing the same sequence with handgrip. Higher percent drops were recorded for infraspinatus and teres minor after performing the sequences without the handgrip. For infraspinatus performing the sequences 1,2, 3 , and 4 resulted in $14.1,12.7,12.5$, and $9.8 \%$ drop in the median frequency, respectively. However, these values were $6.0,5.2,4.2$, and 5.8\%, respectively, after performing the same sequences with the handgrip. For teres minor, performing the sequences without handgrip resulted in $14.2,12.7,11.2$, and $13.4 \%$ drop in the median frequency for sequences $1,2,3$, and 4 , respectively. These values dropped to $5.6,7.0,4.1$, and $5.0 \%$ for sequences $1,2,3$, and 4 , respectively, after performing the sequences with handgrip.

As indicated above, all three muscles exhibited lower percent drop in the median frequency after performing the sequences with handgrip exertion. For supraspinatus, percent drop in the median frequency reduced by $45.8,38.1,47.9$, and $13.3 \%$ for sequences $1,2,3$, and 4 , respectively. For infraspinatus, percent drop in the median frequency reduced by 57.4, 59.3, 66.4, and $40.9 \%$ for sequences $1,2,3$, and 4 , respectively. For teres minor, percent drop in the median frequency reduced by $60.4,44.8,62.9$, and $62.6 \%$ for sequences $1,2,3$, and 4 , respectively. The results of the 2-sample t-test indicated significant differences in the mean percent drop between the with and without handgrip conditions for infraspinatus in sequences 2 and 3, and for teres minor in sequences 1, 3, and 4 (Table 13). No significant differences were observed for supraspinatus.

A reduction in the strength at MVC (Figure 22) was observed for all sequences. Sequences 1 and 2 resulted in almost double the reduction in the strength at MVC when compared to sequence 
3. The highest reduction was observed for sequence 1 , followed by sequences 2 , 4 , and 3 . Statistically, the task rotation sequence with handgrip exertion had no effect on the reduction in the strength at MVC (Table 11). When compared with aim 1 (sequences without the handgrip exertion) data, a lower reduction in the strength at MVC was observed for sequences with the handgrip exertion. The highest difference between the two conditions was observed in sequence 3, where the presence of handgrip exertion lowered the drop in the strength by $33.4 \%$, followed by sequence $2(22.9 \%)$, sequence 4 (14\%), and sequence 1 (5.7\%) (Figure 26). Results of the 2sample t-test indicated no significant differences in the drop in the strength at MVC with and without handgrip exertions (Table 12).

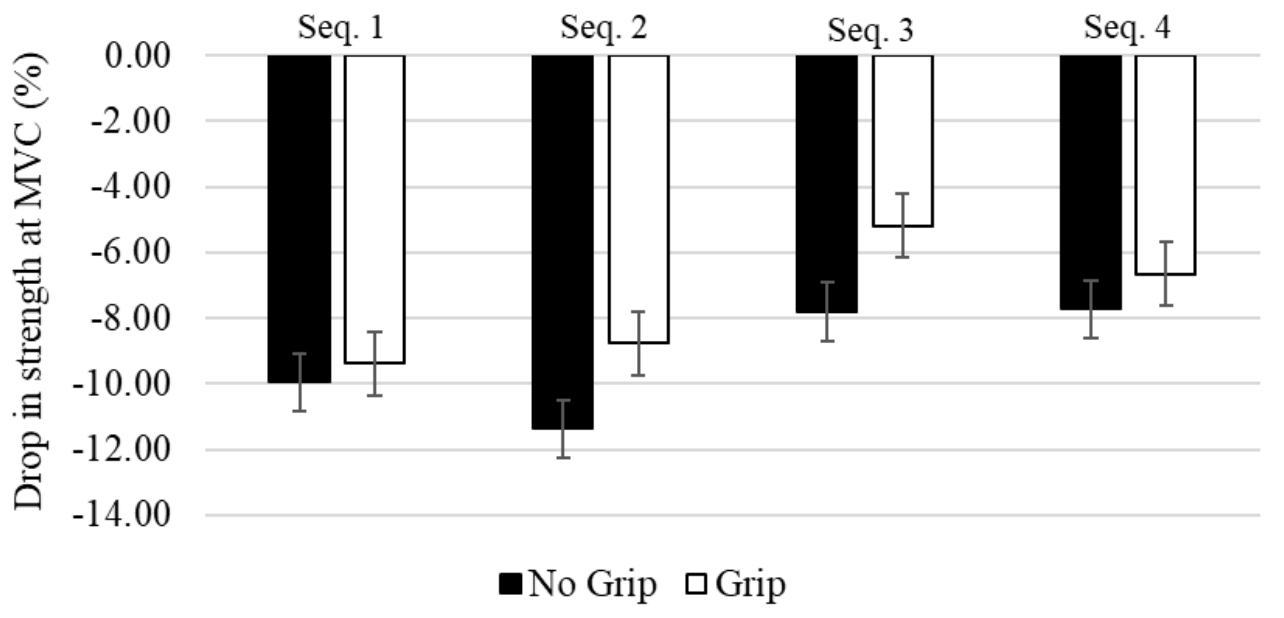

Figure 26. Mean drop in the strength at MVC for the task rotation sequences with and without the handgrip exertion. Error bars represent standard error.

Overall, the mean RPE values were comparable between the sequences. Sequences 1 and 2 showed slightly higher RPE compared to the other sequences. The effect of sequence with handgrip exertion on RPE was statistically insignificant (Table 11). When compared with the aim 1 data, slightly lower RPEs were given by the participants while performing the sequences with 
the handgrip exertion. However, the differences were statistically insignificant (Table 12, Figure 27).

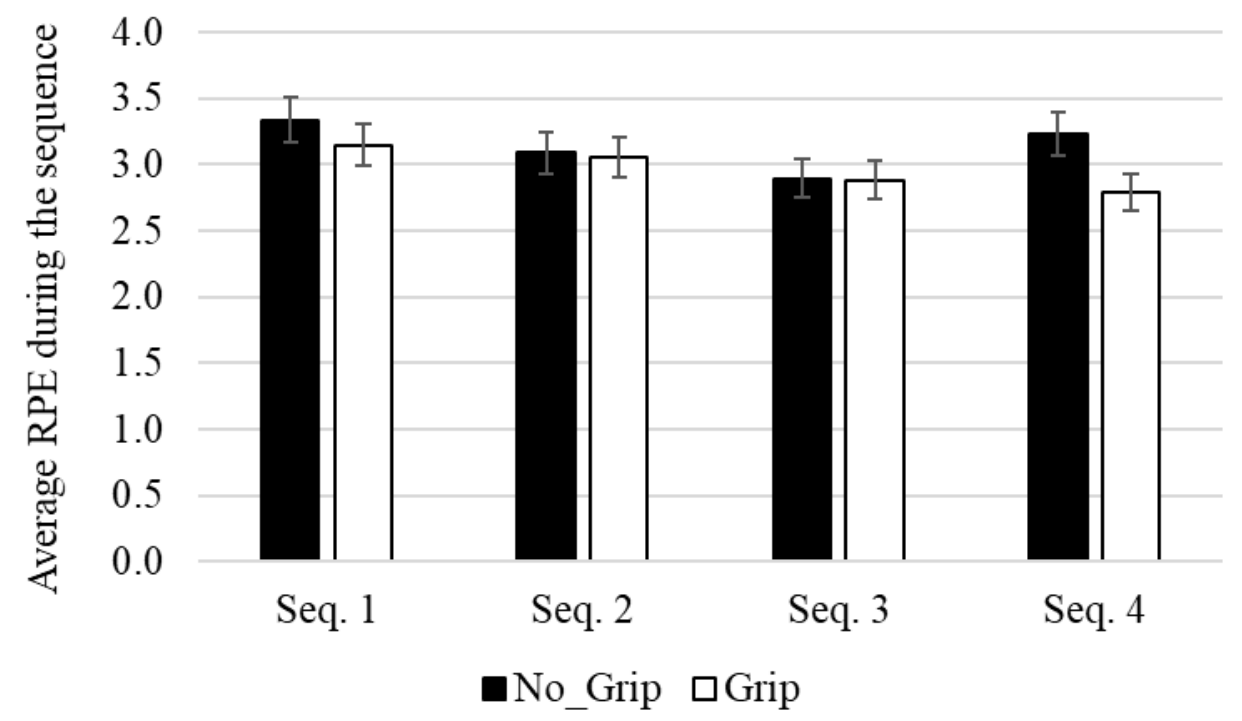

Figure 27. Mean RPE for the task rotation sequences with and without the handgrip exertion. Error bars represent standard error.

\subsection{Discussion}

Performing a moderate activity during the recovery period, also known as active recovery, increases the intramuscular blood flow and provides faster lactate elimination from the muscles. This form of recovery is being widely used to refresh and recover fatigued muscles of athletes after intense activity (Menzies et al., 2010; Ferreira et al., 2011; Mika et al., 2016), but to our knowledge has not been used or tested in the industrial settings. Therefore, this study was designed to evaluate the effectiveness of active recovery for the rotator cuff muscles during (fatigue-inducing) overhead work.

The effect of handgrip exertions on shoulder muscles activity has been studied in the past and it has been shown that such exertions would alter the activity of various muscles in the shoulder 
region (Sigholm et al., 1983; Sporrong et al., 1996; Alizadehkhaiyat et al., 2011, Antony and Keir, 2010; Hodder and Keir, 2012). It has also been suggested that handgrip exertions redistribute the load among the shoulder muscles and in particular, they reduce deltoid muscles activity and increase the activity of infraspinatus and supraspinatus, which were the focus of this study (Sporrong et al., 1995, 1996; Alizadehkhaiyat et al., 2011). In general, lower median frequency slope reductions as well as percent drops were observed with the inclusion of refresher (handgrip) exertion. Previous research reported that a $12 \%$ drop in the median frequency for shoulder muscles could be used as an indicator of localized muscle fatigue (Alasim, 2020). Infraspinatus exhibited more that $12 \%$ drop in sequences 1,2 , and 3 without handgrip and performing the sequences with handgrip exertion reduced the drop below $6 \%$ for all sequences. For teres minor the drop in the median frequency was more than $12 \%$ for sequences 1,2 , and 4 without handgrip and with handgrip resulted in significantly lower percent drop (below $7 \%$ for all sequences). The percent drop values for supraspinatus on the other hand did not reach the fatigue threshold of $12 \%$ with and without handgrip exertions. Thus, one possible conclusion based on the $12 \%$ threshold is that the status of infraspinatus and teres minor changed from "fatigued" to "not-fatigued" when the job rotation sequences were performed with handgrip exertions.

The most impactful effect of handgrip exertions was observed for infraspinatus. Presence of the handgrip exertion resulted in $47 \%$ reduction in the median frequency slopes for infraspinatus followed by teres minor and supraspinatus with $34 \%$ and $25 \%$. The refresher exertion was performed using 60/90 degrees of arm/elbow flexion posture. Such exertion activates infraspinatus to a higher level compared to supraspinatus. Previous studies have also reported a higher effect of handgrip on infraspinatus compared to supraspinatus (Palmerud et al., 2000; Alizadehkhaiyat et al., 2011). Thus, perhaps due to its higher activation during the handgrip (refresher) exertion, such 
exertion may have had a better "refreshing effect" on infraspinatus than supraspinatus. Furthermore, in a cadaveric study by Ackland and Pandy (2011), moment arm and function of the shoulder muscles during glenohumeral axial rotation were studied and it was shown that during shoulder flexion supraspinatus functions differently compared to infraspinatus and teres minor. During shoulder flexion, supraspinatus acts as an internal rotator while infraspinatus and teres minor act as external rotators of the glenohumeral joint. These anatomical/functional differences may be responsible for the muscle specific differences due to job rotation sequences.

Some differences were observed in the median frequency-based fatigue indicator when task rotation sequences with and without handgrip were compared. Lower median frequency drop was recorded when performing the sequences with handgrip exertion. Since the same workload was considered for both studies throughout the sequences, it can be stated that the presence of handgrip has slowed down the fatigue development of the rotator cuff muscles. When performing the sequences without handgrip exertion, in terms of fatigue development, sequence 1 was significantly higher than sequences 3 and 4 (the descending order of the sequences was 1, 2, 4, and 3). When the sequences performed with the handgrip, sequence 1 was (still) on the top followed by sequences 2,3 , and 4 . However, the statistical effect of sequence disappeared when handgrip exertions were performed during the recovery period. This may suggest that active recovery could sufficiently lower the amount of muscle fatigue to a level that performing task rotation might not help any more.

Although statistically insignificant, sequences 3 (upward parabolic) and 4 (downward parabolic) performed the best in terms of lowest median frequency-based fatigue development, and MVC strength drop. As explained in the previous chapter, starting with low and medium intensity exertions in sequence 4 has warmed up the muscles and performing the medium and low 
exertions right after the two high exertions, has acted as a form of active recovery and resulted in less muscle fatigue compared to other sequences. In contrast, sequence 1 started with two high exertions without any warmup and followed by pairs of medium and low exertions, which resulted in the highest fatigue. Although sequence 3 (upward parabolic) was also started with a high exertion, performing the second high exertion at the end of the sequence and performing low and medium exertions in between provided enough time for the muscles to recover and develop considerably less fatigue compared to sequence 1 .

Changes in the strength at MVC along with the average RPE values were used as other fatigue indicators in this study. Both measures ranked sequence 1 as the most fatiguing sequence, which is consistent with the median frequency results. However, these two measures do not share the same trend for the effect of sequence. Unlike median frequency, sequence did not show a significant effect on these factors. As discussed in the previous chapter, participants can voluntarily redistribute muscle activity while keeping a similar force level (Palmerud et al., 1995). Therefore, different muscle groups could have been recruited to keep the force at the required level. Changes in the strength at MVC and the average RPE values, not being muscle specific do not seem to be adequate measures to capture small changes in the muscle fatigue due to different task rotation sequences.

Results of this study indicated that a moderate handgrip exertion could be considered as a refresher exertion for rotator cuff muscles during overhead work. This type of refresher exertion when performed during the rest period may facilitate active recovery and reduce the muscle fatigue. 


\section{Chapter 5. Conclusion}

Rotator cuff muscles are known as the most vulnerable group of muscles to injury in the shoulder region. Among all the etiologies in the pathogenesis of the rotator cuff injuries, posture and in particular overhead work has been a common concern in industrial workplaces.

In this study, a focused approach was used to first model the strength, endurance, and fatigue response of rotator cuff muscles (preliminary study (Motabar et al., 2019)). The MVC strength of supraspinatus, infraspinatus and teres minor, was recorded and subsequently four sub-exertion levels $(15 \%, 30 \%, 45 \%$, and $60 \%$ MVC) were used to model the endurance and fatigue response. Despite muscle specific strength differences (infraspinatus > teres minor $>$ supraspinatus), identical endurance was observed for the rotator cuff muscles. A non-linear trend, i.e., higher change for the increase from $15 \%$ to $30 \%$ and lower change for the increase from $45 \%$ to $60 \%$, in the median frequency and mean muscle activation was observed. This trend suggests an increased risk of injury for exertions performed at $45 \% \mathrm{MVC}$ or higher - possibly due to muscle ischemia, which is a condition that arises from lack of blood supply.

In aim 1, the effect of an administrative control strategy based on four task rotation sequences (increasing, decreasing, upward parabolic, and downward parabolic) on the fatigue development and activation of rotator cuff muscles was studied (Motabar and Nimbarte, 2020). The results indicated that performing similar tasks with a constant workload in different orders could alter rotator cuff muscles' fatigue development. The aim 1 study concluded that upward parabolic and downward parabolic sequences should be preferred over increasing, decreasing job rotation sequences. 
In aim 2, the effect of another administrative control strategy based on intermittent refresher exertion (30\% MVC handgrip) on the fatigue development and activation of rotator cuff muscles was studied. The study concluded that moderate handgrip exertions could be used as the refresher exertions during overhead tasks. Such refresher exertions aid with the activate recovery and reduce the muscle fatigue. It was also concluded that inclusion of refresher exertions might have a masking effect on the job rotation sequence, meaning that the amount of fatigue and risk of injury reduces with refresher exertions to an extent where the differences between job rotation sequences disappear.

\subsection{Practical implications}

Overhead work is common in various industries such as construction, automotive, and aerospace. Some examples of specific overhead tasks include drywall installation, preparation of airplane fuselage for paint, etc. For most of these tasks, the overhead exertions are performed at different intensity levels (analogous with \% MVC levels). Based on our findings, if the tasks can be arranged such that the intensities can follow upward parabolic sequence then the muscle fatigue and consequently the risk of rotator cuff muscle injury can be minimized.

As an example, we can consider three different major tasks which are being done during a drywall installation: carrying the drywalls to the room (Hard), cutting and installing (Medium), taping and mudding (Low)). In most jobsites, each of these steps are being started after the previous one is completely done. In that case, tasks are being completed in a decreasing sequence. In order to create an upward parabolic sequence the tasks can be reordered as follows:

A fraction of the drywalls is being carried to the room and half of them are being cut, installed, and mudded. Next, the second half of the drywalls are being installed and then workers go and carry another portion of the drywalls and follow the same steps until they finish the work 
(Figure 28). Since the mudding has to be done after the installation, there will be some mudding left to do at the end of the process. Mudding being a low-intensity task, performing it at the end of the process would not cause extra fatigue and can even act as a form of active recovery.

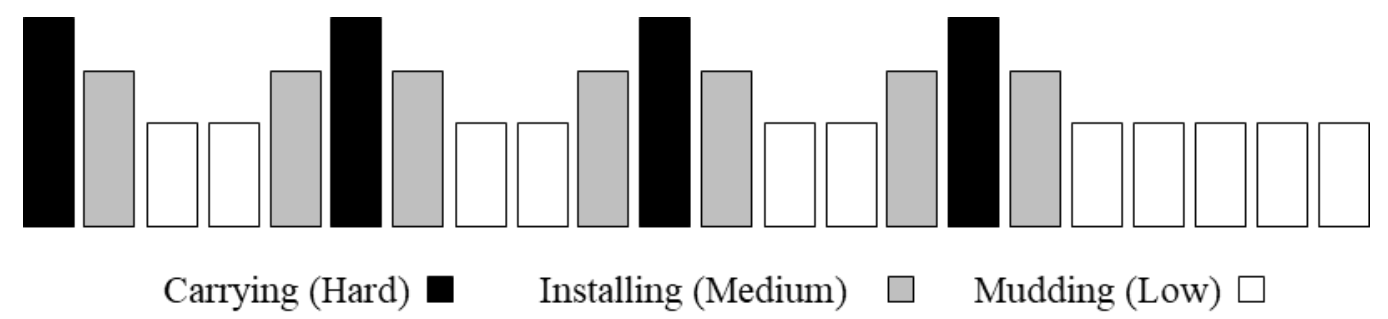

Figure 28. Suggested order for the tasks that are being done during a drywall installation

In many cases, it is not possible to arrange the tasks due to operational or functional requirements. In such cases, use of refresher exertion could be useful in reducing the fatigue and the risk of injury. Some other specific measures that should be considered while designing a task rotation sequence include shorter duty cycle for the intense tasks, performing warm up exertions prior to the intense tasks, as well as performing low intensity exertions to aid with active recovery.

\subsection{Limitations and future work}

There are several limitations that should to be considered when interpreting the results of this study.

- Our participants were recruited from a relatively young student population with limited industrial experiences and no history of musculoskeletal disorders. Older workers with more industrial experience and prior injuries might react differently to the task rotation sequences. Future studies should look at participants with more industrial experiences and prior shoulder injuries. 
- In this study, overhead posture was controlled at 120/150 degrees arm/elbow flexion while in the industry various overhead posture are being used. \%MVC levels can also be generated using different overhead postures. Future studies should look at different overhead postures to study the response of rotator cuff muscles.

- Standardized duty cycle, workload, \%MVC levels, and posture were used to study the response of rotator cuff muscles. Future studies can verify the effect of different variations of these factors on the response of rotator cuff muscles to job rotations sequence.

- Among shoulder muscles, only rotator cuffs were considered for this study. Other shoulder muscles might respond differently to the task rotation sequences and the handgrip exertion. Future studies should look at different groups of muscles and possibly study all shoulder muscles simultaneously to generate more comprehensive results.

- In this study, theoretical framework for different job rotation sequences based on \%MVC level was developed and tested, future studies can implement applied approach using industry specific tasks with different intensities. 


\section{References}

Aarås, A. (1990). Acceptable muscle load on the neck and shoulder regions assessed in relation to the incidence of musculoskeletal sick leave: Implications for human-computer interaction. International Journal of Human-Computer Interaction, 2(1), 29-39.

Ackland, D. C., \& Pandy, M. G. (2011). Moment arms of the shoulder muscles during axial rotation. Journal of Orthopaedic Research, 29(5), 658-667.

Ahmaidi, S. A. I. D., GRANIER, P., Taoutaou, Z. O. H. R. A., MERCIER, J., DUBOUCHAUD, H., \& PREFAUT, C. (1996). Effects of active recovery on plasma lactate and anaerobic power following repeated intensive exercise. Medicine \& Science in Sports \& Exercise, 28(4), 450-456.

Alasim, H. N. (2020). Implications of Variability of Electromyographic Measurements for Assessing Localized Muscle Fatigue.

Alizadehkhaiyat, O., Fisher, A. C., Kemp, G. J., Vishwanathan, K., \& Frostick, S. P. (2011). Shoulder muscle activation and fatigue during a controlled forceful hand grip task. Journal of Electromyography and Kinesiology, 21(3), 478-482.

American Academy of Orthopedic Surgeons (AAOS), (2006). Common Shoulder Injuries. Retrieved from: http://orthoinfo.aaos.org/topic.cfm?topic=a00327

American Automobile Manufacturers Association, personal communication, 1999.

Anderson, N., Adams, D., Bonauto, D., Howard, N., \& Silverstein, B. (2015). Work-related musculoskeletal disorders of the back, upper extremity, and knee in Washington State, 2002-2010. Olympia, WA: Safety and Health Assessment and Research for Prevention (SHARP) Program, Washington State Department of Labor and Industries, 345

Andrews, J.R., Wilk, K.E. \& Reinold, M.M., 2008. The athlete's shoulder: Elsevier Health Sciences.

Anton, D., Shibley, L. D., Fethke, N. B., Hess, J., Cook, T. M., \& Rosecrance, J. (2001). The effect of overhead drilling position on shoulder moment and electromyography. Ergonomics, 44(5), 489-501.

Antony, N. T., \& Keir, P. J. (2010). Effects of posture, movement and hand load on shoulder muscle activity. Journal of Electromyography and Kinesiology, 20(2), 191-198.

Au, A. K., \& Keir, P. J. (2007). Interfering effects of multitasking on muscle activity in the upper extremity. Journal of Electromyography and Kinesiology, 17(5), 578-586.

Bernard, B. P., \& Putz-Anderson, V. (1997). Musculoskeletal disorders and workplace factors; a critical review of epidemiologic evidence for work-related musculoskeletal disorders of the neck, upper extremity, and low back.

Bigland-Ritchie, B., Jones, D. A., Hosking, G. P., \& Edwards, R. H. T. (1978). Central and peripheral fatigue in sustained maximum voluntary contractions of human quadriceps muscle. Clinical Science, 54(6), 609-614. 
Bigland-Ritchie, B., Rice, C. L., Garland, S. J., \& Walsh, M. L. (1995). Task-dependent factors in fatigue of human voluntary contractions. In Fatigue (pp. 361-380). Springer, Boston, MA.

Bishop, D. (2003). Warm up I. Sports medicine, 33(6), 439-454.

Blache, Y., Desmoulins, L., Allard, P., Plamondon, A., \& Begon, M. (2015). Effects of height and load weight on shoulder muscle work during overhead lifting task. Ergonomics, 58(5), 748-761.

Blangsted, A. K., Sjøgaard, G., Madeleine, P., Olsen, H. B., \& Søgaard, K. (2005). Voluntary low-force contraction elicits prolonged low-frequency fatigue and changes in surface electromyography and mechanomyography. Journal of electromyography and kinesiology, 15(2), 138-148.

Boettcher, C. E., Ginn, K. A., \& Cathers, I. (2008). Standard maximum isometric voluntary contraction tests for normalizing shoulder muscle EMG. Journal of orthopaedic research, 26(12), 1591-1597.

Bond, V., Adams, R. G., Tearney, R. J., Gresham, K., \& Ruff, W. (1991). Effects of active and passive recovery on lactate removal and subsequent isokinetic muscle function. The Journal of sports medicine and physical fitness, 31(3), 357-361.

Bureau of Labor Statistics (BLS), (2015). Nonfatal occupational injuries and illnesses requiring days away from work, Retrieved from: http://www.bls.gov/news.release/pdf/osh2.pdf

Calvin, T. F., McDonald, A. C., \& Keir, P. J. (2016). Adaptations to isolated shoulder fatigue during simulated repetitive work. Part I: Fatigue. Journal of Electromyography and Kinesiology, 29, 34-41.

Chaffin, D. B., Andersson, G. B. J., \& Martin, B. J. (2006). Occupational ergonomics.

Cholewicki, J., Panjabi, M. M., \& Khachatryan, A. (1997). Stabilizing function of trunk flexor-extensor muscles around a neutral spine posture. Spine, 22(19), 2207-2212.

Chopp, J. N., Fischer, S. L., \& Dickerson, C. R. (2010). The impact of work configuration, target angle and hand force direction on upper extremity muscle activity during sub-maximal overhead work. Ergonomics, 53(1), 83-91.

Chopp-Hurley, J. N., \& Dickerson, C. R. (2015). The potential role of upper extremity muscle fatigue in the generation of extrinsic subacromial impingement syndrome: a kinematic perspective. Physical Therapy Reviews, 20(3), 201-209.

Côté, P., Kristman, V., Vidmar, M., Van Eerd, D., Hogg-Johnson, S., Beaton, D., \& Smith, P. M. (2008). The prevalence and incidence of work absenteeism involving neck pain. European Spine Journal, 17(1), 192-198.

Croft, P., Pope, D., \& Silman, A. (1996). The clinical course of shoulder pain: prospective cohort study in primary care. Primary Care Rheumatology Society Shoulder Study Group. BMJ: British Medical Journal, 313(7057), 601. 
Dasgupta, P. S., Fulmer, S., Jing, X., Punnett, L., Kuhn, S., \& Buchholz, B. (2014). Assessing the ergonomic exposures for drywall workers. International Journal of Industrial Ergonomics, 44(2), 307-315.

Dasgupta, P. S., Punnett, L., Moir, S., Kuhn, S., \& Buchholz, B. (2016). Does drywall installers' innovative idea reduce the ergonomic exposures of ceiling installation: A field case study. Applied ergonomics, 55, 183-193.

De Luca, C. J. (1984). Myoelectrical manifestations of localized muscular fatigue in humans. Critical reviews in biomedical engineering, 11(4), 251-279.

De Luca, C. J., Foley, P. J., \& Erim, Z. E. Y. N. E. P. (1996). Motor unit control properties in constant-force isometric contractions. Journal of Neurophysiology, 76(3), 1503-1516.

Descatha, A., Chastang, J. F., Cyr, D., Leclerc, A., Roquelaure, Y., \& Evanoff, B. (2008). Do workers with self-reported symptoms have an elevated risk of developing upper extremity musculoskeletal disorders three years later?. Occupational and environmental medicine, 65(3), 205-207.

Dickerson, C. R., Meszaros, K. A., Cudlip, A. C., Chopp-Hurley, J. N., \& Langenderfer, J. E. (2015). The influence of cycle time on shoulder fatigue responses for a fixed total overhead workload. Journal of biomechanics, 48(11), 2911-2918.

DiDomenico, A., \& Nussbaum, M. A. (2008). Interactive effects of physical and mental workload on subjective workload assessment. International journal of industrial ergonomics, 38(11-12), 977-983.

Edwards, R. H. (1981). Human muscle function and fatigue. Human muscle fatigue: physiological mechanisms, 1-18.

Enoka, R. M., \& Duchateau, J. (2008). Muscle fatigue: what, why and how it influences muscle function. The Journal of physiology, 586(1), 11-23.

Essendrop, M., Schibye, B., \& Hansen, K. (2001). Reliability of isometric muscle strength tests for the trunk, hands and shoulders. International Journal of Industrial Ergonomics, 28(6), 379387.

Ferguson, S. A., Marras, W. S., Allread, W. G., Knapik, G. G., \& Splittstoesser, R. E. (2012). Musculoskeletal disorder risk during automotive assembly: current vs. seated. Applied ergonomics, 43(4), 671-678.

Ferguson, S. A., Marras, W. S., Allread, W. G., Knapik, G. G., Vandlen, K. A., Splittstoesser, R. E., \& Yang, G. (2011). Musculoskeletal disorder risk as a function of vehicle rotation angle during assembly tasks. Applied ergonomics, 42(5), 699-709.

Ferreira, J., Carvalho, R. D. S., Barroso, T., Szmuchrowski, L., \& Śledziewski, D. (2011). Effect of different types of recovery on blood lactate removal after maximum exercise. Polish Journal of Sport and Tourism, 18(2), 105-111.

Forde, M. S., \& Buchholz, B. (2004). Task content and physical ergonomic risk factors in construction ironwork. International Journal of Industrial Ergonomics, 34(4), 319-333. 
Frazer, M., Norman, R., Wells, R., \& Neumann, P. (2003). The effects of job rotation on the risk of reporting low back pain. Ergonomics, 46(9), 904-919.

Frost, P., Bonde, J. P. E., Mikkelsen, S., Andersen, J. H., Fallentin, N., Kaergaard, A., \& Thomsen, J. F. (2002). Risk of shoulder tendinitis in relation to shoulder loads in monotonous repetitive work. American journal of industrial medicine, 41(1), 11-18.

Fukuda, H. I. R. O. A. K. I., Mikasa, M., \& Yamanaka, K. (1987). Incomplete thickness rotator cuff tears diagnosed by subacromial bursography. Clinical orthopaedics and related research, (223), 51-58.

Garg, A., Hegmann, K. T., \& Kapellusch, J. (2005). Maximum one-handed shoulder strength for overhead work as a function of shoulder posture in females. Occupational Ergonomics, $5(3), 131-140$.

Garg, A., Hegmann, K. T., Schwoerer, B. J., \& Kapellusch, J. M. (2002). The effect of maximum voluntary contraction on endurance times for the shoulder girdle. International Journal of Industrial Ergonomics, 30(2), 103-113.

Garg, A., Hegmann, K., \& Kapellusch, J. (2006). Short-cycle overhead work and shoulder girdle muscle fatigue. International Journal of Industrial Ergonomics, 36(6), 581-597.

Green, A. (2003). Chronic massive rotator cuff tears: evaluation and management. JAAOSJournal of the American Academy of Orthopaedic Surgeons, 11(5), 321-331.

Grewal, T. J., \& Dickerson, C. R. (2013). A novel three-dimensional shoulder rhythm definition that includes overhead and axially rotated humeral postures. Journal of biomechanics, 46(3), 608-611.

Grieve, J.R., Dickerson, C.R., 2008. Overhead work: identification of evidence-based exposure guidelines. Occup. Ergon. 8 (1), 53-66. Springer.

Gumina, S. (Ed.). (2016). Rotator Cuff Tear: Pathogenesis, Evaluation and Treatment.

Hanvold, T. N., Wærsted, M., Mengshoel, A. M., Bjertness, E., \& Veiersted, K. B. (2015). Work with prolonged arm elevation as a risk factor for shoulder pain: a longitudinal study among young adults. Applied ergonomics, 47, 43-51.

Hatta, T., Giambini, H., Itoigawa, Y., Hooke, A. W., Sperling, J. W., Steinmann, S. P., ... \& An, K. N. (2017). Quantifying extensibility of rotator cuff muscle with tendon rupture using shear wave elastography: a cadaveric study. Journal of biomechanics, 61, 131-136.

Hayes, K., Walton, J. R., Szomor, Z. L., \& Murrell, G. A. (2001). Reliability of five methods for assessing shoulder range of motion. Australian Journal of Physiotherapy, 47(4), 289-294.

Herberts, P., Kadefors, R., Högfors, C., \& Sigholm, G. (1984). Shoulder pain and heavy manual labor. Clinical orthopaedics and related research, (191), 166-178.

Hodder, J. N., \& Keir, P. J. (2012). Targeted gripping reduces shoulder muscle activity and variability. Journal of Electromyography and Kinesiology, 22(2), 186-190. 
Horton, L. M., Nussbaum, M. A., \& Agnew, M. J. (2012). Effects of rotation frequency and task order on localised muscle fatigue and performance during repetitive static shoulder exertions. Ergonomics, 55(10), 1205-1217.

Hunter, S. K., Ryan, D. L., Ortega, J. D., \& Enoka, R. M. (2002). Task differences with the same load torque alter the endurance time of submaximal fatiguing contractions in humans. Journal of neurophysiology, 88(6), 3087-3096.

Hurd, W. J., Morrey, B. F., \& Kaufman, K. R. (2011). The effects of anthropometric scaling parameters on normalized muscle strength in uninjured baseball pitchers. Journal of sport rehabilitation, 20(3), 311-320.

Huri, G., \& Paschos, N. (2017). The shoulder (Orthopaedic study guide series). Cham, Switzerland: Springer. doi:10.1007/978-3-319-51979-1

Hussain, T. (2004). Musculoskeletal symptoms among truck assembly workers. Occupational Medicine, 54(8), 506-512.

Iida, N., Kaneko, F., Aoki, N., \& Shibata, E. (2014). The effect of fatigued internal rotator and external rotator muscles of the shoulder on the shoulder position sense. Journal of Electromyography and Kinesiology, 24(1), 72-77.

Iridiastadi, H., \& Nussbaum, M. A. (2006). Muscular fatigue and endurance during intermittent static efforts: effects of contraction level, duty cycle, and cycle time. Human factors, 48(4), 710-720.

Jakobsen, Markus Due, et al. "Is Borg's perceived exertion scale a useful indicator of muscular and cardiovascular load in blue-collar workers with lifting tasks? A cross-sectional workplace study." European journal of applied physiology 114.2 (2014): 425-434

Järvholm, U., Palmerud, G., Karlsson, D., Herberts, P., \& Kadefors, R. (1991). Intramuscular pressure and electromyography in four shoulder muscles. Journal of Orthopaedic Research, 9(4), 609-619.

Järvholm, U., Palmerud, G., Styf, J., Herberts, P., \& Kadefors, R. (1988). Intramuscular pressure in the supraspinatus muscle. Journal of orthopaedic research, 6(2), 230-238.

Jonsson, B. (1982). Measurement and evaluation of local muscular strain in the shoulder during constrained work. Journal of human ergology, 11(1), 73-88.

Jorgensen, M., Davis, K., Kotowski, S., Aedla, P., \& Dunning, K. (2005). Characteristics of job rotation in the Midwest US manufacturing sector. Ergonomics, 48(15), 1721-1733.

Juul-Kristensen, B., Bojsen-Møller, F., Finsen, L., Eriksson, J., Johansson, G., Ståhlberg, F., \& Ekdahl, C. (2000). Muscle sizes and moment arms of rotator cuff muscles determined by magnetic resonance imaging. Cells Tissues Organs, 167(2-3), 214-222.

Kai, Y., Gotoh, M., Nagata, K., \& Shiba, N. (2012). Infraspinatus fatigue during resisted arm elevation with isometric contraction: an electromyographic study. Journal of shoulder and elbow surgery, 21(8), 1104-1109. 
Keating, J. F., Waterworth, P., Shaw-Dunn, J., \& Crossan, J. (1993). The relative strengths of the rotator cuff muscles. A cadaver study. Bone \& Joint Journal, 75(1), 137-140.

Keir, P. J., \& Brown, M. M. (2012). Force, frequency and gripping alter upper extremity muscle activity during a cyclic push task. Ergonomics, 55(7), 813-824.

Keir, P. J., Sanei, K., \& Holmes, M. W. (2011). Task rotation effects on upper extremity and back muscle activity. Applied Ergonomics, 42(6), 814-819.

Kim, H. M., Teefey, S. A., Zelig, A., Galatz, L. M., Keener, J. D., \& Yamaguchi, K. (2009). Shoulder strength in asymptomatic individuals with intact compared with torn rotator cuffs. The Journal of Bone and Joint Surgery. American volume., 91(2), 289.

Kolstrup, C. L. (2012). Work-related musculoskeletal discomfort of dairy farmers and employed workers. Journal of occupational medicine and toxicology, 7(1), 23.

Kuijer, P. P. F., van der Beek, A. J., van Dieën, J. H., Visser, B., \& Frings-Dresen, M. H. (2005). Effect of job rotation on need for recovery, musculoskeletal complaints, and sick leave due to musculoskeletal complaints: a prospective study among refuse collectors. American journal of industrial medicine, 47(5), 394-402.

Kuijer, P. P. F., Visser, B., \& Kemper, H. C. (1999). Job rotation as a factor in reducing physical workload at a refuse collecting department. Ergonomics, 42(9), 1167-1178.

Kumar, S. (2001). Theories of musculoskeletal injury causation. Ergonomics, 44(1), 17-47.

Kumar, S., \& Narayan, Y. (1999). EMG spectral characteristics of spinal muscles during isometric axial rotation. Journal of Electromyography and Kinesiology, 9(1), 21-37.

Labriola, J. E., Lee, T. Q., Debski, R. E., \& McMahon, P. J. (2005). Stability and instability of the glenohumeral joint: the role of shoulder muscles. Journal of shoulder and elbow surgery, 14(1), S32-S38.

Laursen, B., Jensen, B. R., \& Sjøgaard, G. (1998). Effect of speed and precision demands on human shoulder muscle electromyography during a repetitive task. European Journal of Applied Physiology and Occupational Physiology, 78(6), 544-548.

Lavender, S. A., Mirka, G. A., Schoenmarklin, R. W., Sommerich, C. M., Sudhakar, L. R., \& Marras, W. S. (1989). The effects of preview and task symmetry on trunk muscle response to sudden loading. Human Factors, 31(1), 101-115.

Lee, S. B., Kim, K. J., O'driscoll, S. W., Morrey, B. F., \& An, K. N. (2000). Dynamic glenohumeral stability provided by the rotator cuff muscles in the mid-range and end-range of motion: a study in cadavera. JBJS, 82(6), 849-857.

Lieber, R. L., \& Friden, J. (2000). Functional and clinical significance of skeletal muscle architecture. Muscle and Nerve, 23(11), 1647-1666.

Liu, J., Hughes, R. E., Smutz, W. P., Niebur, G., \& Nan-An, K. (1997). Roles of deltoid and rotator cuff muscles in shoulder elevation. Clinical Biomechanics, 12(1), 32-38.

Lovering, R. M., \& Russ, D. W. (2008). Fiber type composition of cadaveric human rotator cuff muscles. journal of orthopaedic \& sports physical therapy, 38(11), 674-680. 
Luger, T., Bosch, T., Veeger, D., \& de Looze, M. (2014). The influence of task variation on manifestation of fatigue is ambiguous-a literature review. Ergonomics, 57(2), 162-174.

Ma, L., Zhang, W., Hu, B., Chablat, D., Bennis, F., \& Guillaume, F. (2013). Determination of subject-specific muscle fatigue rates under static fatiguing operations. Ergonomics, 56(12), 1889-1900.

Maciukiewicz, J. M., Cudlip, A. C., Chopp-Hurley, J. N., \& Dickerson, C. R. (2016). Effects of overhead work configuration on muscle activity during a simulated drilling task. Applied ergonomics, 53, 10-16.

Maffulli, N. (Ed.). (2011). Rotator cuff tear. Karger Medical and Scientific Publishers.

Manning, D. P., Mitchell, R. G., \& Blanchfield, L. P. (1984). Body movements and events contributing to accidental and nonaccidental back injuries. Spine, 9(7), 734-739.

Martin, E., Lotito, G., Viton, J. M., Delarque, A., Bensoussan, L., Coudreuse, J. M., \& Lecoroller, T. (2012). Teres major and latissimus dorsi myotendinous injury in a professional boxer. Annals of Physical and Rehabilitation Medicine, 55, e258.

Mathiassen, S. E., \& Åhsberg, E. (1999). Prediction of shoulder flexion endurance from personal factors. International Journal of Industrial Ergonomics, 24(3), 315-329.

McDonald, A. C., Calvin, T. F., \& Keir, P. J. (2016). Adaptations to isolated shoulder fatigue during simulated repetitive work. Part II: Recovery. Journal of Electromyography and Kinesiology, 29, 42-49.

McNair, P. J., Depledge, J., Brettkelly, M., \& Stanley, S. N. (1996). Verbal encouragement: effects on maximum effort voluntary muscle: action. British journal of sports medicine, 30(3), 243-245.

Menzies, P., Menzies, C., McIntyre, L., Paterson, P., Wilson, J., \& Kemi, O. J. (2010). Blood lactate clearance during active recovery after an intense running bout depends on the intensity of the active recovery. Journal of sports sciences, 28(9), 975-982.

Mika, A., Oleksy, Ł., Kielnar, R., Wodka-Natkaniec, E., Twardowska, M., Kamiński, K., \& Małek, Z. (2016). Comparison of two different modes of active recovery on muscles performance after fatiguing exercise in mountain canoeist and football players. PloS one, 11(10).

Minning, S., Eliot, C. A., Uhl, T. L., \& Malone, T. R. (2007). EMG analysis of shoulder muscle fatigue during resisted isometric shoulder elevation. Journal of Electromyography and Kinesiology, 17(2), 153-159.

Miranda, H., Viikari-Juntura, E., Heistaro, S., Heliovaara, M., Riihimaki, H., 2005. A population study on differences in the determinants of a specific shoulder disorder versus nonspecific shoulder pain without clinical findings. Am. J. Epidemiol. 161 (9), 847-855.

Montgomery, D. C. (2017). Design and analysis of experiments. John wiley \& sons.

Moosmayer, S., Smith, H. J., Tariq, R., \& Larmo, A. (2009). Prevalence and characteristics of asymptomatic tears of the rotator cuff: an ultrasonographic and clinical study. Bone \& Joint Journal, 91(2), 196-200. 
Moriguchi, C. S., Carnaz, L., Júnior, L. C. M., Marklin, R. W., \& Coury, H. J. C. G. (2012). Are posture data from simulated tasks representative of field conditions? Case study for overhead electric utility workers. Ergonomics, 55(11), 1382-1394.

Moriguchi, C. S., Carnaz, L., Veiersted, K. B., Hanvold, T. N., Hæg, L. B., Hansson, G. Å., \& Coury, H. J. C. G. (2013). Occupational posture exposure among construction electricians. Applied ergonomics, 44(1), 86-92.

Motabar, H. \& Nimbarte, A. D. (2020). The effect of task rotation on activation and fatigue response of rotator cuff muscles during overhead work. Manuscript submitted for publication.

Motabar, H., Madinei, S., \& Ning, X. (2018, September). The Influence of Load Handling Height on Shoulder Biomechanics during Sudden Loading. In Proceedings of the Human Factors and Ergonomics Society Annual Meeting (Vol. 62, No. 1, pp. 828-832). Sage CA: Los Angeles, CA: SAGE Publications.

Motabar, H., Nimbarte, A. D., \& Raub, E. (2019). Strength, endurance and fatigue response of rotator cuff muscles during isometric exertions. International Journal of Industrial Ergonomics, 71, 128-135.

Motabar, H., Raub, E., Nimbarte, A. D., \& Nabiyouni, I. (2016). Safe Loading Thresholds for Rotator Cuff Muscles. Methods.

Nasser Alasim, H., \& Nimbarte, A. D. (2019). Variability of Electromyographic Spectral Measures in Non-fatigued Shoulder Muscles and Implications for Assessing Muscle Fatigue. IISE Transactions on Occupational Ergonomics and Human Factors, 7(2), 119-131.

Niemeyer, L. O., Aronow, H. U., \& Kasman, G. S. (2004). A pilot study to investigate shoulder muscle fatigue during a sustained isometric wheelchair-propulsion effort using surface EMG. American Journal of Occupational Therapy, 58(5), 587-593.

Nimbarte, A. D. (2014). "Risk of neck musculoskeletal disorders among males and females in lifting exertions." International Journal of Industrial Ergonomics 44(2014), 253-259.

Nimbarte, A. D., Aghazadeh, F., Ikuma, L. H. and Harvey, C. M. (2010). "Neck disorders: understanding the physical loads on the cervical spine during static lifting." Industrial Health 48(2): 145-153.

Nimbarte, A. D., Aghazadeh, F., Ikuma, L., \& Sun, Y. (2012). Evaluation of the loading of neck and shoulder musculature in overhead pushing and pulling exertions. Human Factors and Ergonomics in Manufacturing \& Service Industries, 22(4), 317-327.

Nimbarte, A. D., Al Hassan, M. J., Guffey, S. E. and Myers, W. R. (2012). "Influence of psychosocial stress and personality type on the biomechanical loading of neck and shoulder muscles." International Journal of Industrial Ergonomics 42(5): 397-405.

Nimbarte, A. D., Sun, Y., Jaridi, M. and Hsiao, H. (2013). "Biomechanical loading of the shoulder complex and lumbosacral joints during dynamic cart pushing task." Applied Ergonomics 44(5): 841-849.

Nimbarte, A. D., Zreiqat, M., \& Ning, X. (2014). Impact of shoulder position and fatigue on the flexion-relaxation response in cervical spine. Clinical Biomechanics, 29(3), 277-282. 
Ninković, S., Simnjanovski, M., Harhaji, V., Kovačev, N., Janjić, N., \& Obradović, M. (2014). Surgical treatment of shoulder rotator cuff injuries. Medicinski pregled, 67(7-8), 239-245.

Nogueira, H. C., Diniz, A. C. P., Barbieri, D. F., Padula, R. S., Carregaro, R. L., \& de Oliveira, A. B. (2012). Musculoskeletal disorders and psychosocial risk factors among workers of the aircraft maintenance industry. Work, 41(Supplement 1), 4801-4807.

Nordander, C., Ohlsson, K., Balogh, I., Hansson, G. Å., Axmon, A., Persson, R., \& Skerfving, S. (2008). Gender differences in workers with identical repetitive industrial tasks: exposure and musculoskeletal disorders. International archives of occupational and environmental health, 81(8), 939-947.

Nussbaum, M. A., \& Lang, A. (2005). Relationships between static load acceptability, ratings of perceived exertion, and biomechanical demands. International journal of industrial ergonomics, 35(6), 547-557.

Nussbaum, M. A., Clark, L. L., Lanza, M. A., \& Rice, K. M. (2001). Fatigue and endurance limits during intermittent overhead work. AIHAJ-American Industrial Hygiene Association, 62(4), 446-456.

Ohisson, K., Attewell, R. G., Pålsson, B., Karlsson, B., Balogh, I., Johnsson, B., \& Skerfving, S. (1995). Repetitive industrial work and neck and upper limb disorders in females. American journal of industrial medicine, 27(5), 731-747.

Palmerud, G., Forsman, M., Sporrong, H., Herberts, P., \& Kadefors, R. (2000). Intramuscular pressure of the infra-and supraspinatus muscles in relation to hand load and arm posture. European Journal of Applied Physiology, 83(2-3), 223-230.

Palmerud, G., Kadefors, R., SPORRONG, H., Järvholm, U., Herberts, P., Högfors, C., \& Peterson, B. O. (1995). Voluntary redistribution of muscle activity in human shoulder muscles. Ergonomics, 38(4), 806-815.

Park, S. Y., \& Yoo, W. G. (2013). Selective activation of the latissimus dorsi and the inferior fibers of trapezius at various shoulder angles during isometric pull-down exertion. Journal of Electromyography and Kinesiology, 23(6), 1350-1355.

Perotto, A. O. (2011). Anatomical guide for the electromyographer: the limbs and trunk. Charles C Thomas Publisher.

Punnett, L., Fine, L.J., Keyserling, W.R., Herrin, G.D., Chaffin, D.B., 2000. Shoulder disorders and postural stress in automobile assembly work. Scand. J. Work Environ. Health 26 (4), 283-291.

Putz-Anderson, V., \& Galinsky, T. L. (1993). Psychophysically determined work durations for limiting shoulder girdle fatigue from elevated manual work. International Journal of Industrial Ergonomics, 11(1), 19-28.

Putz-Anderson, V., Bernard, B. P., Burt, S. E., Cole, L. L., Fairfield-Estill, C., Fine, L. J., ... \& Nelson, N. (1997). Musculoskeletal disorders and workplace factors. National Institute for Occupational Safety and Health (NIOSH), 104. 
Raina, S. M., \& Dickerson, C. R. (2009). The influence of job rotation and task order on muscle fatigue: A deltoid example. Work, 34(2), 205-213.

Rashedi, E., Kim, S., Nussbaum, M. A., \& Agnew, M. J. (2014). Ergonomic evaluation of a wearable assistive device for overhead work. Ergonomics, 57(12), 1864-1874.

Rempel, D. M., Star, D., Gibbons, B., Barr, A., \& Janowitz, I. (2007). Development and evaluation of a new device for overhead drilling. Professional safety, 52(11), 30.

Rempel, D., Star, D., Barr, A., \& Janowitz, I. (2010). Overhead drilling: Comparing three bases for aligning a drilling jig to vertical. Journal of safety research, 41(3), 247-251.

Rissén, D., Melin, B., Sandsjö, L., Dohns, I., \& Lundberg, U. (2002). Psychophysiological stress reactions, trapezius muscle activity, and neck and shoulder pain among female cashiers before and after introduction of job rotation. Work \& stress, 16(2), 127-137.

Rohmert, W. (1960). Ermittlung von Erholungspausen für statische Arbeit des Menschen. Internationale Zeitschrift fuer Angewandte Physiologie einschliesslich Arbeitsphysiologie, 18(2), 123-164.

Rontoyannis, G. P. (1988). Lactate elimination from the blood during active recovery. The Journal of sports medicine and physical fitness, 28(2), 115.

Roquelaure, Y., Ha, C., Nicolas, G., Pélier-Cady, M. C., Mariot, C., Descatha, A., \& Imbernon, E. (2008). Attributable risk of carpal tunnel syndrome according to industry and occupation in a general population. Arthritis Care \& Research: Official Journal of the American College of Rheumatology, 59(9), 1341-1348.

Roy, J. S., Ma, B., MacDermid, J. C., \& Woodhouse, L. J. (2011). Shoulder muscle endurance: the development of a standardized and reliable protocol. Sports Medicine, Arthroscopy, Rehabilitation, Therapy \& Technology, 3(1), 1.

Saccol, M. F., Almeida, G. P. L., \& de Souza, V. L. (2016). Anatomical glenohumeral internal rotation deficit and symmetric rotational strength in male and female young beach volleyball players. Journal of Electromyography and Kinesiology, 29, 121-125.

Sahlin, K. (1986). Muscle fatigue and lactic acid accumulation. Acta physiologica Scandinavica. Supplementum, 556, 83-91.

Sairyo, K., Iwanaga, K., Yoshida, N., Mishiro, T., Terai, T., Sasa, T., \& Ikata, T. (2003). Effects of active recovery under a decreasing work load following intense muscular exercise on intramuscular energy metabolism. International Journal of Sports Medicine, 24(03), 179-182.

Sakaki, Y., Kaneko, F., Watanabe, K., Kobayashi, T., Katayose, M., Aoki, N., ... \& Yamashita, T. (2013). Effects of different movement directions on electromyography recorded from the shoulder muscles while passing the target positions. Journal of Electromyography and Kinesiology, 23(6), 1362-1369.

Sato, H., Ohashi, J., Iwanaga, K., Yoshitake, R., \& Shimada, K. (1984). Endurance time and fatigue in static contractions. Journal of human ergology, 13(2), 147-154. 
Shanahan, E. M., \& Sladek, R. (2011). Shoulder pain at the workplace. Best Practice \& Research Clinical Rheumatology, 25(1), 59-68.

Sher, J. S., Uribe, J. W., Posada, A., Murphy, B. J., \& Zlatkin, M. B. (1995). Abnormal findings on magnetic resonance images of asymptomatic shoulders. JBJS, 77(1), 10-15.

Sigholm, G., Herberts, P., Almström, C., \& Kadefors, R. (1983). Electromyographic analysis of shoulder muscle load. Journal of Orthopaedic Research, 1(4), 379-386.

Sjøgaard, G., Savard, G., \& Juel, C. (1988). Muscle blood flow during isometric activity and its relation to muscle fatigue. European journal of applied physiology and occupational physiology, 57(3), 327-335.

Sjøgaard, G., Søgaard, K., Hermens, H. J., Sandsjö, L., Läubli, T., Thorn, S., ... \& Kadefors, R. (2006). Neuromuscular assessment in elderly workers with and without work related shoulder/neck trouble: the NEW-study design and physiological findings. European Journal of Applied Physiology, 96(2), 110-121.

Smets, M. P., Potvin, J. R., \& Keir, P. J. (2009). Constrained handgrip force decreases upper extremity muscle activation and arm strength. Ergonomics, 52(9), 1144-1152.

Sokk, J., Gapeyeva, H., Ereline, J., Kolts, I., \& Pääsuke, M. (2007). Shoulder muscle strength and fatigability in patients with frozen shoulder syndrome: the effect of 4-week individualized rehabilitation. Electromyography and clinical neurophysiology, 47(4-5), 205-213.

Sood, D., Nussbaum, M. A., \& Hager, K. (2007). Fatigue during prolonged intermittent overhead work: reliability of measures and effects of working height. Ergonomics, 50(4), 497-513.

Sood, D., Nussbaum, M. A., Hager, K., \& Nogueira, H. C. (2017). Predicted endurance times during overhead work: influences of duty cycle and tool mass estimated using perceived discomfort. Ergonomics, 60(10), 1405-1414.

Sporrong, H., Palmerud, G., \& Herberts, P. (1995). Influences of handgrip on shoulder muscle activity. European journal of applied physiology and occupational physiology, 71(6), 485492.

Sporrong, H., Palmerud, G., \& Herberts, P. (1996). Hand grip increases shoulder muscle activity: An EMG analysis with static handcontractions in 9 subjects. Acta Orthopaedica Scandinavica, 67(5), 485-490.

Srinivasan, R. C., Lungren, M. P., Langenderfer, J. E., \& Hughes, R. E. (2007). Fiber type composition and maximum shortening velocity of muscles crossing the human shoulder. Clinical anatomy, 20(2), 144-149.

Sun, Y. and Nimbarte, A. D. (2012). "Effect of horizontal pushing and pulling exertions on neck muscle activity." Occupational Ergonomics 10(4): 155-164.

Sun, Y., Nimbarte, A. D., \& Motabar, H. (2017). Physical Risk Factors Associated with the Work-Related Neck/Cervical Musculoskeletal Disorders: A Review. Industrial and Systems Engineering Review, 5(1), 44-60. 
Svendsen, S. W., Gelineck, J., Mathiassen, S. E., Bonde, J. P., Frich, L. H., StengaardPedersen, K., \& Egund, N. (2004). Work above shoulder level and degenerative alterations of the rotator cuff tendons: a magnetic resonance imaging study. Arthritis \& Rheumatism: Official Journal of the American College of Rheumatology, 50(10), 3314-3322.

Sylla, N., Bonnet, V., Colledani, F., \& Fraisse, P. (2014). Ergonomic contribution of ABLE exoskeleton in automotive industry. International Journal of Industrial Ergonomics, 44(4), 475481.

Thigpen, C. A., Padua, D. A., Michener, L. A., Guskiewicz, K., Giuliani, C., Keener, J. D., \& Stergiou, N. (2010). Head and shoulder posture affect scapular mechanics and muscle activity in overhead tasks. Journal of Electromyography and kinesiology, 20(4), 701-709.

Urwin, M., Symmons, D., Allison, T., Brammah, T., Busby, H., Roxby, M., ... \& Williams, G. (1998). Estimating the burden of musculoskeletal disorders in the community: the comparative prevalence of symptoms at different anatomical sites, and the relation to social deprivation. Annals of the rheumatic diseases, 57(11), 649-655.

Van der Windt, D. A., Koes, B. W., Boeke, A. J., Deville, W., De Jong, B. A., \& Bouter, L. M. (1996). Shoulder disorders in general practice: prognostic indicators of outcome. Br J Gen Pract, 46(410), 519-523.

Van Rijn, R.M., Huisstede, B.M.A., Koes, B.W., Burdorf, A., 2010. Associations between work-related factors and specific disorders of the shoulder - a systematic review of the literature. Scand. J. Work Environ. Health 36 (3), 189-201.

Wang, D., Dai, F., \& Ning, X. (2015). Risk assessment of work-related musculoskeletal disorders in construction: State-of-the-art review. Journal of construction engineering and management, 141(6), 04015008.

Ward, S. R., Hentzen, E. R., Smallwood, L. H., Eastlack, R. K., Burns, K. A., Fithian, D. C., ... \& Lieber, R. L. (2006). Rotator cuff muscle architecture: implications for glenohumeral stability. Clinical Orthopaedics and Related Research®, 448, 157-163.

Warnken, B. (2012). The Comp Pinkbook. Maryland: 27 Legal, LLC (2012).

Wells, R., McFall, K., \& Dickerson, C. R. (2010). Task selection for increased mechanical exposure variation: Relevance to job rotation. Ergonomics, 53(3), 314-323.

Xu, X., McGorry, R. W., \& Lin, J. H. (2014). A regression model predicting isometric shoulder muscle activities from arm postures and shoulder joint moments. Journal of Electromyography and Kinesiology, 24(3), 419-429.

Yamamoto, A., Takagishi, K., Osawa, T., Yanagawa, T., Nakajima, D., Shitara, H., \& Kobayashi, T. (2010). Prevalence and risk factors of a rotator cuff tear in the general population. Journal of Shoulder and Elbow Surgery, 19(1), 116-120.

Yuan, L., Buchholz, B., Punnett, L., \& Kriebel, D. (2007, October). Estimation of muscle contraction forces and joint reaction forces at the low back and shoulder during drywall installation. In Proceedings of the Human Factors and Ergonomics Society Annual Meeting (Vol. 51, No. 15, pp. 952-956). Sage CA: Los Angeles, CA: SAGE Publications. 


\section{Appendix A: Literature review of the overhead studies on shoulder muscles}

Total number of 25 overhead studies that have been conducted from 2006 to 2018 were assessed to identify ergonomics and biomechanical risk factors associated with overhead tasks. Shoulder structure is the most affected body part by overhead tasks. (Svendsen et al., 2004; Van Rijn et al., 2010; Linaker and Walker-Bone 2015; Cudlip et al., 2016). Multiple static and dynamic studies have analyzed the influence of various factors on shoulder structure. Posture, Force direction, Duration of exertion, and task characteristics were among the most studied risk factors. A summary of the reviewed articles is provided in Table 14. Below is a detailed literature review of the risks factor.

\section{Static Studies}

\section{Posture}

Four of the static studies looked at biomechanical effects of different postures on the shoulder complex. These studies looked at 10 different arm elevation angles combined and three different movement planes (sagittal, scapular, and frontal). Studied arm elevation angles were $0^{\circ}$, $45^{\circ}, 60^{\circ}, 90^{\circ}, 120^{\circ}, 135^{\circ}, 150^{\circ}, 165^{\circ}, 180^{\circ}$ and, $195^{\circ}$.

Chopp et al. (2010) reported that among $150^{\circ}, 165^{\circ}, 180^{\circ}$ and, $195^{\circ}$ elevation angles force applied at $195^{\circ}$ caused the highest muscle activity. Park and Yoo. (2013) looked at the latissimus dorsi and trapezius muscle activity in pull down exercise. These two muscles behaved differently to the elevation angle, where latissimus dorsi showed a decreasing trend with increase in arm elevation angle and trapezius had an opposite trend. Grewal et al. (2013) studied the Kinematics of the shoulder complex in different postures and in conclusion, clavicular angles, posterior tilt and lateral rotation of scapula were mostly affected by the arm elevation angle, while scapular 
protraction was mostly affected by plane of elevation. A study assessed the effect of point of force application on muscle activity (Maciukiewicz et al., 2016). Highest muscle activity was reported from the forces that applied on a far target from the body.

In general, activity of 12 different muscles were assessed in these studies and none of them looked at rotator cuff muscles thoroughly. One study (Maciukiewicz et al., 2016) assessed the activity of infraspinatus and supraspinatus. Only infraspinatus was among the muscles that were studied by Chopp et al. (2010) and The Teres minor was not studied in any of the mentioned papers. Considering rotator cuff muscles being the most prone shoulder muscles to injuries (Ninković et al., 2014) there is a need to assess the effect of different postures on the rotator cuff muscles while working overhead.

\section{Direction}

Two of the static studies assessed the effect of different force direction on different muscles (Maciukiewicz et al., 2016; Chopp et al., 2010). Backwards, forwards, downwards, sideways and, upwards exertions were studied. Upward and backward exertions caused the highest muscle activity while forward and downward exertions generated the lowest average muscle activities. Hand force direction was reported as the most influential factor on muscle activity (Chopp et al, 2010) compared to posture and work configuration. Considering the interaction effects of different factors which are affecting the muscle activity is important during task designs. These two studies reported significant interaction effects between posture and direction as well as direction and point of force application. 


\section{Duration}

Effect of cycle time was assessed on the endurance and fatigue development of shoulder muscles (Ma et al., 2013; Dickerson et al., 2015). Within a fixed workload on a simulated overhead task, shorter cycle time led to a 25 percent increase of endurance time and decrease in shoulder muscle fatigue. It was also reported that changes in cycle time have an integrative effect on shoulder structure rather than affecting individual muscles. Infraspinatus and supraspinatus along with seven different muscles were considered in these studies.

\section{Use of models}

Ma et al. 2015 assessed the usability of a differential muscle fatigue model for describing the fatigue progression of shoulder muscles. Changes in maximum voluntary muscle strength in a simulated overhead drilling task was used as an indicator of fatigue. In the other study, usability

of AnyBody Modeling Systems for strength prediction was assessed. Both studies had somewhat acceptable correlation coefficients $\left(\mathrm{R}^{2}=0.8\right.$ and 0.7$)$ and concluded that models can be used to an extent to predict muscle strength and fatigue. Both studies looked at shoulder structure as a unit and did not take any direct muscle activity measurement.

\section{Use of intervention devices}

Rashedi et al. (2014) evaluated the use of a wearable assistive device on a simulated overhead drilling task. Results of both ratings of perceived discomfort and EMG indicated less discomfort while using the assistive device specially when using heavier tools.

None of the rotator cuff muscles was considered in this study. 


\section{Range of motion}

Saccol et al. (2016) assessed the glenohumeral range of motion in beach volleyball. Both men and women showed a shoulder range of motion adaptation while there were no differences between dominant and non-dominant shoulders.

No specific muscle activity measurement was performed in this study.

\section{Dynamic studies}

\section{Posture}

One of the most studied factors associated with overhead dynamic tasks is posture. 5 out of 15 dynamic studies evaluated effects of posture on shoulder structure (Garg et al., 2006; Moriguchi et al., 2012; Iida et al., 2014; Dasgupta et al., 2014; Moriguchi et al., 2013). While most of these studies were conducted in a laboratory setting some of them observed and evaluated the postures on the jobsite to get a better understanding and collect more realistic data. Moriguchi et al. conducted a study in brazil and Norway and compared the neck and upper arm postures on overhead utility workers on the jobsite with the postures that are commonly being used in a laboratory setting. In conclusion, simple tasks were simulated more similar to the jobsite postures compared to more complex tasks. Moreover, regardless of country and organization these overhead electrical tasks put workers on high risk of upper extremity disorders. A similar field study on drywall installers by Dasgupta et al. suggested the use of intervention devices to reduce the risk of material handling. Results of using the intervention device will be discussed later in this document. 
In a laboratory study by Iida et al., effect of fatigue on shoulder position sense was investigated for external (pectoralis major and latissimus dorsi) and internal rotators (infraspinatus). Position sense error increased significantly with the occurrence of muscle fatigue. Garget al. (2006) performed a comprehensive study on effect of different factors associated with overhead tasks on upper trapezius and middle deltoid muscles. Endurance time was significantly shorter and ratings of perceived discomfort were significantly higher for overhead tasks compared to tasks performed below head level.

It has been suggested that rotator cuff muscles are the most prone muscles to injury during overhead tasks (Sporrong et al., 1996; Svendsen et al., 2004; Miranda et al., 2005; van Rijn et al., 2010). However, none of the discussed studies investigated the behavior of this group of muscles in overhead postures during dynamic exertions.

\section{Direction}

Effect of direction of force on shoulder structure has been assessed in overhead studies to identify risky tasks and to study muscle and joint behavior. In two studies by Calvin et al. (2016) and McDonald et al., (2016) a simulated repetitive overhead task was performed in different directions to study muscle strength and shoulder kinematics adaptation in fatigue and recovery phases. As the result, by appearance of signs of fatigue, glenohumeral flexion strength was reduced and posture changes were observed as an unconscious reaction of body to fatigue.

In a study by Sakaki et al., (2013) effect of movement direction in the same position was assessed on deltoid muscles, supraspinatus and infraspinatus. Four different studied movements were shoulder elevation, depression, horizontal abduction and horizontal adduction. Each muscle 
showed a unique characteristic to the direction. For instance, Infraspinatus and supraspinatus had reverse EMG activity pattern for different movement directions.

\section{Lifting height and weight}

Height and weight are important factors while lifting an object. Among the studied literature, three studies looked at height and weight as possible risk factors (Garg et al., 2006; Blache et al., 2015, motabar et al., 2018). As expected, muscle activity and subjective ratings increased with the increase of hand tool weight and height of lifting. Endurance time was also decreased while using heavier tools. Weight appears to have a greater effect than the effect of posture and other factors specially on subjective ratings.

Activity of supraspinatus, infraspinatus, biceps, triceps, deltoids, latissimus dorsi, and trapezius muscles were monitored in these three studies.

\section{Use of Intervention devices}

Three studies monitored the possible influences of intervention devices on muscle activity, joint endurance time, and perceived ratings of discomfort (Dasgupta et al., 2016; Rashedi et al., 2014; Sylla et al., 2014). A lifting assistive device and an adjustable working platform for construction workers and an exoskeleton device for automotive industry workers were analyzed. It has been concluded that using intervention devices can reduce loads on muscles and joints and improve perceived ratings of discomfort especially on high physical demanding tasks. 
Table 14. Summary of the literature review of the overhead studies on shoulder muscles

\begin{tabular}{|c|c|c|c|c|c|c|}
\hline $\begin{array}{l}\stackrel{2}{E} \\
\sum_{4}^{2} \\
\#\end{array}$ & 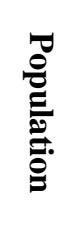 & 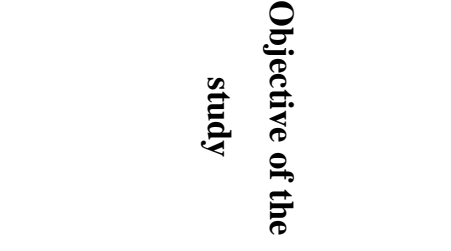 & 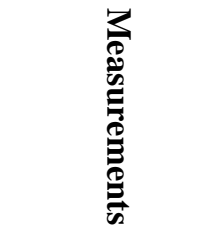 & 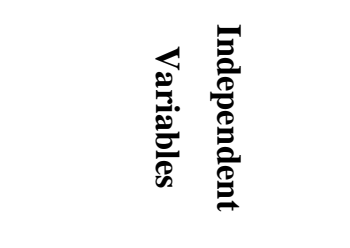 & 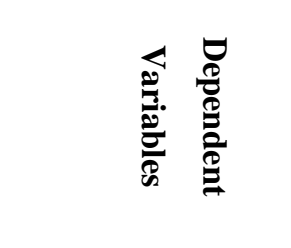 & 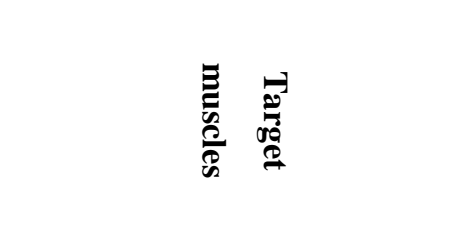 \\
\hline 1 & 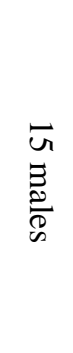 & $\begin{array}{l}\text { Assessing the effect of lifting } \\
\text { height and weight on shoulder } \\
\text { muscles' activity. }\end{array}$ & $\begin{array}{l}\text { Body Motion, } \\
\text { Force, } \\
\text { EMG }\end{array}$ & $\begin{array}{l}\text { Lifting height and } \\
\text { weight }\end{array}$ & $\begin{array}{l}\text { Muscle mechanical } \\
\text { work, } \\
\text { Force, } \\
\text { Changes of muscle } \\
\text { length } \\
\text { and activations }\end{array}$ & $\begin{array}{l}\text { Biceps, triceps, anterior, } \\
\text { middle, and posterior deltoid, } \\
\text { latissimus dorsi, upper, middle, } \\
\text { lower trapezius }\end{array}$ \\
\hline 2 & 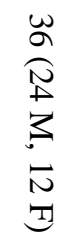 & $\begin{array}{l}\text { To study the effect of duty } \\
\text { cycle and tool mass on } \\
\text { endurance times during } \\
\text { overhead work. }\end{array}$ & RPD & $\begin{array}{l}\text { Tool mass, } \\
\text { duty cycle, } \\
\text { Gender }\end{array}$ & $\begin{array}{l}\text { Endurance time, } \\
\text { Fatigue }\end{array}$ & - \\
\hline 3 & $\begin{array}{l}\bar{N} \\
3\end{array}$ & $\begin{array}{l}\text { To study the effect of a } \\
\text { wearable assistive devices on } \\
\text { upper extremity } \\
\text { musculoskeletal disorders. }\end{array}$ & $\begin{array}{l}\text { RPD, } \\
\text { EMG }\end{array}$ & $\begin{array}{l}\text { Use of assistive device, } \\
\text { Weight of payload, } \\
\text { duty cycle }\end{array}$ & $\begin{array}{l}\text { RPD, } \\
\text { Localized muscle } \\
\text { fatigue }\end{array}$ & $\begin{array}{l}\text { Triceps brachii, anterior and } \\
\text { middle deltoid, iliocostalis } \\
\text { lumborum pars lumborum. } \\
\text { (bilateral) }\end{array}$ \\
\hline
\end{tabular}




\begin{tabular}{|c|c|c|c|c|c|c|}
\hline 4 & $\overrightarrow{3}$ & $\begin{array}{l}\text { To identify working conditions } \\
\text { requiring relatively lower } \\
\text { muscular shoulder load. }\end{array}$ & $\begin{array}{l}\text { EMG, } \\
\text { Force }\end{array}$ & $\begin{array}{l}\text { Work configuration } \\
\text { (fixed, stature-specific), } \\
\text { Target angle (-15, 0, 15, } \\
30 \text { from vertical), } \\
\text { Direction of applied } \\
\text { hand force (pulling } \\
\text { backwards, pushing } \\
\text { forwards, downwards, } \\
\text { sideways, upwards). }\end{array}$ & EMG Muscle activity & $\begin{array}{l}\text { Biceps brachii, triceps brachii, } \\
\text { anterior, middle and posterior } \\
\text { deltoid, upper trapezius, lower } \\
\text { trapezius, latissimus dorsi, } \\
\text { infraspinatus, pectoralis major }\end{array}$ \\
\hline 5 & 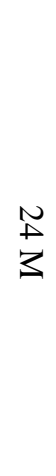 & $\begin{array}{l}\text { To verify whether the postures } \\
\text { recorded for neck } \\
\text { extension/flexion and upper arm } \\
\text { elevation of } \\
\text { overhead electric utility workers } \\
\text { in a simulated environment } \\
\text { were similar to those recorded } \\
\text { in a field environment. }\end{array}$ & $\begin{array}{l}\text { Neck angle, } \\
\text { Upper arm } \\
\text { elevation } \\
\text { angles, }\end{array}$ & $\begin{array}{l}\text { Tasks (relay } \\
\text { replacement, } \\
\text { consumer } \\
\text { connection/disconnectio } \\
\mathrm{n}, \\
\text { changing the bulb) }\end{array}$ & $\begin{array}{l}\text { Neck extension/flexion } \\
\text { angles, } \\
\text { Upper arm elevation } \\
\text { angles }\end{array}$ & - \\
\hline 6 & $\begin{array}{l}5 \\
0 \\
3\end{array}$ & $\begin{array}{l}\text { To determine local muscle } \\
\text { fatigue at shoulder joint based } \\
\text { on an exponential function } \\
\text { derived from a muscle fatigue } \\
\text { model. }\end{array}$ & $\begin{array}{l}\text { Force, } \\
\text { Moment, } \\
\text { Body motion }\end{array}$ & $\begin{array}{l}\text { Task duration, } \\
\text { Drill weight }\end{array}$ & $\begin{array}{l}\text { Shoulder muscle } \\
\text { fatigue }\end{array}$ & - \\
\hline
\end{tabular}




\begin{tabular}{|c|c|c|c|c|c|c|}
\hline 7 & $\begin{array}{l}\text { N } \\
3\end{array}$ & $\begin{array}{l}\text { To assess the effect of Point of } \\
\text { force application, Direction, } \\
\text { body posture and drilling } \\
\text { technique on muscle activity. }\end{array}$ & EMG & $\begin{array}{l}\text { Point of force } \\
\text { application (15, 30, } 45 \\
\mathrm{~cm} \text { in front of the } \\
\text { subjects), } \\
\text { Direction (Forward, } \\
\text { upward), } \\
\text { Body posture (Seated or } \\
\text { standing), } \\
\text { Technique (unilateral } \\
\text { and bilateral) }\end{array}$ & EMG Muscle activity & $\begin{array}{l}\text { Anterior and middle deltoid, } \\
\text { upper trapezius, infraspinatus, } \\
\text { lumbar erector spinae, } \\
\text { supraspinatus }\end{array}$ \\
\hline 8 & $\begin{array}{l}u \\
3\end{array}$ & $\begin{array}{l}\text { To assess an intervention } \\
\text { suggested by the workers to } \\
\text { reduce the physical or } \\
\text { ergonomic exposures of the } \\
\text { drywall installation task. }\end{array}$ & $\begin{array}{l}\text { Video } \\
\text { recording, } \\
\text { RPD }\end{array}$ & Use of intervention & Body posture, Load & - \\
\hline 9 & $\begin{array}{l}\vec{J} \\
\vec{T}\end{array}$ & $\begin{array}{l}\text { Testing the usability of a } \\
\text { musculoskeletal model based } \\
\text { software, AnyBody Modeling } \\
\text { Systems (AMS), in evaluating } \\
\text { the force exertion capability at } \\
\text { different points in the } \\
\text { workspace and for various } \\
\text { exertion directions. }\end{array}$ & $\begin{array}{l}\text { Force, } \\
\text { Moment, } \\
\text { Body motion }\end{array}$ & $\begin{array}{l}\text { Hand angle, } \\
\text { hand height }\end{array}$ & Exerted Force & - \\
\hline
\end{tabular}




\begin{tabular}{|c|c|c|c|c|c|c|}
\hline 10 & 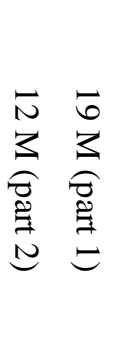 & $\begin{array}{l}\text { To study the effects of hand } \\
\text { activity on both shoulder } \\
\text { muscle loading and task } \\
\text { performance while working on } \\
\text { ladders versus Mobile Elevated } \\
\text { Working Platforms. }\end{array}$ & $\begin{array}{l}\text { EMG, } \\
\text { RPD }\end{array}$ & $\begin{array}{l}\text { Platform (latter or } \\
\text { Mobile working } \\
\text { platforms), } \\
\text { Performed task (drilling, } \\
\text { cabling, assembly) }\end{array}$ & $\begin{array}{l}\text { discomfort rating, } \\
\text { task performance, } \\
\text { EMG }\end{array}$ & $\begin{array}{l}\text { Upper trapezius, anterior } \\
\text { deltoid }\end{array}$ \\
\hline 11 & $\begin{array}{l}\stackrel{N}{A} \\
3\end{array}$ & $\begin{array}{l}\text { To record, objectively describe } \\
\text { and compare working postures } \\
\text { of Brazilian and Norwegian } \\
\text { construction electricians. }\end{array}$ & Body posture & Tasks performed & $\begin{array}{l}\text { Elevation angle, time } \\
\text { spent in zones with the } \\
\text { arm elevated above } 60 \\
\text { and } 90, \\
\text { Flexion/extension } \\
\text { angles of the head and } \\
\text { neck }\end{array}$ & - \\
\hline 12 & $\begin{array}{l}u \\
3 \\
a \\
\text { Tे }\end{array}$ & $\begin{array}{l}\text { To investigate the intra and } \\
\text { inter-session reliability of } \\
\text { scapular muscle activity during } \\
\text { maximal isokinetic shoulder } \\
\text { flexion and extension. }\end{array}$ & $\begin{array}{l}\text { EMG, } \\
\text { Force }\end{array}$ & $\begin{array}{l}\text { Shoulder flexion and } \\
\text { extension, } \\
\text { Range of motion, }\end{array}$ & Reliability & $\begin{array}{l}\text { Upper and lower trapezius, } \\
\text { serratus anterior }\end{array}$ \\
\hline
\end{tabular}




\begin{tabular}{|c|c|c|c|c|c|c|}
\hline 13 & $\begin{array}{l}\bar{N} \\
3\end{array}$ & $\begin{array}{l}\text { To examine adaptation } \\
\text { strategies in response to isolated } \\
\text { anterior deltoid muscle fatigue } \\
\text { while performing simulated } \\
\text { repetitive work. }\end{array}$ & $\begin{array}{l}\text { Body Motion, } \\
\text { EMG, } \\
\text { Force, } \\
\text { RPD }\end{array}$ & $\begin{array}{l}\text { Tasks (handle pull, cap } \\
\text { rotation, } \\
10 \text { s anterior drill press } \\
\text { (50\% MVC), } \\
\text { Handle push, } \\
\text { Height }\end{array}$ & $\begin{array}{l}\text { Muscle fatigue, } \\
\text { Discomfort rating, } \\
\text { Sub-acromial space } \\
\text { changes }\end{array}$ & $\begin{array}{l}\text { Upper and lower trapezius } \\
\text { (bilaterally), pectoralis major } \\
\text { (sternal and clavicular head), } \\
\text { latissimus dorsi, serratus } \\
\text { anterior, infraspinatus, anterior, } \\
\text { middle and posterior deltoid, } \\
\text { biceps brachii, triceps brachii }\end{array}$ \\
\hline 14 & $\begin{array}{l}\bar{N} \\
3\end{array}$ & $\begin{array}{l}\text { To examine changes during } \\
\text { simulated repetitive work in } \\
\text { response to a fatigue protocol. }\end{array}$ & $\begin{array}{l}\text { Body Motion, } \\
\text { EMG, } \\
\text { Force, } \\
\text { RPD }\end{array}$ & $\begin{array}{l}\text { Tasks (handle pull, cap } \\
\text { rotation, } \\
10 \text { s anterior drill press } \\
(50 \% \text { MVC), } \\
\text { Handle push, } \\
\text { Height }\end{array}$ & $\begin{array}{l}\text { Muscle fatigue } \\
\text { recovery, } \\
\text { Discomfort rating }\end{array}$ & $\begin{array}{l}\text { Upper and lower trapezius } \\
\text { (bilaterally), pectoralis major } \\
\text { (sternal and clavicular head), } \\
\text { latissimus dorsi, serratus } \\
\text { anterior, infraspinatus, anterior, } \\
\text { middle and posterior deltoid, } \\
\text { biceps brachii, triceps brachii }\end{array}$ \\
\hline 15 & $\begin{array}{l}\bar{u} \\
\overline{3}\end{array}$ & $\begin{array}{l}\text { To investigate which muscle } \\
\text { group, the agonist or antagonist, } \\
\text { contributes most to the shoulder } \\
\text { position sense (SPS). }\end{array}$ & $\begin{array}{l}\text { Shoulder } \\
\text { ROM, } \\
\text { SPS, } \\
\text { EMG, } \\
\text { Torque }\end{array}$ & $\begin{array}{l}\text { Fatigued shoulder } \\
\text { internal or external } \\
\text { rotator muscles, } \\
\text { Posture }\end{array}$ & $\begin{array}{l}\text { Shoulder position } \\
\text { sense }\end{array}$ & $\begin{array}{l}\text { Pectoralis major, latissimus } \\
\text { dorsi, Infraspinatus }\end{array}$ \\
\hline
\end{tabular}




\begin{tabular}{|c|c|c|c|c|c|c|}
\hline 16 & 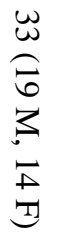 & $\begin{array}{l}\text { To compare the bilateral ROM } \\
\text { and rotation strength in the } \\
\text { shoulders of young beach } \\
\text { volleyball players }\end{array}$ & $\begin{array}{l}\text { ROM, } \\
\text { Isometric } \\
\text { rotational } \\
\text { strength }\end{array}$ & $\begin{array}{l}\text { Direction of rotation, } \\
\text { Posture, }\end{array}$ & Muscle Strength & - \\
\hline 17 & $\begin{array}{l}\vec{E} \\
3\end{array}$ & $\begin{array}{l}\text { To determine the effect of } \\
\text { isometric pull down exercise on } \\
\text { muscle activity with different } \\
\text { shoulder elevation angles and } \\
\text { different movement planes. }\end{array}$ & EMG & $\begin{array}{l}\text { shoulder elevation } \\
\text { angles, Planes of } \\
\text { movement }\end{array}$ & $\begin{array}{l}\text { Latissimus dorsi, } \\
\text { inferior fibers of } \\
\text { trapezius activity and } \\
\text { latissimus } \\
\text { dorsi/inferior fibers of } \\
\text { trapezius activity ratio }\end{array}$ & $\begin{array}{l}\text { Latissimus dorsi, inferior fibers } \\
\text { of trapezius }\end{array}$ \\
\hline 18 & 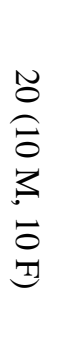 & $\begin{array}{l}\text { To compare scapulothoracic } \\
\text { motion and muscle activity } \\
\text { between the raising and } \\
\text { lowering phases of an overhead } \\
\text { reaching task. }\end{array}$ & $\begin{array}{l}\text { EMG, } \\
\text { Body Motion }\end{array}$ & $\begin{array}{l}\text { Factors of phase (raising } \\
\text { and lowering), } \\
\text { Arm elevation angle ( } 30, \\
50,90,130)\end{array}$ & $\begin{array}{l}\text { Three scapular and } \\
\text { two clavicular } \\
\text { rotations and EMG } \\
\text { RMS amplitudes of the } \\
\text { three scapulothoracic } \\
\text { muscles }\end{array}$ & $\begin{array}{l}\text { Upper and lower trapezius, } \\
\text { serratus anterior }\end{array}$ \\
\hline 19 & $\begin{array}{l}\vec{E} \\
3\end{array}$ & $\begin{array}{l}\text { To assess the Influence of Load } \\
\text { Handling Height on Shoulder } \\
\text { Biomechanics during Sudden } \\
\text { Loading }\end{array}$ & $\begin{array}{l}\text { EMG, Body } \\
\text { Motion }\end{array}$ & load handling height & $\begin{array}{l}\text { Normalized EMG, } \\
\text { Load travel distance }\end{array}$ & $\begin{array}{l}\text { Supraspinatus, } \\
\text { Infraspinatus, } \\
\text { Anterior deltoid }\end{array}$ \\
\hline
\end{tabular}




\begin{tabular}{|c|c|c|c|c|c|c|}
\hline 20 & $\begin{array}{l}\vec{u} \\
\overrightarrow{3}\end{array}$ & $\begin{array}{l}\text { Comparing EMG recorded from } \\
\text { shoulder joint muscles in the } \\
\text { same position for different } \\
\text { movement directions. }\end{array}$ & $\begin{array}{l}\text { EMG, } \\
\text { Body Motion }\end{array}$ & $\begin{array}{l}\text { Shoulder elevation from } \\
\text { angle } 0 \text { to } 120 \text {, } \\
\text { Shoulder depression } \\
\text { from } 120 \text { to } 0, \\
\text { Shoulder horizontal } \\
\text { adduction from } 15 \text { to } \\
105 \text {, Shoulder horizontal } \\
\text { abduction from } 105 \text { to } \\
15\end{array}$ & $\begin{array}{l}\text { Muscle activity, } \\
\text { Angular velocity }\end{array}$ & $\begin{array}{l}\text { Supraspinatus, infraspinatus, } \\
\text { anterior, middle and posterior } \\
\text { deltoid }\end{array}$ \\
\hline 21 & $\begin{array}{l}\overrightarrow{0} \\
\text { T1 }\end{array}$ & $\begin{array}{l}\text { To determine shoulder girdle } \\
\text { fatigue for different } \\
\text { combinations of weight of } \\
\text { workpieces, weight of hand- } \\
\text { tools, shoulder postures, arm up } \\
\text { time and down time that are } \\
\text { commonly used in automotive } \\
\text { assembly operations }\end{array}$ & $\begin{array}{l}\text { EMG, } \\
\text { RPD, } \\
\text { Fatigue and } \\
\text { pain rating }\end{array}$ & $\begin{array}{l}\text { Weight of object, } \\
\text { Task }\end{array}$ & $\begin{array}{l}\text { Muscle activity, } \\
\text { Fatigue, } \\
\text { Time, } \\
\text { RPD, } \\
\text { Fatigue rating, } \\
\text { Pain rating }\end{array}$ & Upper trapezius, middle deltoid \\
\hline 22 & 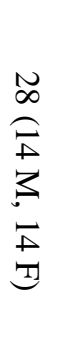 & $\begin{array}{l}\text { To develop novel parsimonious } \\
\text { models of 3-D multi-planar } \\
\text { shoulder rhythms using an } \\
\text { unprecedented range of humeral } \\
\text { orientations. }\end{array}$ & Body Motion & $\begin{array}{l}\text { Plane of elevation, } \\
\text { Elevation angle, } \\
\text { Axial rotation, } \\
\text { Gender, } \\
\text { Participant age, height } \\
\text { and weight }\end{array}$ & $\begin{array}{l}\text { Scapular and } \\
\text { clavicular orientation }\end{array}$ & - \\
\hline
\end{tabular}




\begin{tabular}{|c|c|c|c|c|c|c|}
\hline 23 & $\infty$ & $\begin{array}{l}\text { To assess the effect of an } \\
\text { ergonomic assistive device } \\
\text { (ABLE) on the ergonomic } \\
\text { performances of an } \\
\text { exoskeleton, human joint angles } \\
\text { and torques, ground reaction } \\
\text { forces, and duration of } \\
\text { operations. }\end{array}$ & Body Motion & $\begin{array}{l}\text { Use of assistive device, } \\
\text { Task cycle }\end{array}$ & $\begin{array}{l}\text { Foot/floor contact } \\
\text { forces, } \\
\text { Joints angles, } \\
\text { Joint torques, } \\
\text { Movement durations }\end{array}$ & - \\
\hline 24 & $\begin{array}{l}\tilde{\sigma} \\
3\end{array}$ & $\begin{array}{l}\text { To assess the ergonomic } \\
\text { exposures to risk factors that } \\
\text { may lead to the reported } \\
\text { musculoskeletal injuries } \\
\text { (especially back, neck and wrist } \\
\text { injuries) of drywall workers }\end{array}$ & Observation & $\begin{array}{l}\text { Postures, } \\
\text { Activities, } \\
\text { Different tools and } \\
\text { materials and their } \\
\text { weights }\end{array}$ & $\begin{array}{l}\text { Inter-rater reliability } \\
\text { (IRR), } \\
\text { body parts' posture }\end{array}$ & - \\
\hline 25 & $\begin{array}{l}\overrightarrow{0} \\
1\end{array}$ & $\begin{array}{l}\text { To investigate the effect of task } \\
\text { variation, as parameterized by } \\
\text { cycle time within a fixed overall } \\
\text { workload on musculoskeletal } \\
\text { health in overhead work. }\end{array}$ & $\begin{array}{l}\text { EMG, } \\
\text { RPD, } \\
\text { Static } \\
\text { strength }\end{array}$ & Cycle time & $\begin{array}{l}\text { Static strength } \\
\text { capability, } \\
\text { EMG (RMS } \\
\text { amplitude), } \\
\text { Rating of perceived } \\
\text { exertion, } \\
\text { Endurance time. }\end{array}$ & $\begin{array}{l}\text { Upper, middle and lower } \\
\text { trapezius, anterior, middle and } \\
\text { posterior deltoid, } \\
\text { Supraspinatus, Infraspinatus, } \\
\text { pectoralis major }\end{array}$ \\
\hline
\end{tabular}


Appendix B: Preliminary study Consent form 


\section{Only Minimal Risk \\ Consent Information and HIPAA Form}

$\begin{array}{ll}\text { Principal Investigator } & \text { Dr. Ashish Nimbarte } \\ \text { Department } & \text { ENGINEERING-Industrial and Management Systems Engineering } \\ \text { Protocol Number } & 1603050627 \\ \text { Study Title } & \text { Safe Loading Thresholds for the Rotator Cuff Muscles } \\ \text { Co-Investigator(s) } & \text { Mohammad Motabarzadeh and Esther Raub } \\ \text { Sponsor } & \text { None }\end{array}$

\section{Contact Persons}

In the event you experience any side effects or injury related to this research, you should contact Dr. Ashish Nimbarte at (304) 293-9473. If you have any questions, concerns, or complaints about this research, you can contact Mohammad Motabarzadeh at (304) 777-8441.

For information regarding your rights as a research subject, to discuss problems, concerns, or suggestions related to the research, to obtain information or offer input about the research, contact the Office of Research Compliance at (304) 293-7073.

In addition if you would like to discuss problems, concerns, have suggestions related to research, or would like to offer input about the research, contact the Office of Research Integrity and Compliance at 304-293-7073.

\section{Introduction}

You, have been asked to participate in this research study, which has been explained to you by Mohammad Motabarzadeh, and Esther Raub. This study is being conducted by Dr. Ashish Nimbarte (PhD), Mohammad Motabarzadeh, and Esther Raub in the Department of Industrial and Management System Engineering at West Virginia University.

\section{Purpose(s) of the Study}

Phone: 304-293-7073

Fax: 304-293-3098 http://oric.research.wvu.edu
Chestnut Ridge Research Building

886 Chestnut Ridge Road

PO Box 6845

Morgantown, WV 26506-6845

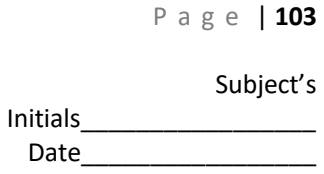


The purpose of this study is to analyze fatigue in the rotator cuff muscles under different joint demands and establish safe loading thresholds for these muscles.

\section{Description of Procedures}

Upon arrival, the procedures of the experiment will be explained to you in detail and you will be asked to sign an informed consent form. Next, basic anthropometric data including age, body weight, height and elbow height will be measured. You will be then given approximately a 10 minutes training session in order to become familiar with the tasks to be performed and also to warm-up your shoulder muscles. Surface electromyography electrodes (EMG) will be placed over the skin at the following muscles: supraspinatus, infraspinatus, and teres major. EMG electrodes are being used to measure electrical activity from muscles in order to determine whether a particular muscle is responding appropriately under different loads. Then you will be asked to perform maximum voluntary contraction (MVC) exertions in order to measure the maximum exertion using EMG from all selected muscles. Each maximum voluntary contraction trial will be five seconds long and a rest period (minimum of two minute) will be provided between exertions in order to reduce the chance of fatigue and injury. Next you will be asked to perform a series of exertions for each muscle at a percentage $(15,30,45$, or $60 \%)$ of your MVC value. You will be asked to hold this exertion for a maximum of one minute. A total of 12 percentage MVC exertion trials will be performed. After the completion of each task, you will be asked to numerically rate your perceived fatigue caused by the shoulder load exertion using Borg's CR-10 scale. The Borg CR-10 scale contains two columns, one for subjective categories ranging from "nothing at all" to "extremely strong" and the other for numerical ratios ranging on a scale of 0 to 10 that are associated with the different categories. The purpose of performing percentage MVC exertions during those trials is to generate fatigue in the shoulder muscles. During all exertions you will be seated in a padded chair in an upright position and secured with the four-point harness to prevent any upper body movement which could interfere with the data collection. Total length of this session will be less than 120 minutes.

\section{Discomforts}

There are no known or expected risks of injury from participating in this study. There is just minimal risk for shoulder muscle strain and fatigue while performing the maximum exertions. Therefore, you will be given sufficient rest between trials.

Phone: 304-293-7073

Fax: 304-293-3098 http://oric.research.wvu.edu
Chestnut Ridge Research Building

886 Chestnut Ridge Road

PO Box 6845

Morgantown, WV 26506-6845
$P$ a g e | 104

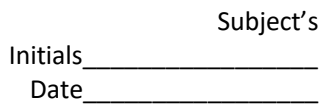




\section{Alternatives}

This study is not mandatory. You may withdraw from this study at any time if you do not feel comfortable with the procedure.

\section{Benefits}

Although you may not receive any direct benefit from this study, the knowledge gained from this study may eventually benefit others. Participating in this study will not be counted as extra credit and will have no effect on your grades or your standing at WVU.

\section{Financial Considerations}

You will not receive any compensation for participation in the study and will not incur any costs related to the study.

\section{Voluntary Compensation}

It is very important for you to understand that neither the investigator nor WVU or it associated affiliates has the funds set aside to pay for the cost work wages or any care or treatment that might be necessary because you get hurt or sick taking part in this study. Any injuries that may result from this study would not be eligible for workers' Compensation as this is not a job related injury. Understand that any treatments necessary will be billed to the participant or to your personal health insurance, and you may wish to consult your insurance provider before participating in this study.

\section{Confidentiality}

Any information about you that is obtained as a result of your participation in this research will be kept as confidential as legally possible. Your research records and test results, just like hospital records, may be subpoenaed by court order or may be inspected by the study sponsor or federal regulatory authorities (including the FDA if applicable) without your additional consent.

\section{Voluntary Participation}

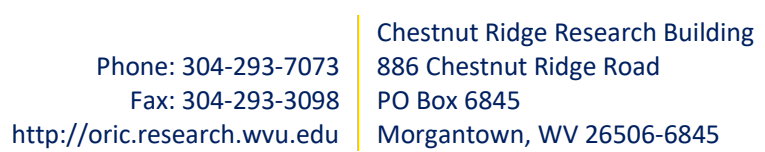

Phone: 304-293-7073 http://oric.research.wvu.edu

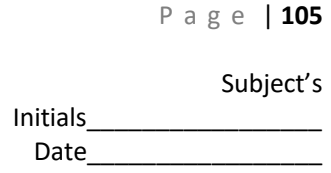


Participation in this study is voluntary. You are free to withdraw your consent to participate in this study at any time.

Refusal to participate or withdrawal will not affect [your class standing or grades, as appropriate] and will involve no penalty to you. Refusal to participate or withdrawal will not affect your future care, or your employee status at West Virginia University.

In the event new information becomes available that may affect your willingness to participate in this study, this information will be given to you so that you can make an informed decision about whether or not to continue your participation.

You have been given the opportunity to ask questions about the research, and you have received answers concerning areas you did not understand.

Upon signing this form, you will receive a copy.

I willingly consent to participate in this research.

\section{Signatures}

Signature of Subject

$\begin{array}{lll}\text { Printed Name } & \text { Date }\end{array}$

Participant has had the opportunity to have questions addressed. The participant willingly agrees to be in the study.

Signature of Investigator or Co-Investigator

Printed Name
Date

Time
Phone: 304-293-7073

Fax: 304-293-3098 http://oric.research.wvu.edu
Chestnut Ridge Research Building

886 Chestnut Ridge Road

PO Box 6845

Morgantown, WV 26506-6845

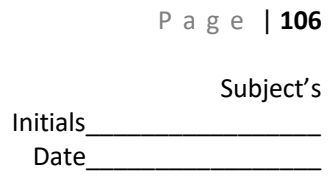


Appendix C: Specific Aim \#1 and \#2. Consent form 


\section{W. WestVriginiaUniversity.}

Key Information for:

\section{The effect of task rotation and handgrip on rotator cuff muscles fatigue development during isometric overhead work.}

We are asking you to choose whether or not to volunteer in the research described below. This page provides key information that may help you to make this decision; more detailed information can be found after this section.

Why is this research being done and what is involved?

- The purpose of this study is to analyze the effect of 1) different task rotation scenarios and 2) handgrip on rotator cuff muscles behavior and fatigue development. These factors will be evaluated in two different sessions, which are being conducted in two different days.

- Electromyography sensors will be attached to the shoulder using special double-sided tape to measure muscle activity.

- In the first session, to study the effect of task rotation on shoulder muscle fatigue, the participant will be asked to perform overhead exertions with three different force levels $(5 \%, 20 \%$, and $35 \%$ of their maximum voluntary contraction). These exertions will be performed in four different orders (Increasing, Decreasing, parabolic, and hyperbolic) with the goal of finding the best task order to reduce muscle fatigue. In the second session, same exertions as the first visit will be performed and a handgrip exertion will be added in between overhead exertions to see whether handgrip can act as a refresher for the shoulder muscles and reduce fatigue. The handgrip task will be $30 \%$ of the participant's maximum handgrip force.

- After each exertion participant will be asked to rate their discomfort level using the Borg's CR-10 scale.

- The participant can choose to attend one or both sessions with no restriction.

- Each session takes a maximum of four hours to complete and the participant receives a $\$ 40$ gift card at the completion of each session. 


\section{W. WestVirginiaUniversity.}

Do I have to participate and what are the risks?

Participation in this research study is completely voluntary and you are free to withdraw from the research at any time. By completing each session, you will receive a $\$ 40$ gift card.

There are no known or expected risks of injury from participating in this study. There is just minimal risk for shoulder muscle strain and fatigue while performing the maximum exertions. Therefore, you will be given sufficient rest between trials

Who can I talk to if I have questions or concerns?

If you have any questions or concerns about this research, you can contact Dr. Ashish Nimbarte at 304.293.9473 from the Dept. of industrial and management systems at West Virginia University.

For more information, please see the Informed Consent Form.

Informed Consent $\mid$ Minimal Risk Research-Measuring muscle activity (Version date December 20, 2018)

Principal Investigator (PI) $\mid$ Dr. Ashish Nimbarte

PI Department $\mid$ Industrial and Management Systems Engineering

Co-Investigator(s) $\mid$ Hossein Motabar

Funding Source $\mid$ National Institute for Occupational Safety and Health (NIOSH)

WVU IRB Protocol \# | 1901427355

Title Effect of task rotation and handgrip on rotator cuff muscles fatigue development during isometric overhead work.

\section{Contact Persons}




\section{WestVirginiaUniversity.}

If you are hurt from being in this research, you should contact Dr. Ashish Nimbarte at 304 293 9473. If injury occurs outside of business hours and is related to your participation in this research, please contact Hossein Motabar at 3047778441.

If you have any questions, concerns, or complaints about this research, you can contact Dr. Ashish Nimbarte at 3042939473.

For information regarding your rights as a person in research or to talk about the research, contact the WVU Human Research Protection Program (HRPP) at (304) 293-7073 or by email at IRB@mail.wvu.edu.

\section{Introduction}

You, , have been asked to participate in this research study, which has been explained to you by This study is being conducted by Dr. Ashish Nimbarte in the Department of Industrial and Management Systems Engineering at West Virginia University, along with Hossein Motabar PhD student in the Department of Industrial and Management Systems Engineering at West Virginia University. Funding for this research is provided by National Institute for Occupational Safety and Health (NIOSH).

This research is being conducted to fulfill the requirements for a $\mathrm{PhD}$ in Industrial Engineering from the Department of Industrial and Management Systems Engineering at West Virginia University. This research is being conducted under the supervision of Dr. Ashish Nimbarte.

\section{Purpose}

The purpose of this study is to analyze the effect of different task rotation scenarios and handgrip on rotator cuff muscles behavior and fatigue development. A total of approximately 30 subjects at all sites are expected to participate in this study.

\section{Description of Procedures}




\section{WWestVriginiaUniversity.}

Upon arrival, the procedures of the experiment will be explained to you in detail and you will be asked to sign an informed consent form. Next, basic anthropometric data including age, body weight, and height will be measured. You will then be given approximately a 10 minutes training session in order to become familiar with the tasks to be performed and also to warm-up your shoulder muscles. Then, surface electromyography sensors (EMG) will be placed over the shoulder skin to measure muscle activity. Then you will be asked to perform maximum voluntary contraction (MVC) exertions for all selected muscles. Each maximum voluntary contraction trial will be five seconds long and a rest period (minimum of two minutes) will be provided between exertions in order to reduce the chance of fatigue. This study consists of two independent sessions which are being performed in two different days. In session one, you will be asked to perform overhead exertions with three different force levels (5\%, 20\%, and 35\% of your maximum voluntary contraction). These exertions will be performed in four different task orders (Increasing, Decreasing, parabolic, and hyperbolic) with the goal of finding the best task order to avoid muscle fatigue. In session two, the same process as session one will be performed plus a handgrip task, which will be added in between the overhead exertions. The goal of session two is to identify whether handgrip exertions can act as a shoulder muscle refresher and reduce fatigue. The handgrip exertion will be $30 \%$ of your maximum handgrip force. In both sessions, after each exertion, you will be asked to rate your discomfort level using the Borg's CR-10 scale. The total length of each session will be no more than four hours. You can choose to attend one or both sessions. If you choose to attend one session only, the study personnel will choose the session to make sure enough data is available for both sessions.

\section{Risks and Discomforts}

There are no known or expected risks of injury from participating in this study. There is just minimal risk for shoulder muscle strain and fatigue while performing the maximum exertions. Therefore, you will be given sufficient rest between trials 


\section{W.WestVirginiaUniversity.}

Alternative

The alternative is not to participate in the study.

\section{Benefits}

There is no guarantee that you will benefit from participating in this research. Although you may not receive any direct benefit from this study, the knowledge gained from this study may eventually benefit others. Participating in this study will not be counted as extra credit and will have no effect on your grades or your standing at WVU.

\section{Financial Considerations}

You will be paid a $\$ 40$ gift card after completing each session. You can earn up to $\$ 80$ by participating in both sessions of this study. No payments will be made if you do not complete the study.

Your information may be provided to the appropriate parties for billing and/or payment purposes. Please be advised that any compensation received for participation in a research study, including a gift card, is considered taxable income and must be reported to the IRS. If you are a WVU employee or a WVU student-employee, you are required to report the total amount of compensation received for your participation in a research study to the WVU Tax Services Office upon receipt of payment.

Your research results or any and all other information related to this research study used in this research study may contribute to a new discovery or treatment. In some instances, your research results or any other information related to this research study may be of commercial value and may be sold, patented, or licensed by the investigators and West Virginia University for use in other research or the development of new products. You will not retain any property rights nor will you share in any money that the investigators, West Virginia University, or their agents may realize. 


\section{W. WestVriginiaUniversity.}

\section{Confidentiality}

Any information about you that is obtained as a result of your participation in this research will be kept as confidential as legally possible. Your research records and test results, just like hospital records, may be subpoenaed by court order or may be inspected by the study sponsor or federal regulatory authorities without your additional consent.

In any publications that result from this research, neither your name nor any information from which you might be identified will be published without your consent.

\section{Voluntary Participation}

Participation in this study is voluntary. You are free to withdraw your consent to participate in this study at any time and there will be no penalty to you.

Refusal to participate or withdraw will not affect your class standing or grades and will involve no penalty to you.

Refusal to participate or withdraw will not affect your employee status at West Virginia University.

Refusal to participate or your decision to stop participating will not affect your future care at West Virginia University.

In the event new information becomes available that may affect your willingness to participate in this study, this information will be given to you so that you can make an informed decision about whether or not to continue your participation. 


\section{WestVirginiaUniversity.}

\section{Signatures}

You have been given the opportunity to ask questions about the research, and you have received answers concerning areas you did not understand. Upon signing this form, you will receive a copy.

\section{Participant Signature}

I willingly consent to participate in this research.

Signature of Subject or Subject's Legal Representative

Printed Name

Date

\section{Consenting Individual Signature}

The participant has had the opportunity to have questions addressed. The participant willingly agrees to be in the study.

Signature of Person Obtaining Informed Consent 


\section{Borg's CR-10 Scale}

\begin{tabular}{|cll|}
\hline Rating & & Description \\
0 & Nothing at all & Just Noticeable \\
0.5 & Very, very weak & \\
1 & Very weak & Light \\
2 & Weak (light) & \\
3 & Moderate & \\
4 & Somewhat strong & Heavy \\
5 & Strong (heavy) & \\
6 & & \\
7 & Very strong & \\
8 & & \\
9 & & \\
10 & Extreme & \\
\hline
\end{tabular}




\section{Appendix E: Matlab scripts for EMG analysis}

\section{E.1 Matlab script for Median frequency computation}

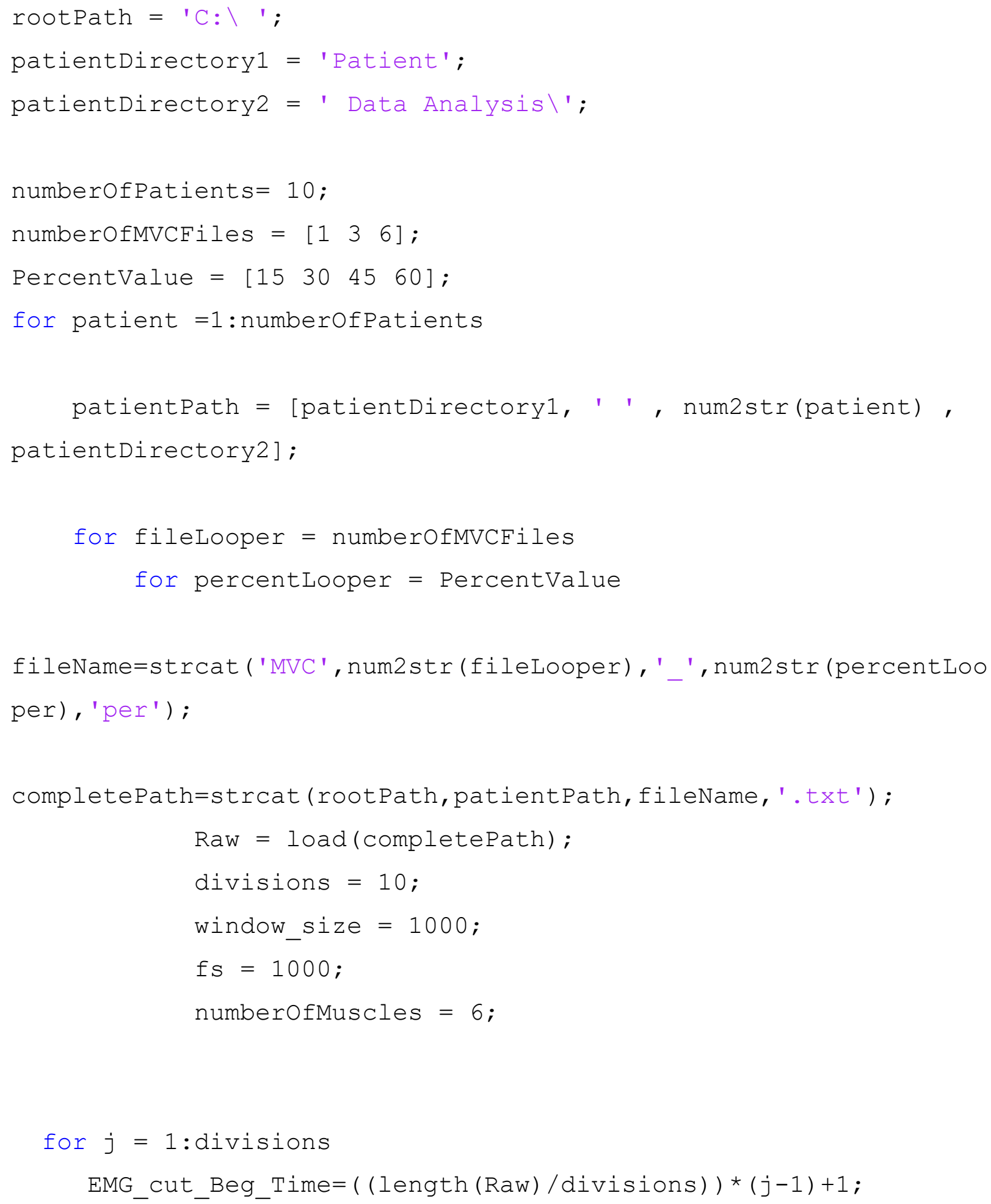


EMG_cut_End_Time=(length $($ Raw $) /$ divisions $) *(j-1)$ +window_size;

for $i=1:$ numberofmuscles

EMG_R=Raw (EMG_cut_Beg_Time:EMG_cut_End_Time, i) ;

$[\mathrm{m}, \mathrm{z}]=\operatorname{size}(\mathrm{EMG} R)$;

EMG_R = EMG_R - mean (EMG_R);

$\mathrm{n}=\mathrm{floor}(\mathrm{m} / \mathrm{fs})$;

$\mathrm{sn}=\mathrm{n} * \mathrm{f} \mathrm{s} ;$

$\mathrm{EMG}=$ EMG_R(1:sn, : );

$\mathrm{N}=\mathrm{n} * \mathrm{fs} / 2$;

$f=f S^{*}(0: N-1) / 2 / N$;

$X=\operatorname{fft}(\mathrm{EMG})$;

Filters $0-12 \mathrm{~Hz}$

$\mathrm{X}((\mathrm{n} * 0+1):(\mathrm{n} *(12)+1))=0$;

$X(\operatorname{length}(X)-(n *(12)-1)$ : length $(X)-(n * 1-1))=0$;

oFilters 59-61 Hz

$X((n * 59+1):(n *(61)+1))=0$;

$X(\operatorname{length}(X)-(n *(61)-1)$ : length $(X)-(n * 59-1))=0 ; \quad \frac{0}{0}$

Attenuating line interference

Filters 119-121 $\mathrm{Hz}$

$\mathrm{X}((\mathrm{n} * 119+1):(\mathrm{n} *(121)+1))=0$;

$X($ length $(X)-(n *(121)-1)$ : length $(X)-(n * 119-1))=0$; \%

Attenuating line interference

Filters 179-181 $\mathrm{Hz}$

$\mathrm{X}((\mathrm{n} * 179+1):(\mathrm{n} *(181)+1))=0$;

$\mathrm{X}($ length $(\mathrm{X})-(\mathrm{n} *(181)-1)$ : length $(\mathrm{X})-(\mathrm{n} * 179-1))=0$;

Attenuating line interference

Filters 239-241 Hz

$\mathrm{X}((\mathrm{n} * 239+1):(\mathrm{n} *(241)+1))=0$; 
$X($ length $(X)-(n *(241)-1)$ : length $(X)-(n * 239-1))=0 ; \quad \frac{0}{0}$

Attenuating line interference

Filters 299-301 $\mathrm{Hz}$

$\mathrm{X}((\mathrm{n} * 299+1):(\mathrm{n} *(301)+1))=0$;

$X($ length $(X)-(n *(301)-1)$ : length $(X)-(n * 299-1))=0 ; \quad \circ$

Attenuating line interference

Filters 359-361 $\mathrm{Hz}$

$x((n * 359+1):(n *(361)+1))=0$;

$X($ length $(X)-(n *(361)-1)$ : length $(X)-(n * 359-1))=0 ; \quad \%$

Attenuating line interference

Filters 400-1000 Hz

$X((n * 400+1):(n *(500)+1))=0$ ；

$X($ length $(X)-(n *(500)-1)$ : length $(X)-(n * 400-1))=0 ; \quad \frac{0}{0}$ low pass

\section{filtering}

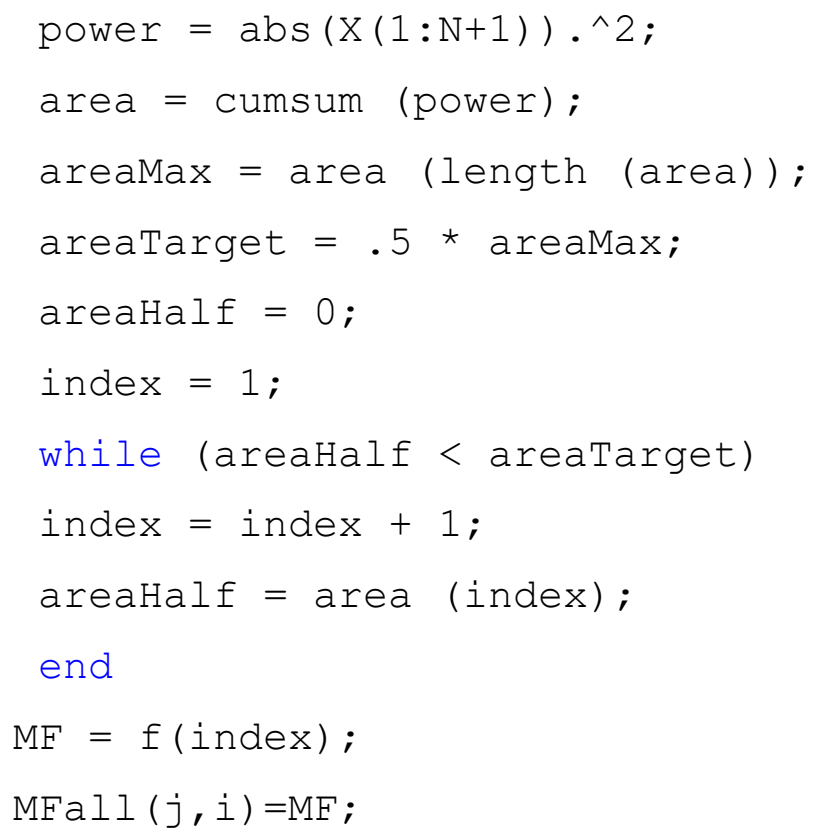

end;

save (strcat ('MFall', num2str (patient), fileName), 'MFall') ; end

end 


\section{E.2 Matlab script for average muscle activity computation}

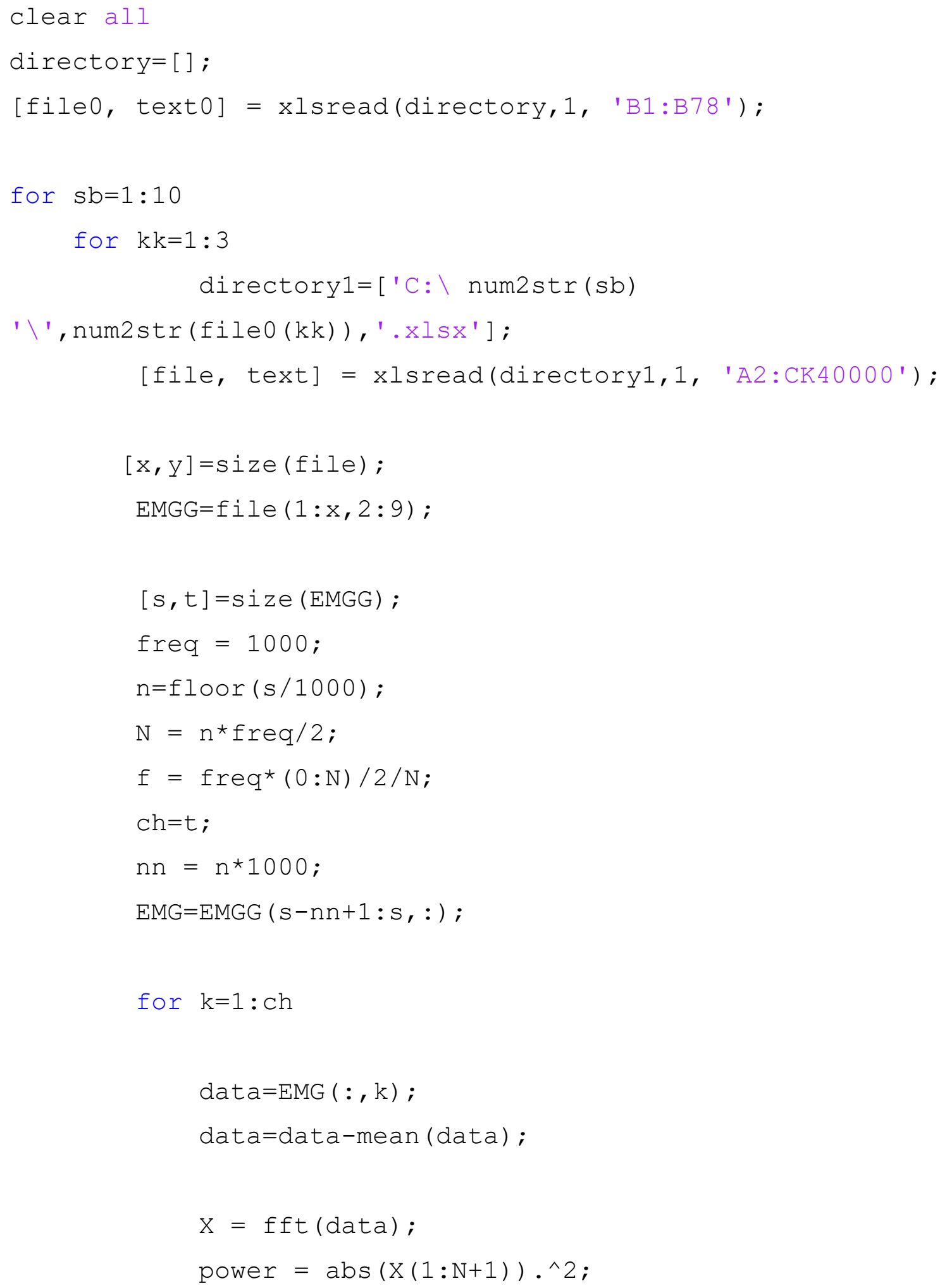




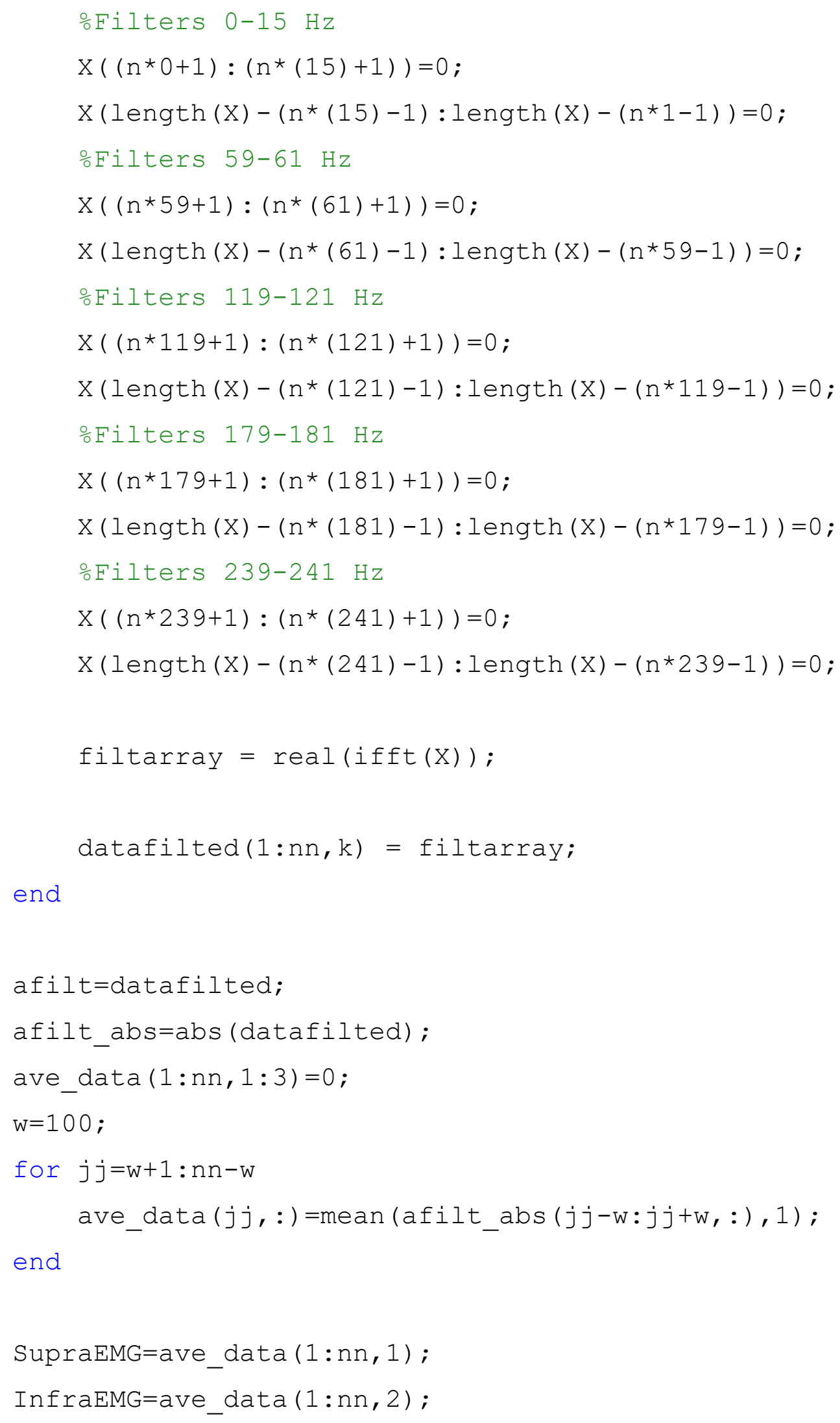


TeresEMG=ave_data $(1: \mathrm{nn}, 3)$;

MeanEMG $(k k,:)=[$ mean (SupraEMG), mean (InfraEMG), mean (TeresEMG) $]$; $\mathrm{kk}$

clearvars -except fileo sb kk directory directoryl

MeanNeckAngle MeanEMG

end

sb

end 


\section{Appendix F: Analysis of Variance}

Analysis of Variance for performing the sequences without the handgrip exertion

Normalized muscle activity

\begin{tabular}{llllll}
\hline \multicolumn{2}{l}{ Supraspinatus } & & & & \\
Source & DF & Adj SS & Adj MS & F-Value & P-Value \\
\hline Sequence & 3 & 1.97 & 0.6568 & 0.82 & 0.489 \\
\hline Error & 36 & 28.706 & 0.7974 & & \\
Total & 39 & 30.676 & & & \\
\hline
\end{tabular}

\begin{tabular}{llllll}
\hline Infraspinatus & & & & & \\
\hline Source & DF & Adj SS & Adj MS & F-Value & P-Value \\
\hline Sequence & 3 & 1.285 & 0.4284 & 0.42 & 0.739 \\
\hline Error & 36 & 36.631 & 1.0175 & & \\
\hline Total & 39 & 37.916 & & & \\
\hline
\end{tabular}

\begin{tabular}{llllll} 
Teres minor & & & & & \\
Source & DF & Adj SS & Adj MS & F-Value & P-Value \\
\hline Sequence & 3 & 1.512 & 0.504 & 0.57 & 0.638 \\
\hline Error & 36 & 31.832 & 0.8842 & & \\
\hline Total & 39 & 33.344 & & &
\end{tabular}

Normalized MVC

\begin{tabular}{llllll}
\hline Source & DF & Adj SS & Adj MS & F-Value & P-Value \\
\hline Sequence & 3 & 112.7 & 37.55 & 0.31 & 0.819 \\
\hline Error & 44 & 5347.5 & 121.53 & & \\
\hline Total & 47 & 5460.1 & & & \\
\hline
\end{tabular}


Median Frequency

\begin{tabular}{|c|c|c|c|c|c|}
\hline \multicolumn{6}{|c|}{ Supraspinatus } \\
\hline Source & $\mathrm{DF}$ & Adj SS & Adj MS & F-Value & P-Value \\
\hline Sequence & 7 & 18.35 & 2.622 & 2.86 & 0.01 \\
\hline Error & 88 & 80.76 & 0.9177 & & \\
\hline Total & 95 & 99.11 & & & \\
\hline
\end{tabular}

\begin{tabular}{|c|c|c|c|c|c|}
\hline \multicolumn{6}{|c|}{ Infraspinatus } \\
\hline Source & $\mathrm{DF}$ & Adj SS & Adj MS & F-Value & P-Value \\
\hline Sequence & 7 & 7 & 20.03 & 2.8621 & 3.21 \\
\hline Error & 88 & 88 & 78.4 & 0.8909 & \\
\hline Total & 95 & 95 & 98.44 & & \\
\hline
\end{tabular}

\begin{tabular}{|c|c|c|c|c|c|}
\hline \multicolumn{6}{|c|}{ Teres minor } \\
\hline Source & $\mathrm{DF}$ & Adj SS & Adj MS & F-Value & P-Value \\
\hline Sequence & 7 & 5.626 & 0.8037 & 2.18 & 0.043 \\
\hline Error & 88 & 32.428 & 0.3685 & & \\
\hline Total & 95 & 38.054 & & & \\
\hline
\end{tabular}

RPE

\begin{tabular}{llllll}
\hline Source & DF & Adj SS & $\begin{array}{l}\text { Adj } \\
\text { MS }\end{array}$ & $\begin{array}{l}\text { F- } \\
\text { Value }\end{array}$ & P-Value \\
\hline Sequence & 3 & 6.96 & 2.319 & 0.45 & 0.72 \\
\hline Error & 332 & 1724.24 & 5.194 & & \\
\hline Total & 335 & 1731.2 & & & \\
\hline
\end{tabular}


Analysis of Variance for performing the sequences with the handgrip exertion

Normalized muscle activity

\begin{tabular}{llllll}
\hline \multicolumn{2}{l}{ Supraspinatus } & & & & \\
\hline Source & DF & Adj SS & Adj MS & F-Value & P-Value \\
\hline Sequence & 3 & 75.83 & 25.28 & 0.51 & 0.679 \\
\hline Error & 44 & 2188.95 & 49.75 & & \\
\hline Total & 47 & 2264.78 & & & \\
\hline
\end{tabular}

\begin{tabular}{llllll}
\hline Infraspinatus & & & & & \\
\hline Source & DF & Adj SS & Adj MS & F-Value & P-Value \\
\hline Sequence & 3 & 1.866 & 0.6219 & 0.54 & 0.659 \\
\hline Error & 44 & 50.873 & 1.1562 & & \\
\hline Total & 47 & 52.739 & & & \\
\hline
\end{tabular}

\begin{tabular}{llllll}
\hline Teres minor & & & & & \\
\hline Source & DF & Adj SS & Adj MS & F-Value & P-Value \\
\hline Sequence & 3 & 85.49 & 28.5 & 0.47 & 0.705 \\
\hline Error & 44 & 2668.27 & 60.64 & & \\
\hline Total & 47 & 2753.75 & & & \\
\hline
\end{tabular}

Normalized MVC

\begin{tabular}{llllll}
\hline Source & DF & Adj SS & Adj MS & F-Value & P-Value \\
\hline Sequence & 3 & 133.9 & 44.65 & 0.46 & 0.71 \\
\hline Error & 44 & 4249.9 & 96.59 & & \\
\hline Total & 47 & 4383.9 & & & \\
\hline
\end{tabular}


Median Frequency

\begin{tabular}{lrrrrr}
\multicolumn{2}{l}{ Supraspinatus } & & & & \\
Source & DF & Adj SS & Adj MS & F-Value & P-Value \\
\hline Sequence & 7 & 2.456 & 0.3509 & 1.11 & 0.365 \\
\hline Error & 88 & 27.872 & 0.3167 & & \\
Total & 95 & 30.328 & & &
\end{tabular}

\begin{tabular}{|c|c|c|c|c|c|}
\hline \multicolumn{6}{|c|}{ Infraspinatus } \\
\hline Source & DF & Adj SS & Adj MS & F-Value & P-Value \\
\hline Sequence & 7 & 6.022 & 0.8603 & 0.91 & 0.5 \\
\hline Error & 88 & 83.181 & 0.9452 & & \\
\hline Total & 95 & 89.203 & & & \\
\hline
\end{tabular}

\begin{tabular}{lccccc}
\hline \multicolumn{2}{l}{ Teres minor } & & & \\
\hline Source & DF & Adj SS & Adj MS & F-Value & P-Value \\
\hline Sequence & 7 & 3.744 & 0.5348 & 0.47 & 0.856 \\
\hline Error & 88 & 100.893 & 1.1465 & & \\
\hline Total & 95 & 104.637 & & & \\
\hline
\end{tabular}

\begin{tabular}{llllll} 
RPE & & & & & \\
\hline Source & DF & Adj SS & Adj MS & F-Value & P-Value \\
\hline Sequence & 3 & 6.61 & 2.203 & 0.46 & 0.711 \\
\hline Error & 332 & 1592.31 & 4.796 & & \\
\hline Total & 335 & 1598.92 & & & \\
\hline
\end{tabular}


Results of 2-sample t-test for comparison of performing the sequences with and without the handgrip exertion

Normalized EMG

\begin{tabular}{cccc|ccc|ccc} 
& \multicolumn{3}{c}{ Supraspinatus } & \multicolumn{3}{c|}{ Infraspinatus } & \multicolumn{3}{c}{ Teres minor } \\
\cline { 2 - 10 } & T-Value & DF & P-Value & T-Value & DF & P-Value & T-Value & DF & P-Value \\
\hline Sequence1 & 1.83 & 21 & 0.081 & 0.8 & 17 & 0.432 & -0.55 & 20 & 0.591 \\
\hline Sequence2 & 1.6 & 21 & 0.129 & 0.53 & 18 & 0.604 & -0.12 & 21 & 0.906 \\
\hline Sequence3 & 1.52 & 21 & 0.143 & -0.75 & 20 & 0.464 & -1.61 & 21 & 0.122 \\
\hline Sequence4 & 0.91 & 21 & 0.375 & -0.22 & 21 & 0.831 & -0.37 & 21 & 0.718
\end{tabular}

Median Frequency Slope

\begin{tabular}{cccc|ccc|ccc} 
& \multicolumn{3}{c}{ Supraspinatus } & \multicolumn{3}{c|}{ Infraspinatus } & \multicolumn{3}{c}{ Teres minor } \\
\cline { 2 - 7 } & T-Value & DF & P-Value & T-Value & DF & P-Value & T-Value & DF & P-Value \\
\hline Sequence1 & -0.56 & 21 & 0.583 & -1.04 & 20 & 0.312 & -0.43 & 21 & 0.672 \\
\hline Sequence2 & -0.52 & 19 & 0.606 & -1.04 & 21 & 0.31 & -0.46 & 16 & 0.651 \\
\hline Sequence3 & 0.01 & 17 & 0.989 & -0.3 & 21 & 0.766 & -0.5 & 21 & 0.625 \\
\hline Sequence4 & -0.31 & 19 & 0.758 & -0.72 & 19 & 0.483 & -0.38 & 18 & 0.71
\end{tabular}

Percent drop in the median frequency

\begin{tabular}{cccc|ccc|ccc} 
& \multicolumn{3}{c}{ Supraspinatus } & \multicolumn{3}{c|}{ Infraspinatus } & \multicolumn{3}{c}{ Teres minor } \\
\cline { 2 - 10 } & T-Value & DF & P-Value & T-Value & DF & P-Value & T-Value & DF & P-Value \\
\hline Sequence1 & -1.13 & 21 & 0.272 & -1.91 & 21 & 0.069 & -2.41 & 21 & 0.025 \\
\hline Sequence2 & -1.02 & 13 & 0.325 & -2.44 & 19 & 0.025 & -1.91 & 20 & 0.07 \\
\hline Sequence3 & -1.77 & 15 & 0.097 & -2.82 & 20 & 0.01 & -2.56 & 16 & 0.021 \\
\hline Sequence4 & -0.39 & 21 & 0.703 & -1.36 & 16 & 0.193 & -2.48 & 21 & 0.022
\end{tabular}


Normalized MVC

\begin{tabular}{cccc}
\hline & T-Value & DF & P-Value \\
\hline Sequence1 & -0.4 & 21 & 0.695 \\
\hline Sequence2 & -0.98 & 21 & 0.34 \\
\hline Sequence3 & -0.51 & 21 & 0.614 \\
\hline Sequence4 & -0.58 & 21 & 0.571
\end{tabular}

RPE

\begin{tabular}{cccc}
\hline & T-Value & DF & P-Value \\
\hline Sequence1 & 0.41 & 20 & 0.689 \\
\hline Sequence2 & 0.07 & 21 & 0.945 \\
\hline Sequence3 & 0.02 & 21 & 0.982 \\
\hline Sequence4 & 0.97 & 19 & 0.345
\end{tabular}

